\title{
Review - Nuclear Fuels and Reprocessing Technologies: A U.S. Perspective
}

Guy Fredrickson

Tae-Sic Yoo

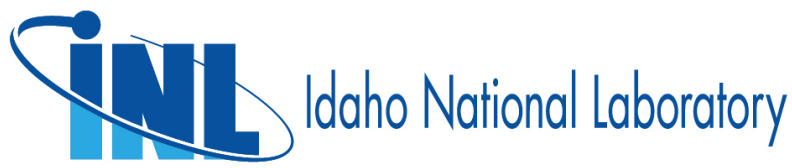




\section{DISCLAIMER}

This information was prepared as an account of work sponsored by an agency of the U.S. Government. Neither the U.S. Government nor any agency thereof, nor any of their employees, makes any warranty, expressed or implied, or assumes any legal liability or responsibility for the accuracy, completeness, or usefulness, of any information, apparatus, product, or process disclosed, or represents that its use would not infringe privately owned rights. References herein to any specific commercial product, process, or service by trade name, trademark, manufacturer, or otherwise, does not necessarily constitute or imply its endorsement, recommendation, or favoring by the U.S. Government or any agency thereof. The views and opinions of authors expressed herein do not necessarily state or reflect those of the U.S. Government or any agency thereof. 


\title{
Review - Nuclear Fuels and Reprocessing Technologies: A U.S. Perspective
}

\author{
Guy Fredrickson \\ Tae-Sic Yoo
}

March 2021

\section{Idaho National Laboratory \\ Pyrochemistry \& Molten Salt Systems Department \\ Idaho Falls, Idaho 83415}

http://www.inl.gov

Prepared for the U.S. Department of Energy Office of Nuclear Energy Under DOE Idaho Operations Office

Contract DE-AC07-05ID14517 
Page intentionally left blank 


\begin{abstract}
Reprocessing and/or waste management issues are of concern to the "back end" of the nuclear fuel cycle. Of course, there are a great many "nuclear fuel cycle" scenarios to consider; if not in practice, then at least in theory. The simplest conceptually is the "once through" fuel cycle in which the spent fuel is discarded. The more complex fuel cycle scenarios involve reprocessing spent nuclear fuels and a family of nuclear reactor technologies to accommodate burning and breeding for various military and commercial needs. Therefore, the selection of a specific "fuel cycle" is what ultimately imposes the engineering requirements of the reprocessing and waste management technologies. No one part is independent of the other parts in a fuel cycle flowsheet; all parts should be fully integrated.

This paper presents a summary of nuclear chemistry processes, nuclear reactor technologies, associated nuclear fuel types, and the reprocessing technologies that serve the different nuclear fuel types. Comprehending how this series of topics are related to each other is a prerequisite to understanding the requirements of any reprocessing strategy. The summary materials presented here are selective, as opposed to comprehensive. More detailed information on any one subject can be found in the reference materials.
\end{abstract}


Page intentionally left blank 


\section{CONTENTS}

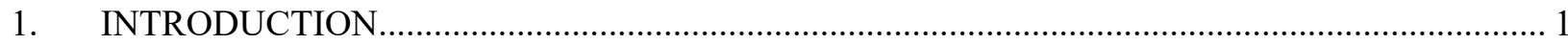

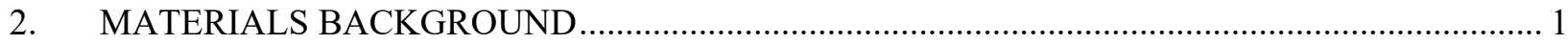

2.1 Mining and Extraction of Uranium and Thorium ........................................................... 5

2.2 Uranium, Lithium, Chlorine, and Nitrogen Enrichment ................................................... 5

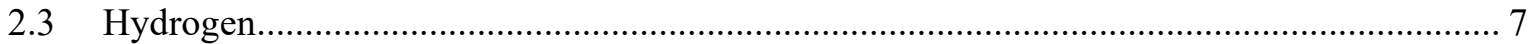

2.4 Krypton, Xenon, and Iodine Fission Products …................................................................ 7

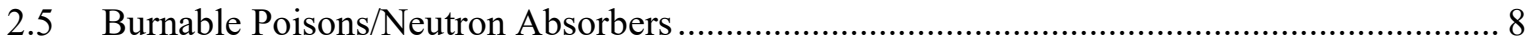

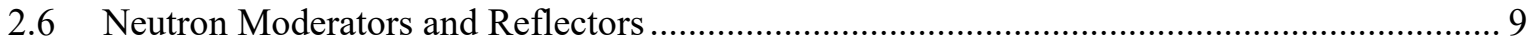

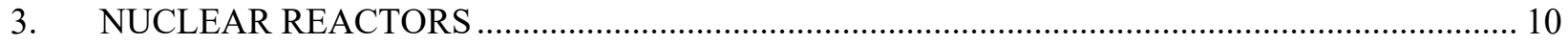

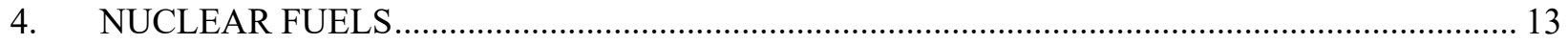

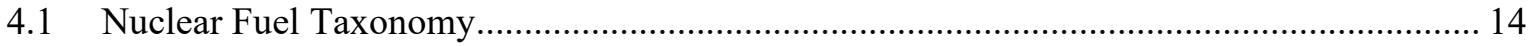

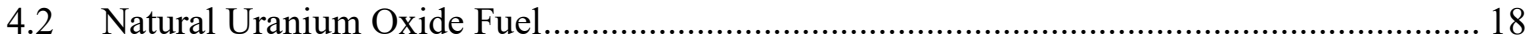

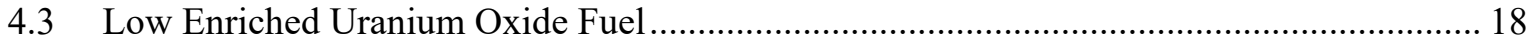

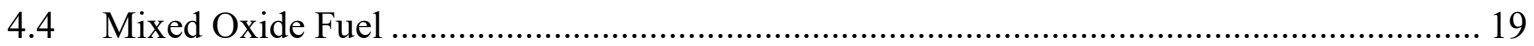

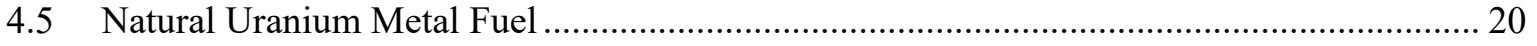

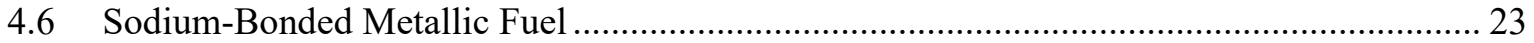

4.7 Research Reactor Dispersion Fuel …................................................................................. 24

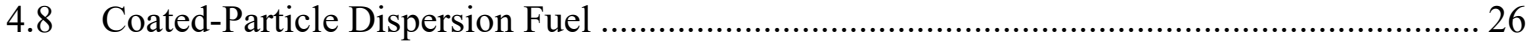

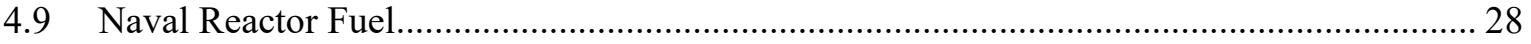

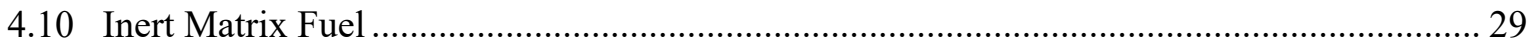

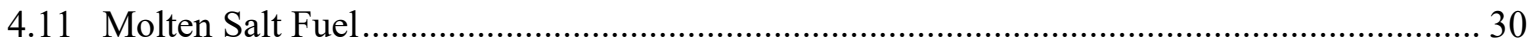

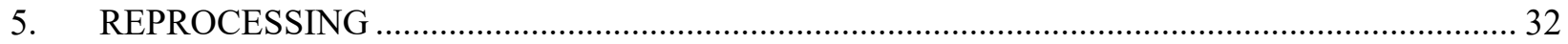

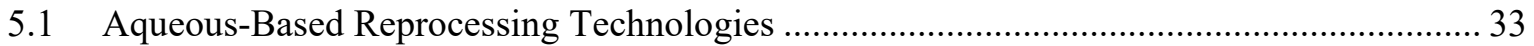

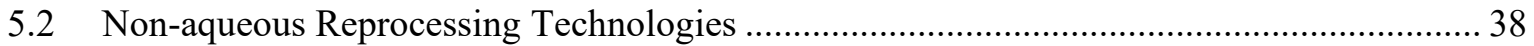

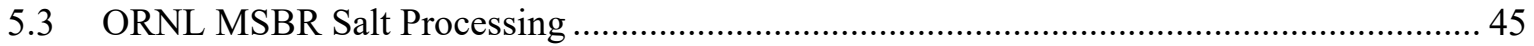

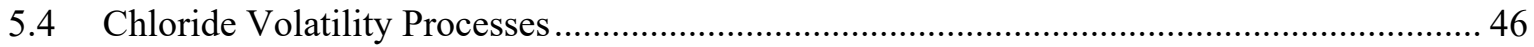

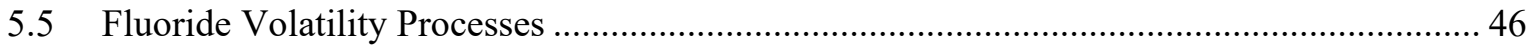

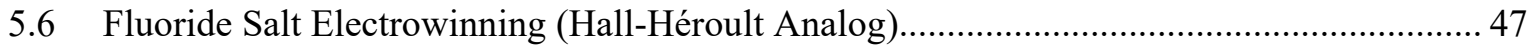

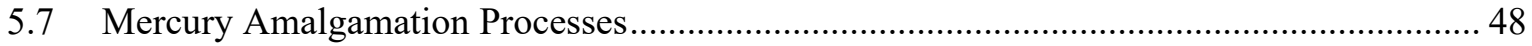

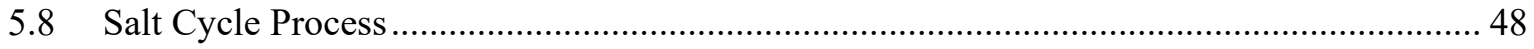

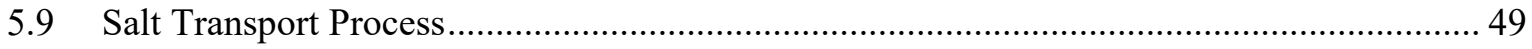

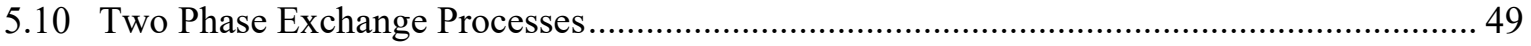

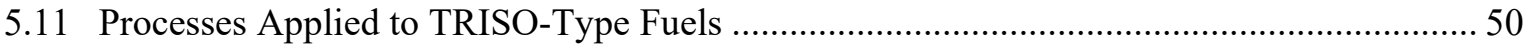




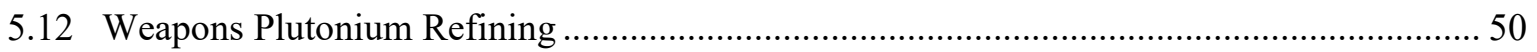

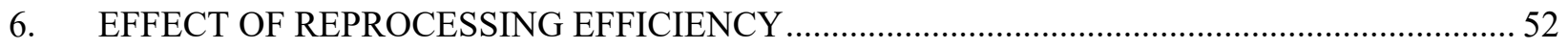

6.1 The Importance of Maximizing the Retention of Fissile Materials .................................... 53

6.2 The Importance of Maximizing the Rejection of Fission Products..................................... 54

6.3 Remarks on the Abstracted Fuel Cycle Models ................................................................. 56

6.4 The Considerations of Fundamental Complexities ........................................................... 57

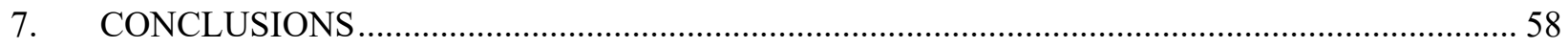

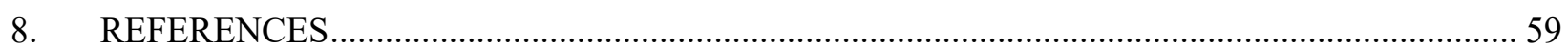

\section{FIGURES}

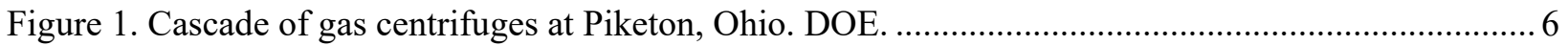

Figure 2. Photograph of CANDU reactor fuel bundle. A typical CANDU fuel bundle is about 0.1 -m-diameter and 0.5 -m-length, and weighs about $24 \mathrm{~kg}$. This bundle appears to contain 37 fuel elements in sequential layers of $18,12,6$, and 1 .

Figure 3. Photograph of PWR fuel assembly. Typical PWR and BWR grids are square and contain 14 to 18 and 8 to 10 fuel elements per row, respectively. The square dimensions range from about 0.14 to $0.23 \mathrm{~m}$, lengths from 3.9 to $4.8 \mathrm{~m}$, and weights from 500 to $700 \mathrm{~kg}$. Enrichment levels range up to about $5 \mathrm{wt} \%{ }^{235} \mathrm{U}$.

Figure 4. Photograph of BN-800 Reactor fuel assemblies, Beloyarsk Nuclear Power Station, Sverdlovsk Oblast, Russia. MOX fuel clad in stainless steel. The BN-800 reactor is an SFR.

Figure 5. Photograph of Ohma Nuclear Power Plant fuel assembly, Aomori Prefecture, Japan. MOX fuel clad in zirconium alloy. The Ohma reactor is an ABWR.

Figure 6. Photograph of typical Hanford Reactor fuel elements (single-pass-coolant reactor design). Single extruded tube of NU clad in aluminum alloy. 20-cm-length, 2.5-cmoutside-diameter, weighing $4 \mathrm{~kg}$.

Figure 7. Photograph of Hanford N-Reactor fuel element (circulating-primary-coolant reactor design). Two coextruded concentric tubes (tube-in-tube design) of natural or slightly enriched $\left(1.25 \mathrm{wt} \%{ }^{235} \mathrm{U}\right)$ uranium clad in zirconium alloy. 66-cm-length, 5-cmoutside-diameter, weighing $24 \mathrm{~kg}$.

Figure 8. Photograph of examples of MAGNOX fuel cans. NU clad in magnesium alloy. MAGNOX fuel slugs ranged in size from about 50 to 90 -cm-length, weights 5 to $12 \mathrm{~kg}$, and all were close to 2.8 -cm-diameter.

Figure 9. Photograph of a cut-away EBR-II driver fuel subassembly. (DOE photograph)

Figure 10. Mosaic microphotographs of a cross section of an EBR-II Mk-IIIA driver fuel element after $10 \%$ burnup. The outer grey ring is the stainless steel cladding that has an $0.23-$ in.-OD. The arrows mark the ID of the cladding wall. The fuel has swelled and is touching the cladding wall. (Luca Capriotto, INL) 24

Figure 11. Photograph of typical research reactor plate fuel assemblies. (BWXT photograph) 26 
Figure 12. Photograph of breached TRISO fuel particle. The spherical uranium oxide kernel is encapsulated by successive layers of pyrolytic carbon and silicon carbide. (DOE photograph).

Figure 13. Photographs of graphite cylinder containing a dispersion of TRISO fuel particles. The image on the left is a cross section of the cylinder. (DOE photographs).

Figure 14. Photographs of a graphite sphere ("pebble") containing a dispersion of TRISO fuel particles. The image on the left is a partial cross section of a graphite sphere. (DOE photographs)

Figure 15. Operational chronology of U.S. LMRs. 39

Figure 16. Illustration of the Integrated Fuel Reprocessing Scheme 52

Figure 17. Process Model for Fissile Material Retention. 53

Figure 18. Process Model for Fission Product Rejection 54

\section{TABLES}

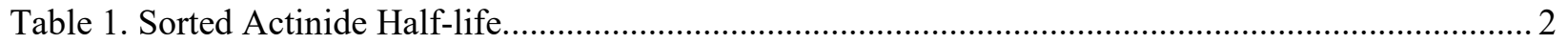

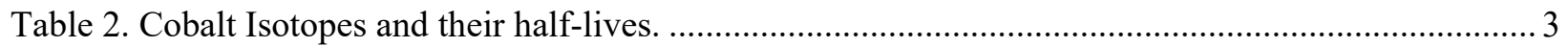

Table 3. Summary of High-Level Nuclear Reactor Design Options. ......................................................... 10

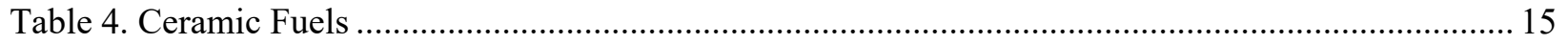

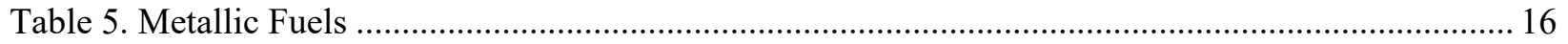

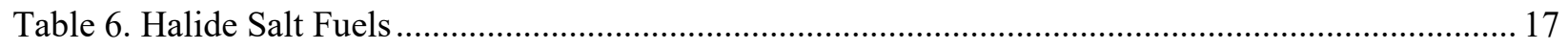

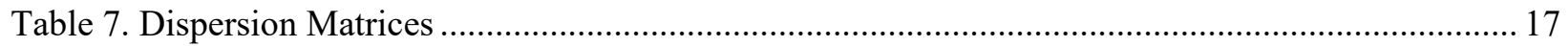

Table 8. Summary of Major International Reprocessing Facilities. ......................................................... 35

Table 9. Summary Technical Specifications and References of U.S. LMRs.......................................... 41

Table 10. Fissile Material Loss Results of Fissile Material Model............................................................ 54

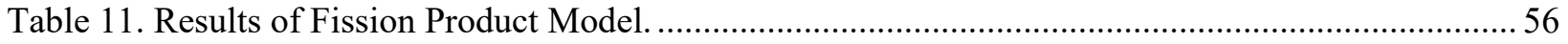


Page intentionally left blank 


\section{ACRONYMS}

ABWR Advanced Boiling Water Reactor

AEC

Atomic Energy Commission

AGR

Advanced Gas-Cooled Reactor

ALMR

Advanced Liquid Metal Reactor

ANL

Argonne National Laboratory

ANL-W

Argonne National Laboratory West

AHR

Aqueous Homogenous Reactor

BARC

Bhabha Atomic Research Centre

BISO

Bi-Structural Isotropic Fuel

BWR

Boiling Water Reactor

CANDU Canada Deuterium Uranium

CORAL Compact Reprocessing Facility for Advanced Fuels

CR

Conversion Ratio

CRBRP Clinch River Breeder Reactor Project

CVD Chemical Vapor Deposition

DFRP Demonstration Fast Reactor Plant

DOE Department of Energy

DU Depleted Uranium

EBR-I Experimental Breeder Reactor I

EBR-II Experimental Breeder Reactor II

EFFBR Enrico Fermi Fast Breeder Reactor

FBTR Fast Breeder Test Reactor

FCF Fuel Cycle Facility and Fuel Conditioning Facility

FFR Fluid Flow Reactor

FFTF Fast Flux Test Facility

FRFRP Fast Reactor Fuel Reprocessing Plant

FRR Foreign Research Reactor

GGR Graphite Gas-Cooled Reactor

GTRI Global Threat Reduction Initiative 


\begin{tabular}{|c|c|}
\hline HEU & High Enriched Uranium \\
\hline HNPF & Hallam Nuclear Power Facility \\
\hline HS & Hanford Site \\
\hline HTI & High Temperature Isotropic \\
\hline HTGR & High Temperature Gas-Cooled Reactor \\
\hline HTR & High Temperature Reactor \\
\hline HWR & Heavy Water Reactor \\
\hline IFR & Integral Fast Reactor \\
\hline IGCAR & Indira Gandhi Centre for Atomic Research \\
\hline IMF & Inert Matrix Fuel \\
\hline INL & Idaho National Laboratory \\
\hline KARP & Kalpakkam Atomic Reprocessing Plant \\
\hline kWth & Kilowatt Thermal \\
\hline LAMPRE & Los Alamos Moten Plutonium Reactor Experiment \\
\hline LANL & Los Alamos National Laboratory \\
\hline LEU & Low Enriched Uranium \\
\hline LFR & Lead-Cooled Fast Reactor \\
\hline LLNL & Lawrence Livermore National Laboratory \\
\hline LMFBR & Liquid Metal-Cooled Fast Breeder Reactor \\
\hline LMFR & Liquid Metal Fueled Reactor \\
\hline LMR & Liquid Metal-Cooled Reactor \\
\hline LWR & Light Water Reactor \\
\hline LTI & Low Temperature Isotropic \\
\hline MA & Minor Actinides \\
\hline MAGNOX & MAGnesium No OXidation Aluminum \\
\hline MAPS & Madras Atomic Power Station \\
\hline MOX & Mixed Oxide Fuel \\
\hline MSBR & Molten Salt Breeder Reactor \\
\hline MSR & Molten Salt Reactor \\
\hline MSRE & Molten Salt Reactor Experiment \\
\hline
\end{tabular}




\begin{tabular}{|c|c|}
\hline MT & Metric Ton $(1000$ kg) \\
\hline MTHM & Metric Ton Heavy Metal \\
\hline MWth & Megawatt Thermal \\
\hline $\mathrm{NRC}$ & Nuclear Regulatory Commission \\
\hline NU & Natural Uranium \\
\hline ORNL & Oak Ridge National Laboratory \\
\hline PDC & Pilot Demonstration Centre \\
\hline PDPC & Pilot Demonstration Power Complex \\
\hline PHWR & Pressurized Heavy Water Reactors \\
\hline PRISM & Power Reactor Innovative Small Module \\
\hline PRP & Plutonium Reprocessing Plant \\
\hline PRTRF & Power Reactor Thoria Reprocessing Facility \\
\hline PUREX & Plutonium Uranium Reduction by Extraction \\
\hline PWR & Pressurized Water Reactor \\
\hline RAPS & Rajasthan Atomic Power Station \\
\hline RBMK & Reaktor Bolshoy Moshchnosty Kanalny (Russian Designation) \\
\hline $\mathrm{RCW}$ & Radiochemical Works \\
\hline REDOX & Reduction Oxidation \\
\hline RERTR & Reduced Enrichment for Research and Test Reactors \\
\hline RFP & Rocky Flats Plant \\
\hline RIAR & Research Institute of Atomic Reactors \\
\hline $\mathrm{RR}$ & Research Reactor \\
\hline $\mathrm{S} 1 \mathrm{G}, \mathrm{S} 2 \mathrm{G}$ & $\mathrm{S}=$ Submarine, $1=$ First, $2=$ Second, $\mathrm{G}=$ General Electric \\
\hline $\mathrm{S} 1 \mathrm{~W}, \mathrm{~S} 2 \mathrm{~W}$ & $\mathrm{~S}=$ Submarine, $1=$ First, $2=$ Second, $\mathrm{W}=$ Westinghouse \\
\hline SAFR & Sodium Advanced Fast Reactor \\
\hline SCE & Siberia Chemical Enterprise \\
\hline $\mathrm{SCP}$ & Salt Cycle Process \\
\hline SEFOR & Southwest Experimental Fast Oxide Reactor \\
\hline SFR & Sodium-Cooled Fast Reactor \\
\hline SFT & Spent Fuel Treatment \\
\hline
\end{tabular}


SGBR Sodium-Cooled Graphite Breeder Reactor

SGR Sodium-Cooled Graphite Reactor

SIR Submarine Intermediate Reactor

SMR Small Modular Reactor

SNF Spent Nuclear Fuel

SRE Sodium Reactor Experiment

SRS Savannah River Site

SFL Santa Susana Field Laboratory

SSN U.S. Navy Designation for Attack Submarine

THORP Thermal Oxide Reprocessing Plant

TRIGA Training, Research, Isotopes, General Atomics

TRISO Tri-structural isotropic

TVA Tennessee Valley Authority

UNGG Uranium Naturel Graphite Gaz-Cooled

UTSF Uranium Thorium Separation Facility

VVER Water-Water Energetic Reactor (Russian Designation) 


\section{Review - Nuclear Fuels and Reprocessing Technologies: A U.S. Perspective}

\section{INTRODUCTION}

In the U.S. since the 1940s research has pursued almost every imaginable avenue of nuclear technology development. Exploitation of natural resources involved the mining and extraction of uranium and thorium. Deployment of nuclear reactors required the development and testing of fuel and reactor designs. Military pursuits included weapons, propulsion, and remote power systems. And the requirements for supporting technologies introduced isotopic separations, spent fuel reprocessing, and nuclear waste management. Remarkable is the great number of options available to each of these engineering and scientific pursuits.

Nuclear energy has been proposed for explosives for military and civil engineering purposes, naval propulsion, airplane propulsion, rocket propulsion, radiation sources, electrical power generation, chemical process heat generation, and hydrogen generation. Nuclear fuel forms include metals, alloys, liquid metals, molten salts, aqueous solutions, organic solutions, oxides, hydrides, carbides, nitrides, and other ceramics.

The objective of this report is to provide a perspective on the history and body of knowledge associated with nuclear fuels and reprocessing technologies. Information in these areas is spread throughout the literature. Hopefully, the information consolidated and presented here will provide a convenient summary for those interested in these disciplines.

\section{MATERIALS BACKGROUND}

Nuclear reactors generate thermal energy (heat) by the processes of controlled fission. Fission occurs when a heavier element splits (fissions) into two lighter element fission products. There are only two fundamental sources of fissionable elements for use as nuclear fuel: i) recovery from the earth's crust and

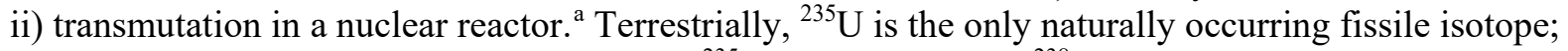
natural uranium (NU) is nominally $0.73 \mathrm{wt} \%{ }^{235} \mathrm{U}$ with the balance ${ }^{238} \mathrm{U}$. As will be discussed later, reactors can operate with NU or uranium enriched in ${ }^{235} \mathrm{U} .{ }^{232} \mathrm{Th}$ is the only naturally occurring thorium isotope, and ${ }^{232} \mathrm{Th}$ and ${ }^{238} \mathrm{U}$ are the only naturally occurring fertile isotopes. Reactors can be used to create fissile isotopes by exploiting the transmutation of ${ }^{238} \mathrm{U}$ to ${ }^{239} \mathrm{Pu}$, and ${ }^{232} \mathrm{Th}$ to ${ }^{233} \mathrm{U}$. ${ }^{239} \mathrm{Pu}$ and ${ }^{233} \mathrm{U}$ are, like ${ }^{235} \mathrm{U}$, fissile isotopes.

Elements originate from cosmic stellar processes. It is theorized that the elements comprising earth formed during a supernova about $6.5 \mathrm{E}+9$ years ago, while the earth itself formed into a planet about $4.5 \mathrm{E}+9$ years ago. Therefore, the inventory of elements that comprised the earth at its formation have only been subject to the processes of radioactive decay. Consequently, all the actinide elements whose halflives are considerably shorter than the age of the earth have, for all practical purposes, disappeared. For example, after a period of 20 half-lives, only one millionth of the original quantity remains. After 27 halflives, about one billionth.

a. Reprocessing technologies are a means of recovering fissionable elements from spent nuclear fuels, and for the purpose of this discussion are not considered a fundamental source of these elements. 
The heaviest stable isotope is ${ }^{209} \mathrm{Bi}$. All elements heavier than bismuth are subject to radioactive decay and are in the process of disappearing. Consequently, elements heavier than uranium ${ }^{\mathrm{b}}$ do not exist in nature beyond trace quantities that are much too small to serve as resources. Table 1 lists the actinide isotopes with long half-lives. Note that ${ }^{232} \mathrm{Th},{ }^{238} \mathrm{U}$, and ${ }^{235} \mathrm{U}$ have the longest half-lives, which explains the abundance of these isotopes in the earth's crust. Also, the relatively long half-lives of ${ }^{233} \mathrm{U}$ and ${ }^{239} \mathrm{Pu}$, man-made fissile isotopes with transmutation of ${ }^{232} \mathrm{Th}$ and ${ }^{238} \mathrm{U}$, render these isotopes useful for nuclear fission applications.

Table 1. Sorted Actinide Half-life.

\begin{tabular}{|c|c|c|}
\hline Isotope & Half-life (year) & $\begin{array}{c}\text { Half-lives Since } \\
\text { Formation of Earth }\end{array}$ \\
\hline${ }^{232} \mathrm{Th}$ & $1.41 \mathrm{E}+10$ & 0.32 \\
\hline${ }^{238} \mathrm{U}$ & $4.51 \mathrm{E}+09$ & 1.0 \\
\hline${ }^{235} \mathrm{U}$ & $7.10 \mathrm{E}+08$ & 6.4 \\
\hline${ }^{244} \mathrm{Pu}$ & $8.28 \mathrm{E}+07$ & 55 \\
\hline${ }^{236} \mathrm{U}$ & $2.39 \mathrm{E}+07$ & 190 \\
\hline${ }^{247} \mathrm{Cm}$ & $1.64 \mathrm{E}+07$ & 280 \\
\hline${ }^{237} \mathrm{~Np}$ & $2.14 \mathrm{E}+06$ & 2100 \\
\hline${ }^{242} \mathrm{Pu}$ & $3.79 \mathrm{E}+05$ & 12000 \\
\hline${ }^{248} \mathrm{Cm}$ & $3.52 \mathrm{E}+05$ & 12906 \\
\hline${ }^{234} \mathrm{U}$ & $2.47 \mathrm{E}+05$ & 18393 \\
\hline${ }^{233} \mathrm{U}$ & $1.62 \mathrm{E}+05$ & 28043 \\
\hline${ }^{230} \mathrm{Th}$ & $8.00 \mathrm{E}+04$ & 56788 \\
\hline${ }^{231} \mathrm{~Pa}$ & $3.25 \mathrm{E}+04$ & 139785 \\
\hline${ }^{239} \mathrm{Pu}$ & $2.44 \mathrm{E}+04$ & 186189 \\
\hline & & \\
\hline
\end{tabular}

Fission cross section is a measure of the probability of a fissionable nucleus capturing an incident neutron and undergoing fission. There is a distinction made between fissionable and fissile isotopes. Fissile isotopes are a subset of fissionable isotopes; therefore, the number of fissionable isotopes is greater than the number of fissile isotopes. Fissile isotopes are readily fissionable in any spectrum. Whereas fissionable isotopes are only readily fissionable in a fast neutron spectrum. As stated earlier, ${ }^{235} \mathrm{U},{ }^{233} \mathrm{U},{ }^{239} \mathrm{Pu}$, and ${ }^{241} \mathrm{Pu}$ are fissile isotopes. ${ }^{232} \mathrm{Th}$ and ${ }^{238} \mathrm{U}$ are not considered fissile isotopes because their fission cross section is very low in the thermal neutron spectrum. However, they are both readily fissionable in a fast neutron spectrum. Therefore, ${ }^{232} \mathrm{Th}$ and ${ }^{238} \mathrm{U}$ are fissionable isotopes.

Capture cross section is a measure of the probability of a nucleus capturing an incident neutron and undergoing transmutation. The isotopes of many elements exhibit this property and are capable of transmutation to heavier isotopes via the process of neutron capture. Fertile isotopes are those capable of transmutating into fissile isotopes by the process of neutron capture in a thermal neutron spectrum. As stated earlier, ${ }^{232} \mathrm{Th}$ and ${ }^{238} \mathrm{U}$ are the only two naturally occurring fertile isotopes. ${ }^{1}$

b. Actinide elements heavier than uranium are called transuranics. Elements heavier than the actinide series are called transactinides. 
Transmutation by neutron capture also leads to the formation of activation products (radioisotopes) in the materials of construction of the reactor core. For example, ${ }^{59} \mathrm{Co}$ is the only naturally occurring cobalt isotope because all other cobalt isotopes have short half-lives and are not stable in a geologic sense, see Table 2. Cobalt is a common alloying element in stainless steels. A common phenomenon in nuclear reactor stainless steel hardware is ${ }^{59} \mathrm{Co}$ transmutation to ${ }^{60} \mathrm{Co}$, which is subject to decay by beta and gamma emissions to stable ${ }^{60} \mathrm{Ni}$. However, transmutation is not restricted to the process of neutron capture; transmutation involves any process by which an isotope can convert to another isotope of the same element or a different element. Radioactive decay is another process by which transmutation can occur.

Table 2. Cobalt Isotopes and their half-lives.

\begin{tabular}{|c|c|}
\hline Isotope & Half-life \\
\hline${ }^{58} \mathrm{Co}$ & $7.13 \mathrm{E}+01$ days \\
\hline${ }^{58 m} \mathrm{Co}$ & $9.00 \mathrm{E}+00 \mathrm{hr}$ \\
\hline${ }^{59} \mathrm{Co}$ & Stable \\
\hline${ }^{60} \mathrm{Co}$ & $5.26 \mathrm{E}+00 \mathrm{yr}$ \\
\hline${ }^{60 \mathrm{~m}} \mathrm{Co}$ & $1.05 \mathrm{E}+01 \mathrm{~min}$ \\
\hline${ }^{61} \mathrm{Co}$ & $9.90 \mathrm{E}+01 \mathrm{~min}$ \\
\hline${ }^{62} \mathrm{Co}$ & $1.39 \mathrm{E}+01 \mathrm{~min}$ \\
\hline${ }^{72} \mathrm{Co}$ & $1.23 \mathrm{E}-01 \mathrm{sec}$ \\
\hline${ }^{73} \mathrm{Co}$ & $1.16 \mathrm{E}-01 \mathrm{sec}$ \\
\hline${ }^{74} \mathrm{Co}$ & $1.08 \mathrm{E}-01 \mathrm{sec}$ \\
\hline${ }^{75} \mathrm{Co}$ & $8.02 \mathrm{E}-02 \mathrm{sec}$ \\
\hline
\end{tabular}

All fissionable isotopes are radioisotopes, which means they are not stable isotopes. All radioisotopes are constantly subject to the processes of radioactive decay until they become stable isotopes. The decay chain is the path by which a radioisotope becomes a stable isotope. Mechanisms of radioactive decay include alpha decay ( $\alpha$ or ${ }^{4} \mathrm{He}$ ), beta decay $(\beta)$, gamma decay $(\gamma)$, electron capture, neutron emission, and spontaneous fission. Isotopes that undergo the processes of spontaneous fission are a subset of fissionable isotopes. This implies that as a material property, fissionable isotopes are always associated with an inherent, albeit small, neutron flux. However, the inherent neutron flux of fissionable isotopes can promote and accelerate nuclear fission when enough mass in accumulated under the right conditions of geometry, neutron moderation, and neutron reflection. Critical mass is the minimal mass required to sustain nuclear fission under a defined set of these conditions.

A reactor's core is designed to facilitate controlled fission. Control of a reactor's core is maintained by several mechanisms, from both external sources and internal sources. Control rods are an example of the former, and fuel reactivity is an example of the latter. Control rods work on the principle of inserting select isotopes into the reactor core that readily absorb neutrons. The reactor cannot achieve criticality with the control rods inserted into the core. An example is cadmium-bearing control rods in which ${ }^{113} \mathrm{Cd}$ (with its large capture cross section) absorbs thermal neutrons and transmutes to ${ }^{114} \mathrm{Cd}$. However, capture cross section of cadmium drops precipitously in the fast neutron spectrum, meaning that cadmium is not an effective control mechanism in fast reactors. ${ }^{10} \mathrm{~B}$ has applications in both thermal and fast reactors. Natural boron is nominally $19.9 \mathrm{wt} \%{ }^{10} \mathrm{~B}$ with the balance ${ }^{11} \mathrm{~B}$. Upon capturing a neutron, ${ }^{10} \mathrm{~B}$ fissions into ${ }^{7} \mathrm{Li}$ and ${ }^{4} \mathrm{He}$. Boron used for control applications is often enriched with respect to ${ }^{10} \mathrm{~B}$ to levels greater than $90 \%{ }^{2}$ A fueled control rod is the opposite approach. The reactor cannot achieve criticality unless the fueled control rods are inserted into the core. 
The primary purpose of the fissile inventory is to support fission, and the primary purpose of the fertile inventory is to support transmutation leading ultimately to the creation of fissile isotopes. Fissile and fertile materials can be in two very distinct regions of the reactor, such as fuel and blanket regions, respectively; or they can be intermixed. Of course, even when partitioned into two very distinct regions some degree of transmutation always occurs in the fuel; just as some degree of fission always occurs in the blanket. The proportions and types of fissile and fertile materials, and how they are distributed within the reactor, are designed to control the reactor's breeding ratio. A reactor with a breeding ratio less than one is a net consumer of fissile material. A reactor with a breeding ratio equal to one is self-sustaining with respect to fissile material but will require a feed of fertile material. A reactor with a breeding ratio greater than one is a net producer of fissile material, but again will require a feed of fertile material. Nuclear fuel cycle reprocessing schemes are a requirement of the latter two.

Nuclear fuel cycle strategies are determined by government policy makers for both commercial and military applications. An "open fuel cycle" entails no form of reprocessing, the fresh fuels are fabricated from virgin reserves and the spent fuels are slated for interim storage and eventual geologic disposal. A "closed fuel cycle" utilizes reprocessing technologies for the combined purposes of natural resource conservation, carbon emission reduction, and waste minimization. As stated earlier, ${ }^{235} \mathrm{U}$ is the only naturally occurring fissile isotope and its concentration is only $0.73 \mathrm{wt} \%$ in NU. There are far greater reserves of the fertile isotopes ${ }^{232} \mathrm{Th}$ and ${ }^{238} \mathrm{U}$, than the fissile isotope ${ }^{235} \mathrm{U}$. Obviously, the most conservative utilization of ${ }^{235} \mathrm{U}$ necessitates a closed fuel cycle based on breeder reactor technologies. ${ }^{\mathrm{c}}$ The energy density differential between carbon fuels and nuclear fuels is many orders of magnitude, and due to its extremely high energy density, nuclear energy produces a correspondingly low mass of radionuclide waste. Waste minimization strategies are mostly concerned with the exclusion of long-lived radioisotopes and the stabilization of the waste forms designed for geologic repositories.

Nuclear fuel reprocessing technologies are designed to support nuclear fuel cycle objectives. Chemical separations lie at the heart of any reprocessing technology. The goal of chemical separations is to selectively separate the elements to be retained in the fuel cycle from the elements to be rejected from the fuel cycle as waste. Generally, all fissile elements are retained, all or a fraction of the fertile elements are retained, and all other fission product elements are rejected. However, the exact goal of chemical separations is largely dependent on the exact objectives of the fuel cycle. For example, in some fuel cycle scenarios the minor actinides are retained in the fuel cycle to lessen the radioisotope burden of these elements reporting to the process waste streams.

It is important to realize that there are a great variety of reactor designs and, consequently, an even greater variety of nuclear fuel types, as in some cases a single reactor design can utilize several different fuel types. The reasons for these great varieties of reactors and fuels are many fold and stem, fundamentally, from the great many varieties of size, application, location, and fuel cycle requirements. Sizes range from $\mathrm{kWth}$ to multiples of MWth. Applications include the production of neutrons, isotopes, heat, thrust, and electrical power. Locations are based on land, sea, air, and space. And fuel cycle objectives include open fuel cycles and many variants of closed fuel cycles, including breeding ${ }^{239} \mathrm{Pu}$ from ${ }^{238} \mathrm{U}$, breeding ${ }^{233} \mathrm{U}$ from ${ }^{232} \mathrm{Th}$, burning weapons grade plutonium, and burning minor actinides.

The public and governmental perception of nuclear energy was severely negatively impacted by the accidents at Three Mile Island (1979), Chernobyl (1986), and Fukushima (2011), and by the legacy nuclear wastes generated during the U.S./USSR cold war at sites like Hanford, Savannah River, and the Nevada Test Site. To make matters worse, nuclear wastes continue to be generated by the U.S. civilian energy reactor fleet and the U.S. military naval reactor fleet with no commercial reprocessing capabilities and no geologic repository to serve as the final destination for these materials. As a result of this history, safety and waste generation considerations are, more than ever before, the factors most significantly

c. During the early years of nuclear development in the 1940 s to the 1960 s, minable uranium reserves were considered to be very limited and mush attention was focused on breeder reactor technologies. 
influencing reactor and fuel design requirements, particularly in the arena of civilian power production, which is the greatest application of nuclear energy.

\subsection{Mining and Extraction of Uranium and Thorium}

Uranium and thorium are recovered from the earth's crust via various mining and extraction methods. ${ }^{3-8}$ In its raw form, refined uranium is recovered from ore as a mill concentrate called "yellow cake." The name is derived from its bright yellow color, and the fact that it is recovered as a vacuum-filter cake following precipitation during the final stages of the solvent extraction operations. Yellow cake has a process-dependent complex composition, but it is mostly ammonium diuranate $\left(\left(\mathrm{NH}_{4}\right)_{2} \cdot \mathrm{U}_{2} \mathrm{O}_{7}\right)$ with minor amounts of other uranium compounds. Subsequent purification and controlled calcination are required to convert yellow cake into nuclear-grade $\mathrm{U}_{3} \mathrm{O}_{8}$ or $\mathrm{UO}_{2}$. Different process chemistries, but similar methodologies, are used to produce nuclear-grade $\mathrm{ThO}_{2}$ from ores.

If the yellow cake, natural uranium oxide, or thorium oxide are to be used in any other forms, these materials must be converted by additional chemical processing such as reduction to metals, constitution into alloys, and conversion to carbides, nitrides, fluorides, chlorides, etc. When enriched uranium is required, the yellow cake is converted to uranium hexafluoride $\left(\mathrm{UF}_{6}\right)$ at a "conversion plant" by the action of hydrogen fluoride $(\mathrm{HF})$. And the $\mathrm{UF}_{6}$ is subsequently enriched at an "enrichment plant" by processes of diffusion-based or centrifuge-based isotopic enrichment.

\subsection{Uranium, Lithium, Chlorine, and Nitrogen Enrichment}

As stated earlier, NU is nominally $0.73 \mathrm{wt} \%{ }^{235} \mathrm{U}$ with the balance ${ }^{238} \mathrm{U}$. Although NU is used to fuel certain types of reactors, it is also the practice to use enriched uranium. The levels of uranium enrichment (with respect to $\mathrm{wt} \%{ }^{235} \mathrm{U}$ ) are categorized as depleted uranium $(\mathrm{DU}<0.73)$, natural uranium $(\mathrm{NU}=$ $0.73)$, low enriched uranium $(0.73<\mathrm{LEU}<20)$, and high enriched uranium (HEU $\geq 20)$. High assay low enriched uranium $(5<$ HALEU $<20)$ is another category of interest for use in research reactors and the development of technologies like small modular reactors (SMRs).

The two most common technologies used for uranium enrichment are gaseous diffusion and centrifuging. In preparation for these processes, NU is purified and converted to uranium hexafluoride $\left(\mathrm{UF}_{6}\right)$, which is gaseous at moderate temperatures and pressures. Natural fluorine is isotopically pure ${ }^{19} \mathrm{~F}$. $\mathrm{UF}_{6}$ from ${ }^{238} \mathrm{U}$ is $0.86 \mathrm{wt} \%$ heavier than $\mathrm{UF}_{6}$ from ${ }^{235} \mathrm{U}$. This small mass difference is exploited by the enrichment technologies to create two $U_{6}$ product streams, one enriched with respect to ${ }^{235} \mathrm{U}$ and one depleted with respect to ${ }^{235} \mathrm{U}$. The enriched $\mathrm{UF}_{6}$ is converted to metallic uranium or uranium oxide depending on its intended use. These technologies can produce enrichment levels greater than $93 \mathrm{wt} \%$ ${ }^{235}$ U. The U.S. has large stockpiles of depleted $U_{6}$ stored in steel cylinders because, historically, the supply of DU is much greater than the demand for DU. The U.S. had gaseous diffusion plants at Paducah, Kentucky; Piketon, Ohio; and Oak Ridge, Tennessee. These plants are now shut down. Gaseous diffusion technologies have been supplanted by centrifuge technologies. A centrifuge cascade is shown in Figure 1. Variants of laser-based technologies, which are a third means of enriching uranium, are possibly gaining economic advantage. ${ }^{9-11}$ The following is a list of historic enrichment plants in the U.S.

- K-25, K-27, K-29, K-31, and K-33 Plants: These were gaseous diffusion plants located at Oak Ridge National Laboratory (ORNL), Oak Ridge, Tennessee. They produced HEU and operated from 1944 to 1985 . All plants were completely dismantled by 2017 .

- Paducah Gaseous Diffusion Plant, Paducah, Kentucky. Produced LEU that was further refined to HEU at the Portsmouth and Oak Ridge plants and operated from 1952 to 2013.

- Portsmouth Gaseous Diffusion Plant (a.k.a., A-Plant), Piketon, Ohio. Produced HEU and operated from 1956 to 2001.

- S-50 Plant: Liquid Thermal Diffusion Plant. Produced HEU and operated from 1942 to 1946. 


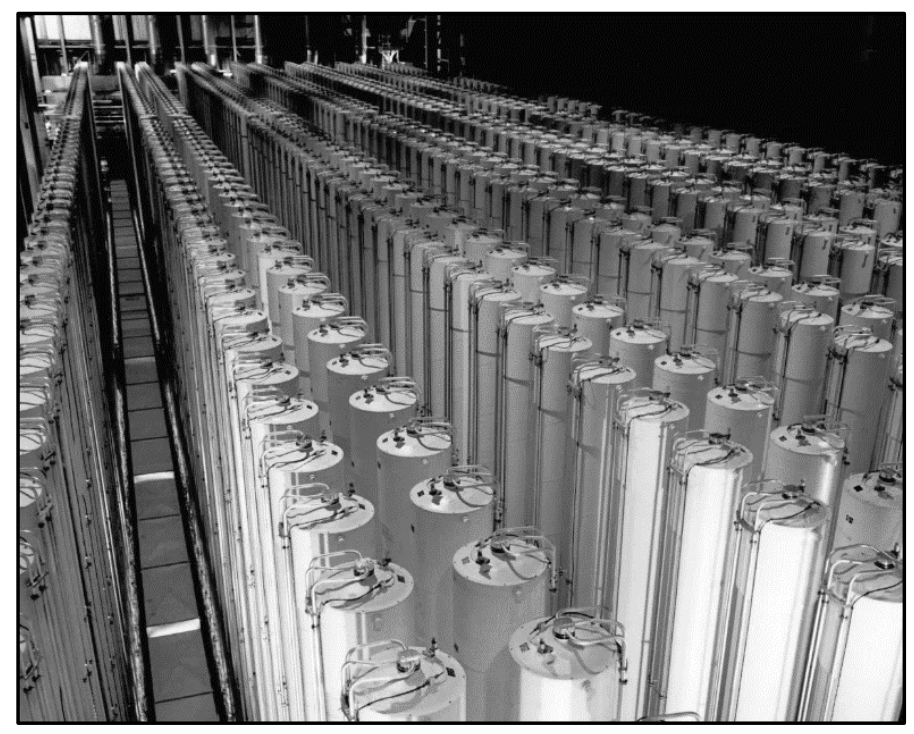

Figure 1. Cascade of gas centrifuges at Piketon, Ohio. DOE.

- Y-12 Plant: Used calutron technologies to perform isotopic separations based on electromagnetic principles. Produced HEU and other isotopes. Included 1152 calutrons arranged in nine Alpha and eight Beta "racetracks." The product of the Alpha process was feed to the Beta process. Operated from 1943 to 1946 when all Alpha and six Beta racetracks were dismantled. The Beta-3 racetrack still exists.

There are other elements whose enrichments are necessary to support molten salt reactor (MSR) technologies: lithium and chlorine. Lithium is proposed for use in fluoride salt MSRs as lithium fluoride (LiF). Natural lithium is $7.5 \mathrm{wt} \%{ }^{6} \mathrm{Li}$ with the balance ${ }^{7} \mathrm{Li}$. Interestingly, ${ }^{6} \mathrm{Li}$ is the only stable light element that can produce net energy through fission. The fission of ${ }^{6} \mathrm{Li}$ by neutron capture produces ${ }^{4} \mathrm{He}$ and ${ }^{3} \mathrm{H}$. MSR applications desire lithium enriched with respect to ${ }^{7} \mathrm{Li}$ to suppress the production of tritium. For example, the ORNL molten salt reactor experiment (MSRE) used lithium that was $99.99 \mathrm{wt} \%$ ${ }^{7} \mathrm{Li} .{ }^{12,13} \mathrm{The}{ }^{7} \mathrm{Li}$ used in the MSRE was the biproduct of former ${ }^{6} \mathrm{Li}$ enrichment activities at ORNL for use in nuclear weapons. ${ }^{14}$

MSR concepts also include chloride salts. Natural chlorine is $75.8 \mathrm{wt} \%{ }^{35} \mathrm{Cl}$ with the balance ${ }^{37} \mathrm{Cl}$. The capture cross section of ${ }^{35} \mathrm{Cl}$ is 10 times greater than that of ${ }^{37} \mathrm{Cl}$. Therefore, ${ }^{35} \mathrm{Cl}$ has a significant effect on the neutron economy within the core. Also, ${ }^{35} \mathrm{Cl}$ transmutes to ${ }^{36} \mathrm{Cl}$ by ${ }^{35} \mathrm{Cl}(\mathrm{n}, \gamma)={ }^{36} \mathrm{Cl}$, capturing a neutron and ejecting a gamma ray, which is a long-lived radionuclide with high energy beta emissions. The former issue must be considered in reactor design and application, and the latter in salt waste management. Therefore, chloride salt MSRs will desire chlorine enriched with respect to ${ }^{37} \mathrm{Cl}$. However, this remains conceptual as there have been no chloride salt MSRs operated.

Nitride-based ceramic fuels require enrichment with respect to ${ }^{15} \mathrm{~N} .{ }^{15-17}$ Natural nitrogen is $99.6 \mathrm{wt} \%$ ${ }^{14} \mathrm{~N}$ and $0.4 \mathrm{wt} \%{ }^{15} \mathrm{~N}$. In the presence of thermal neutrons, ${ }^{14} \mathrm{~N}$ transmutes to ${ }^{14} \mathrm{C}$ by ${ }^{14} \mathrm{~N}(\mathrm{n}, \mathrm{p}) \rightarrow{ }^{14} \mathrm{C}$ (capturing a neutron and ejecting a proton). The capture cross section of ${ }^{14} \mathrm{~N}$ is five orders of magnitude greater than that of ${ }^{15} \mathrm{~N}$. This $(\mathrm{n}, \mathrm{p})$ reaction affects the neutron economy of the core and produces the undesirable radioisotope ${ }^{14} \mathrm{C}$ as a byproduct. The same $(\mathrm{n}, \mathrm{p})$ reaction occurs in earth's upper atmosphere and is a natural source of ${ }^{14} \mathrm{C}$, which has a half-life of about 5,700 years; much too short to otherwise be a naturally occurring isotope if there was not a natural mechanism for its generation.

Isotopic enrichment of any kind is a costly process, which is one of the reasons why much consideration is given to fuel cycle scenarios involving the recovery of ${ }^{235} \mathrm{U}$. Another reason is the conservation of ${ }^{235} \mathrm{U}$ as a natural resource. Since there are no natural resource shortages of lithium and 
chlorine, in MSR applications the decision to recycle ${ }^{7} \mathrm{Li}$ and ${ }^{37} \mathrm{Cl}$ is purely based on technical and economic considerations. Likewise, for the use of ${ }^{15} \mathrm{~N}$ in nitride fuels.

\subsection{Hydrogen}

The three most significant hydrogen isotopes are ${ }^{1} \mathrm{H}$ (protium), ${ }^{2} \mathrm{H}$ (deuterium), and ${ }^{3} \mathrm{H}$ (tritium). Natural hydrogen is $99.99 \mathrm{wt} \%{ }^{1} \mathrm{H}$ and $0.01 \mathrm{wt} \%{ }^{2} \mathrm{H}$. Heavy water is water enriched with respect to ${ }^{2} \mathrm{H} .{ }^{18-20}$ As a neutron moderator in nuclear reactor applications, heavy water can be enriched up to $99.75 \%$ ${ }^{2} \mathrm{H}$ and it is used in reactors that operate on NU. In contrast, light water is simply natural water.

Like ${ }^{14} \mathrm{C},{ }^{3} \mathrm{H}$ occurs naturally only in trace quantities from the transmutation of ${ }^{14} \mathrm{~N}$ in earth's upper atmosphere $\left({ }^{14} \mathrm{~N}+\mathrm{n} \rightarrow{ }^{12} \mathrm{C}+{ }^{3} \mathrm{H}\right)$. The half-life of ${ }^{3} \mathrm{H}$ is about 12.3 years. There are many mechanisms, both intentional and unintentional, that produce ${ }^{3} \mathrm{H}$ in nuclear reactors. ${ }^{21,22}$ If the purpose of the reactor is to generate electrical energy, then the goal is generally to minimize tritium production. However, a certain degree of tritium production is inevitable, and it is impossible to completely contain tritium within the reactor system. The most detrimental aspect of tritium release is its mobility in the natural environment, particularly when it exists as tritiated water.

The mechanisms for generating tritium in a reactor include the following transmutation reactions, which highlight the inevitability of experiencing some degree of tritium formation.

- Ternary Fission. ${ }^{3} \mathrm{H}$ is produced as a ternary fission product, i.e., when a nucleus fissions into three particles. The fission formation of ${ }^{3} \mathrm{H}$ is favored by heavy fissile isotopes and hard neutron spectrums. Therefore, this mechanism is more pronounced in fast reactors than thermal reactors.

- $\quad{ }^{2} \mathrm{H}(\mathrm{n}, \gamma) \rightarrow{ }^{3} \mathrm{H}$. Deuterium exists in heavy water moderated reactors and, to a lesser extent, in any light water reactor or water-cooled reactor.

- $\quad{ }^{3} \mathrm{He}\left(\mathrm{n},{ }^{1} \mathrm{H}\right) \rightarrow{ }^{3} \mathrm{H}$. Helium is present in some gas-cooled reactors.

- $\quad{ }^{6} \mathrm{Li}\left(\mathrm{n},{ }^{4} \mathrm{He}\right) \rightarrow{ }^{3} \mathrm{H}$ and ${ }^{7} \mathrm{Li}\left(\mathrm{n},{ }^{4} \mathrm{He}\right) \rightarrow{ }^{3} \mathrm{H}$. Lithium is present in MSRs and as an impurity in graphite.

- $\quad{ }^{10} \mathrm{~B}\left(\mathrm{n},{ }^{4} \mathrm{He},{ }^{4} \mathrm{He}\right) \rightarrow{ }^{3} \mathrm{H}$ and ${ }^{10} \mathrm{~B}\left(\mathrm{n},{ }^{4} \mathrm{He}\right) \rightarrow{ }^{7} \mathrm{Li}\left(\mathrm{n},{ }^{4} \mathrm{He}\right) \rightarrow{ }^{3} \mathrm{H}$. Boron is used in control rods, as a cooling system chemical additive in water-cooled reactors, and as an impurity in graphite.

- $\quad{ }^{12} \mathrm{C}\left(\mathrm{n},{ }^{4} \mathrm{He}\right) \rightarrow{ }^{9} \mathrm{Be}\left(\mathrm{n},{ }^{4} \mathrm{He}\right) \rightarrow{ }^{6} \mathrm{Li}\left(\mathrm{n},{ }^{4} \mathrm{He}\right) \rightarrow{ }^{3} \mathrm{H}$. Carbon is used as a moderator and/or fuel matrix in some reactors.

An important fusion reaction involving hydrogen isotopes that generates both energy and neutrons for applications in fusion reactors and thermonuclear weapons is ${ }^{2} \mathrm{H}+{ }^{3} \mathrm{H} \rightarrow{ }^{4} \mathrm{He}(\mathrm{n})$. Therefore, ${ }^{3} \mathrm{H}$ production supports these research and military sectors. Furthermore, weapons physics utilize ${ }^{6} \mathrm{Li}$ (in the form of solid lithium deuteride) for the in situ generation of ${ }^{3} \mathrm{H}$ to enhance the ${ }^{2} \mathrm{H} /{ }^{3} \mathrm{H}$ fusion reaction for the purpose of generating additional fast neutrons capable of increasing the fission yields of ${ }^{239} \mathrm{Pu}$ and ${ }^{238} \mathrm{U} .{ }^{23}$

\subsection{Krypton, Xenon, and lodine Fission Products}

Krypton, iodine, and xenon are generated as fission products. And like ${ }^{3} \mathrm{H}$, all are potentially highly mobile in the natural environment; krypton and xenon because they are noble gases, and iodine because it is an essential bio-nutrient (e.g., accumulated in the thyroid in humans). Krypton and xenon each have several stable isotopes; iodine has only one, ${ }^{127} \mathrm{I}$. The longest-lived radioisotopes of these elements are ${ }^{85} \mathrm{Kr}(10.76 \mathrm{y}),{ }^{127} \mathrm{Xe}(36.4 \mathrm{~d})$, and ${ }^{129} \mathrm{I}(1.57 \mathrm{E} 7 \mathrm{y})$. Radioisotopes with short half-lives cause few chronic environmental effects simply by virtue of their not remaining in the environment long enough to cause greater harm. In this regard, the long-lived radioisotopes are of greater concern and care must be taken to assure their containment. For example, the release of ${ }^{129} \mathrm{I}$ is likely to be a much more serious event than the equivalent release of ${ }^{127} \mathrm{Xe}$. 
Xenon is of particular interest in another way unrelated to spent fuels. ${ }^{135} \mathrm{Xe}$ has a very high neutron capture cross section and because of this xenon management is an important aspect of reactor operations with regards to neutron economy and core reactivity. ${ }^{135} \mathrm{Xe}$ is produced directly as a fission product, and also by the decay of other fission products such as ${ }^{135} \mathrm{Te}$ and ${ }^{135} \mathrm{I}$ according to the following decay series ${ }^{24}$ :

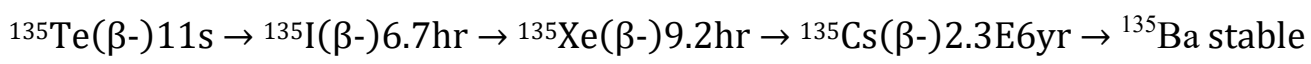

While the reactor is operating, two factors limit the ${ }^{135} \mathrm{Xe}$ equilibrium concentration: the natural decay of ${ }^{135} \mathrm{Xe}$ to ${ }^{135} \mathrm{Cs}$ (shown above), and the neutron capture of ${ }^{135} \mathrm{Xe}(\mathrm{n})={ }^{136} \mathrm{Xe}$ stable. However, following reactor core shutdown, the ${ }^{135} \mathrm{Xe}$ concentration will temporarily spike as the latter mechanism is extinguished and the decay of ${ }^{135} \mathrm{I}$ continues and dominates. However, the short half-life of ${ }^{135} \mathrm{Xe}$ renders it much less of an environmental concern than its decay product ${ }^{135} \mathrm{Cs}$.

Spent nuclear fuel contains many other long-lived radioisotopes, but these are less mobile in the natural environment than krypton, xenon, and iodine. Notable long-lived fission product radioisotopes include ${ }^{79} \mathrm{Se}(3.5 \mathrm{E} 5 \mathrm{y}),{ }^{90} \mathrm{Sr}(28.9 \mathrm{y}),{ }^{93} \mathrm{Zr}(1.5 \mathrm{E} 6 \mathrm{y}),{ }^{99} \mathrm{Tc}(2.13 \mathrm{E} 5 \mathrm{y}),{ }^{107} \mathrm{Pd}(6.5 \mathrm{E} 6 \mathrm{y}),{ }^{135} \mathrm{Cs}(2.3 \mathrm{E} 6 \mathrm{y})$, and ${ }^{137} \mathrm{Cs}(30.2 \mathrm{y}) .{ }^{131} \mathrm{I}(8 \mathrm{~d})$ is of concern in, for example, fallout from a nuclear weapon detonation or a reactor core failure, but its half-life is too short to be of concern in typical spent nuclear fuel.

\subsection{Burnable Poisons/Neutron Absorbers}

The function of control rods was briefly discussed earlier and the isotopes that act as burnable poisons are related to this topic. Burnable poisons are simply neutron absorbers which transmute into isotopes that may or may not themselves be neutron absorbers. If not, the neutron absorption process ends; if so, it continues. In this scheme the neutron capture cross section of the poison should be large, and that of the resulting terminal transmutation product should be small. This transition from large to small capture cross sections does not necessarily occur in one transmutation cycle, as will be discussed shortly. If the reactor control scheme uses poisons, for example, in the discrete control rod assemblies or in the cooling water, then these materials are generally isolated from the fuel assemblies and the subsequent reprocessing operations. However, poisons are sometimes intimately incorporated into the fuel assemblies, in which case they become part of the separations burden of the reprocessing operations.

Generally, the function of burnable poisons is to control the reactivity of the core. However, in some reactors the core is refueled periodically and incrementally. In others the core is refueled all at once, and yet in others the core is never refueled because it is intended to last for the lifetime of the reactor. In each of these cases, burnable poisons can play an important role in managing the core reactivity. As fission continues, the fissile inventory of the core is depleted, and to maintain fission chain reactions, the reactivity of the core must be increased. Control rods can only provide so much reactivity control due to engineering and physics limitations of these mechanical systems. To compensate, burnable poisons can provide additional reactivity control via in situ placement in the core. As the fissile inventory is decreased, core reactivity is maintained by the consumption of the poisons, which in some regards is functionally equivalent to the slow removal of control rods from the core.

Elements are sometimes used as burnable poisons in their natural isotopic abundances, and sometimes burnable poisons are enriched with respect to select stable isotopes. Isotopes that are exploited as burnable poisons are listed below. ${ }^{25}$ The first isotope in each series is naturally occurring, i.e., stable, or extremely long half-life. In each series transmutations and decays lead to isotopes with smaller neutron capture cross sections; in other words, the poison is consumed or "burned." Of course, the behaviors of burnable poisons are more nuanced than what is depicted here; but the principle of performance is adequately illustrated.

- $\quad{ }^{10} \mathrm{~B}\left(\mathrm{n},{ }^{4} \mathrm{He}\right) \rightarrow{ }^{7} \mathrm{Li}$

- ${ }^{113} \mathrm{Cd}(\mathrm{n}, \gamma) \rightarrow{ }^{114} \mathrm{Cd}$

- $\quad{ }^{149} \mathrm{Sm}(\mathrm{n}, \gamma) \rightarrow{ }^{150} \mathrm{Sm}$ 
- $\quad{ }^{151} \mathrm{Eu}(\mathrm{n}, \gamma) \rightarrow{ }^{152} \mathrm{Eu}(\mathrm{n}, \gamma) \rightarrow{ }^{153} \mathrm{Eu}$

- $\quad{ }^{153} \mathrm{Eu}(\mathrm{n}, \gamma) \rightarrow{ }^{154} \mathrm{Eu}(\mathrm{n}, \gamma) \rightarrow{ }^{155} \mathrm{Eu}(\mathrm{n}, \gamma) \rightarrow{ }^{156} \mathrm{Eu}(\beta-) 15.2 \mathrm{~d} \rightarrow{ }^{156} \mathrm{Gd}$

- $\quad{ }^{155} \mathrm{Gd}(\mathrm{n}, \gamma) \rightarrow{ }^{156} \mathrm{Gd}$

- $\quad{ }^{157} \mathrm{Gd}(\mathrm{n}, \gamma) \rightarrow{ }^{158} \mathrm{Gd}$

- ${ }^{164} \operatorname{Dy}(\mathrm{n}, \gamma) \rightarrow{ }^{165} \mathrm{Dy}$

- $\quad{ }^{167} \operatorname{Er}(\mathrm{n}, \gamma) \rightarrow{ }^{168} \mathrm{Er}$

- ${ }^{175} \mathrm{Lu}(\mathrm{n}, \gamma) \rightarrow{ }^{176} \mathrm{Lu}$

- $\quad{ }^{176} \mathrm{Lu}(\mathrm{n}, \gamma) \rightarrow{ }^{177} \mathrm{Lu}(\mathrm{n}, \gamma) \rightarrow{ }^{178} \mathrm{Lu}(\mathrm{n}, \gamma) \rightarrow{ }^{179} \mathrm{Lu}(\beta-)$ 4.6h $\rightarrow{ }^{179} \mathrm{Hf}$

- ${ }^{177} \mathrm{Hf}(\mathrm{n}, \gamma) \rightarrow{ }^{178} \mathrm{Hf}$

- $\quad{ }^{180} \mathrm{Hf}(\mathrm{n}, \gamma) \rightarrow{ }^{181} \mathrm{Hf}(\beta-) 42.4 \mathrm{~d} \rightarrow{ }^{181} \mathrm{Ta}$.

\subsection{Neutron Moderators and Reflectors}

Materials that are good moderators and reflectors will elastically interact with neutrons. That is, the materials are likely to absorb a fraction of the neutron's energy while not capturing it. In other words, these materials exhibit low neutron capture cross sections and high neutron scattering cross sections. Moderators are placed in the reactor to control the energy of the neutron spectrum within the core; reflectors are placed to keep neutrons in the core. There are several light elements that act as neutron moderators and reflectors. These include the hydrogen nuclides ${ }^{1} \mathrm{H}$ and ${ }^{2} \mathrm{H}$ (previously discussed), ${ }^{9} \mathrm{Be}$ (the only natural occurring beryllium isotope), ${ }^{26}$ and carbon (naturally occurring carbon is $98.9 \mathrm{wt} \%{ }^{12} \mathrm{C}$ with the balance ${ }^{13} \mathrm{C}$ ). These materials can be present in their pure forms, or as oxides, hydrides, and carbides. Like burnable poisons, moderators and reflectors may or may not be intimately associated with the fuel assemblies. Stainless steels are also adopted as reflector materials. 


\section{NUCLEAR REACTORS}

A unique feature of nuclear reactors is the great latitude of options available for their design. From a high-level perspective, the process of engineering design begins by defining the functional requirements of the engineered system, which, in turn, begins to constrain and limit the engineering design options. Nuclear reactors serve two overarching purposes: the production of useful heat and/or the production of useful radiation. The heat generated from a nuclear reactor can be used for the same purposes as the heat generated from the combustion of coal, fuel oil, natural gas, etc. There is nothing unique about the heat generated from a nuclear reactor, other than how the heat is generated, which is by nuclear reactions (e.g., fission) as opposed to chemical reactions (e.g., combustion). The radiation can be used for transmutation, medical and industrial radioisotope production, materials irradiation, materials interrogation, etc.

Therefore, both the functional requirements and, consequently, the designs of nuclear reactors are varied and wide.

Another significant design factor is the selection of coolant. The processes of fission, transmutation, and radioactive decay release energy, manifested as heat, into the reactor core. This heat must be extracted from the core by a suitable coolant. Common coolants are water (e.g., light water and heavy water), ${ }^{27}$ liquid metals (e.g., sodium, NaK-alloy, lead, and $\mathrm{PbBi}$-alloy), ${ }^{28}$ gases (e.g., air, carbon dioxide, and helium), ${ }^{29}$ and molten salts (e.g., fluoride and chloride salts). ${ }^{30,31}$ There are also design concepts incorporating water and carbon dioxide coolants as supercritical fluids. Some coolants serve multiple purposes, performing the function of moderator, fuel, blanket, or some combination of these.

Of the 1,000 different types of reactors proposed, 100 were built and tested, and 10 have found commercial success. Of course, this is only an anecdotal statement made for effect. However, it does highlight the fact that, of the seemingly limitless number of imaginable reactor designs, few have ever come to fruition, and fewer still have found commercial success. It is evident from the preceding discussions that design options for nuclear reactors are nearly unbounded. This is illustrated in Table 3 , which lists several engineering options for different major design requirements. For example, Function is a major design feature, and several choices, such as Electrical Power, are listed in the adjoining column. The choices are not necessarily independent of each other, but even at this high-level it is apparent that there are a great many design options, and when the many underlying layers of technical detail are considered, the design options grow exponentially. That is why, during the early development of nuclear reactors, a great many distinct reactor concepts were pursued simultaneously. It was simply impossible at that time to predict which of the many avenues of research would prove successful.

Table 3. Summary of High-Level Nuclear Reactor Design Options.

\begin{tabular}{|l|l|}
\hline \multicolumn{1}{|c|}{ Design Requirement } & \multicolumn{1}{c|}{ Engineering Options } \\
\hline Primary Function & Electrical Power Generation \\
\hline & Military, Medical, and Industrial Isotope Production \\
\hline & Naval Propulsion \\
\hline & Irradiation Experiments \\
\hline & Weapons Plutonium Production \\
\hline & Industrial Process Heat \\
\hline Secondary Function & Plutonium production reactors can generate electrical power \\
\hline & Electrical power reactors can produce plutonium and isotopes \\
\hline & Other Dual Use \\
\hline Conversion Ratio (CR) & Breeder $(\mathrm{CR}>1)$ \\
\hline & Converter $(\mathrm{CR}=1)$ \\
\hline & Non-Breeder or Burner $(\mathrm{CR}<1)$ \\
\hline
\end{tabular}




\begin{tabular}{|c|c|}
\hline Design Requirement & Engineering Options \\
\hline \multirow[t]{3}{*}{ Conversion Cycle } & ${ }^{232} \mathrm{Th} /{ }^{233} \mathrm{U}$ \\
\hline & ${ }^{238} \mathrm{U} /{ }^{239} \mathrm{Pu}$ \\
\hline & No Conversion Cycle \\
\hline \multirow{4}{*}{ Neutron Spectrum } & Thermal \\
\hline & Epithermal \\
\hline & Fast \\
\hline & Variable Thermal or Fast Biased \\
\hline \multirow{5}{*}{ Neutron Moderator } & Graphite \\
\hline & Water (e.g., heavy water or light water) \\
\hline & Ceramic (e.g., beryllia) \\
\hline & Organic Liquid \\
\hline & No Moderator \\
\hline \multirow[t]{6}{*}{ Primary Coolant } & Water (e.g., heavy water or light water) \\
\hline & Gas (e.g., helium, air, carbon dioxide) \\
\hline & Liquid Metal (e.g., sodium, lead, lead/bismuth alloy) \\
\hline & Molten Salt (e.g., fluoride salt or chloride salt) \\
\hline & Organic Liquid \\
\hline & No Coolant (e.g., radiant energy release) \\
\hline \multirow[t]{3}{*}{ Secondary Coolant } & Light Water \\
\hline & Molten Salt \\
\hline & No Secondary Coolant \\
\hline \multirow[t]{6}{*}{ Major Fissile Component } & ${ }^{235} \mathrm{U}$ as NU \\
\hline & ${ }^{235} \mathrm{U}$ as LEU \\
\hline & ${ }^{235} \mathrm{U}$ as $\mathrm{HEU}$ \\
\hline & ${ }^{233} \mathrm{U}$ \\
\hline & ${ }^{239} \mathrm{Pu}$ \\
\hline & Minor Actinides \\
\hline \multirow[t]{8}{*}{ Fuel Form } & Metallic \\
\hline & Metallic Alloy \\
\hline & Oxide \\
\hline & Mixed Oxide \\
\hline & Nitride \\
\hline & Hydride \\
\hline & Carbide/Oxy-carbide \\
\hline & Molten Salt \\
\hline \multirow[t]{4}{*}{ Fuel Cladding } & Ferro Alloy \\
\hline & Zirconium Alloy \\
\hline & Nickel Alloy \\
\hline & Aluminum Alloy \\
\hline
\end{tabular}




\begin{tabular}{|l|l|}
\hline Design Requirement & \multicolumn{1}{|c|}{ Engineering Options } \\
\hline & Magnesium Alloy \\
\hline & Silicon Carbide \\
\hline & No Cladding (e.g., liquid fuels) \\
\hline
\end{tabular}

A breeder reactor, on a net basis, produces more fissile inventory by transmutation than it consumes by fission. In other words, a breeder reactor produces excess fissile inventory, which can be recovered to fabricate new fuel for itself and for additional nuclear reactors. In contrast, a burner reactor, on a net basis, consumes more fissile inventory by fission than it produces by transmutation. The objective of a burner reactor is to consume, as much as possible, its initial fissile inventory and to minimize transmutation processes. There are only a few operating breeder reactors around the world; the majority of operating reactors are burner reactors. A converter reactor, on a net basis, also consumes more fissile inventory by fission than it produces by transmutation. However, the objective of a converter reactor is to exploit, as much as possible, transmutation processes to breed and burn fissile inventory simultaneously. Conversion ratio is the ratio of fissile inventory produced to fissile inventory consumed. The conversion ratios of breeder and burner reactors are greater than one and less than one, respectively. The conversion ratio of a converter reactor is also less than 1 .

The major avenues pursued during early research and development into reactors for civilian power production included light water reactors (LWRs) (e.g., pressurized water reactors (PWRs) and boiling water reactors (BWRs)), heavy water reactors (HWRs) (e.g., pressurized heavy water reactors (PHWRs)), fluid flow reactors (FFRs) (e.g., MSRs, molten salt breeder reactors (MSBRs), aqueous homogeneous reactors (AHRs), and lead-cooled fast reactors (LFRs)), and liquid metal-cooled reactors (LMRs) (e.g., sodium-graphite reactors (SGRs), sodium-graphite breeder reactors (SGBRs)), liquid metal fueled reactors (LMFRs), and liquid metal fast breeder reactors (LMFBRs)). Today, PWRs dominate the application of civilian power production. But not because PWRs are the optimal design for this application, but because PWRs were viewed as the least-risk design for successful demonstration of commercial-scale civilian power production at a key point in U.S. history. ${ }^{32}$ This perception was a consequence of the U.S. Navy's successful development and adoption of PWRs for naval propulsion.

Since the 1940s, a great many nuclear reactors have been operated in the U.S. A single comprehensive list of all U.S. reactors would include the following: over 130 commercial civilian power reactors; 52 research reactors at the Idaho National Laboratory (INL) Site; ${ }^{33-35} 28$ research reactors designed, built, and operated by Argonne National Laboratory (ANL); ${ }^{33,34,36,37} 13$ research reactors at ORNL; ${ }^{38} 9$ research reactors at Los Alamos National Laboratory (LANL); ${ }^{39-41}$ additional commercial and university research reactors; 9 plutonium production reactors at Hanford Site (HS); ${ }^{42-46} 5$ plutonium production reactors at Savannah River Site (SRS) ${ }^{43,47}$ and numerous military reactors for training, naval propulsion, and power production. A series of such lists were compiled between 1959 and $1996 .{ }^{48,49}$ 


\section{NUCLEAR FUELS}

As stated earlier, the process of fission generates fission products (lighter elements), transmutation products (lighter and heavier elements), and heat (mostly in the form of the kinetic energies of the fission fragments). Fission product elements and isotopes range across most of the periodic table. Exactly which fission products are generated is a complex function of the nucleonic physics within the core; but these relationships are understood and are well within the realm of computer simulation and modeling capabilities. Because there is a wide spectrum of fission product elements, there is an equally wide spectrum of fission product element physical-chemical properties. For example, there are noble gases, elements and compounds with low melting temperatures, and elements and compounds with high vapor pressures at the operating temperatures of the reactor. Managing this wide variety of physical-chemical properties is the source of one of the main challenges of fuel design.

In a broad sense, all fuels can be categorized into one of two groups: fuels that are contained within cladding, and fuels that are not contained with cladding. Examples of the former are LWR uranium oxide fuels contained in zirconium alloy cladding, and SFR metal fuels contained in stainless steel cladding. Certainly, the majority of operating reactors have employed contained fuels. Examples of the latter are molten salt fuels and liquid-media dispersion fuels; these are concepts that have been tested experimentally but have not yet been adopted for commercial or military applications. A reactor core must also serve as a heat exchanger. Typically, the heat generated within the core is transferred to a fluid that carries the heat from the core. Contained fuels are typically stationary within the core, as the heat exchange fluid flows through the core. Heat exchange fluids include water, heavy water, sodium, lead alloys, molten salt, air, carbon dioxide, and helium. The first two fluids serve the dual purpose of moderator. Uncontained fuels typically serve the dual purpose of fuel and heat exchange fluid. Heat is intrinsically generated as the fluid fuel flows through the core and carries the heat with it as it flows from the core. Additional requirements are that these materials must be chemically compatible. In the case of contained fuels, the inside of the cladding must be compatible with the fuel, and the outside of the cladding must be compatible with the heat exchange fluid. In the case of uncontained fuels, the fluid fuels must be compatible with the materials of construction of the reactor core, fluid pumps, and the subsequent primary heat exchangers.

Fuel systems experience extreme materials challenges during irradiation. For example, fission processes are not uniform throughout the fuel element, much less the entire reactor core. The compositional changes due to fission are spatially dependent and, consequently, create chemical compositional gradients. In addition, heat generated from within the fuel element creates temperature gradients which can be quite extreme in some cases. Based largely on fuel symmetry, the highest temperatures are experienced at the most central locations. For example, the highest temperature within a typical uranium oxide fuel pellet can reach in excess of $1,200^{\circ} \mathrm{C}$ in a PWR, and $1,800^{\circ} \mathrm{C}$ in a Canadian deuterium uranium (CANDU) reactor, while the outer Zircalloy cladding surface is in contact with pressurized water that is less than $400^{\circ} \mathrm{C}$ in most cases. Like fission, temperature gradients also cause chemical compositional gradients by processes such as chemical diffusion and phase segregation. However, these extreme temperatures are not always the case. The design thermal power and coolant temperature of the reactor, and the thermal conductivity of the fuel will influence the fuel temperature.

Fission gas generation and radiation damage also contribute to chemical and mechanical changes within the fuel. These effects are highly dependent on the fuel characteristics and the radiation history. For example, solid fuels can swell (due to fission gas generation) and develop chemical/physical properties gradients (due to thermal gradients) and interact with the cladding materials. The fission products in liquid fuels are free to migrate through the system and chemically interact with the materials of construction. 
Thermal power and cooling are intimately related. Thermal power is a measure of the rate at which thermal energy is produced in the core, e.g., units of MW. At steady state, the thermal power is dissipated from the core by the flow of coolant at the same rate it is produced. The required flowrate of coolant is dictated by the thermal power, the efficiency of the core to function as a heat exchanger, the density and heat capacity of the coolant, and the design inlet and outlet temperatures of the coolant. These parameters are not all independent of each other. And the efficiency of the core to function as a heat exchanger is intimately related to fuel design. Coolants such as water, liquid sodium, molten salt, and helium all have unique densities and heat capacities that dictate their mass and volumetric flowrates for their intended applications.

From the preceding discussions it is evident that there are many factors affecting reactor, fuel, and fuel cycle designs. Other competing factors include resource conservation, societal acceptance, and public safety, which further complicates and sometimes dominates the fuel cycle design arguments.

The following sections provide brief descriptions of the major fuel types and the reactors that use them, of which there are many, and the reprocessing technologies that are applied to, or have been proposed for, their treatment. Instances where reprocessing considerations are absent are noted. Where such distinctions are possible, what is or has been done at the industrial scale to support commercial or military activities, what is or has been done at the laboratory scale in the course of research and development activities, and what is or has been merely conceptualized and proposed are noted. The order in which the following information is presented is not a reflection of the chronology in which the technologies were developed.

\subsection{Nuclear Fuel Taxonomy}

Why? There are many types of reactors for many types of applications developed at different stages of technical understanding during different socio-politico conditions. Therefore, there are many types of fuels. It is useful to have a system for categorizing fuels according to similarities in material characteristics.

The intent here is to provide a useful means of categorizing fuel types according to their as-fabricated material characteristics and subsequent incorporation into fuel forms. These are important considerations for selecting and designing applicable spent fuel reprocessing technologies. Although the details vary from case to case, the following categories are those that appear to have a shared agreement in the technical literature.

The three broadest categories are ceramic, metallic, and halide salt, which are summarized in Table 4 to Table 6, respectively. These summaries are selective, not comprehensive. Ceramics include oxides, carbides, nitrides, hydrides, silicides, and composites of these. Metallics include pure metals, alloys, and intermetallics, and halides include fluoride and chloride salts. These subcategories are summarized in Column 1 of the tables. Two other fuel systems worth mentioning, but not included in the tables, are aqueous and liquid metals. ${ }^{50}$ Aqueous fuel systems relied on fertile and fissile materials dissolved in aqueous media, e.g., sulfates, nitrates, fluorides, phosphates, chromates, and carbonates. Liquid metal fuel systems were mostly based on dispersion fuel concepts in which insoluble compounds like $\mathrm{UO}_{2}, \mathrm{UC}, \mathrm{UF}_{3}$, $\mathrm{ThBi}_{2}$, and $\mathrm{ThO}_{2}$ were dispersed in liquid metals like bismuth and $\mathrm{NaK}$. Presently, there does not appear to be any active research in these two areas.

Column 2 of Table 4, Table 5, and Table 6, provides examples of the basic constituent material forms containing uranium, plutonium, thorium (fertile), and minor actinides (MA). Only the basic compositions are shown without the stoichiometries, which are quite variable in some cases. Furthermore, in many cases these material forms are not complete descriptions of the fuel forms. For example, uranium oxide (fuel material) is pressed and sintered into high-density ceramic pellets (fuel form) for use in LWRs. This is an example of a homogenous fuel; the ceramic pellet is made of uranium oxide. On the other hand, uranium oxide (fuel material) is formed into small spherical kernels, coated with layers of pyrolytic 
graphite and silicon carbide to form tri-structural isotropic (TRISO) fuel particles that are imbedded in graphite (fuel form) for use in high-temperature reactors (HTRs). This is an example of a heterogeneous fuel: the dispersed TRISO particles contain kernels of uranium oxide. With other fuel types the distinction between homogeneous and heterogeneous is less clear and not particularly important.

In Table 4 to Table 6, Column 3 (subcategorized into Columns A to K) provides more information about the fuel forms. The meanings of the letters in Column 3 are described in Table 7. This table provides examples of how the materials in Column 2 are incorporated into fuel forms. From the point of view of reprocessing, these tables indicate the material forms from which select elements must be separated. The final Columns in Table 4 to Table 6 indicate if the fuel forms are free of uranium. These uranium-free fuel forms contain only plutonium and minor actinides and require special considerations as fuels with additions of neutron absorbers and burnable poisons.

Table 4. Ceramic Fuels

\begin{tabular}{|c|c|c|c|c|c|c|c|c|c|c|c|c|c|}
\hline \multirow[b]{2}{*}{ Subcategory } & \multirow[b]{2}{*}{ Example } & \multicolumn{11}{|c|}{ Fuel Form Designation } & \multirow{2}{*}{$\begin{array}{c}\text { Uranium } \\
\text { Free? }\end{array}$} \\
\hline & & $\mathrm{A}$ & $\mathrm{B}$ & $\mathrm{C}$ & $\mathrm{D}$ & $\mathrm{E}$ & $\mathrm{F}$ & $\mathrm{G}$ & $\mathrm{H}$ & $\mathrm{I}$ & $\mathrm{J}$ & $\mathrm{K}$ & \\
\hline \multirow{12}{*}{ Oxide } & (U)O & $\mathrm{A}$ & & & $\mathrm{D}$ & & & & $\mathrm{H}$ & I & & & \\
\hline & $(\mathrm{Pu}) \mathrm{O}$ & $\mathrm{A}$ & & & $\mathrm{D}$ & & & $\mathrm{G}$ & $\mathrm{H}$ & & & & $\mathrm{Y}$ \\
\hline & $(\mathrm{U}, \mathrm{Pu}) \mathrm{O}$ & $\mathrm{A}$ & & & & & & & $\mathrm{H}$ & & & & \\
\hline & $(\mathrm{Th}) \mathrm{O}$ & $\mathrm{A}$ & & & & & & & $\mathrm{H}$ & & & & \\
\hline & $(\mathrm{U}, \mathrm{Th}) \mathrm{O}$ & $\mathrm{A}$ & & & & & & & $\mathrm{H}$ & & & & \\
\hline & $(\mathrm{Pu}, \mathrm{Th}) \mathrm{O}$ & $\mathrm{A}$ & & & & & & & & & & & \\
\hline & $(\mathrm{U}, \mathrm{Pu}, \mathrm{Th}) \mathrm{O}$ & $\mathrm{A}$ & & & & & & & & & & & \\
\hline & $(\mathrm{Pu}, \mathrm{Zr}) \mathrm{O}$ & & & & & & & $\mathrm{G}$ & & & & & $\mathrm{Y}$ \\
\hline & $(\mathrm{Pu}, \mathrm{Zr}, \mathrm{Y}) \mathrm{O}$ & & & & & & & $\mathrm{G}$ & & & & & $\mathrm{Y}$ \\
\hline & $(\mathrm{Pu}, \mathrm{Ce}) \mathrm{O}$ & & & & & & & $\mathrm{G}$ & & & & & $\mathrm{Y}$ \\
\hline & $(\mathrm{U}, \mathrm{Pu}, \mathrm{MA}) \mathrm{O}$ & A & & & & & & & & & & & \\
\hline & $(\mathrm{Pu}, \mathrm{MA}) \mathrm{O}$ & & & & & & & $\mathrm{G}$ & & & & & $\mathrm{Y}$ \\
\hline \multirow[t]{5}{*}{ Carbide } & $(\mathrm{U}) \mathrm{C}$ & A & & & & $\mathrm{E}$ & & & $\mathrm{H}$ & & & & \\
\hline & $(\mathrm{Pu}) \mathrm{C}$ & $\mathrm{A}$ & & & & $\mathrm{E}$ & & & & & & & $\mathrm{Y}$ \\
\hline & $(\mathrm{U}, \mathrm{Pu}) \mathrm{C}$ & $\mathrm{A}$ & & & & $\mathrm{E}$ & & & & & & & \\
\hline & $(\mathrm{Th}, \mathrm{U}) \mathrm{C}$ & $\mathrm{A}$ & & & & & & & $\mathrm{H}$ & & & & \\
\hline & $(\mathrm{Th}, \mathrm{Pu}) \mathrm{C}$ & $\mathrm{A}$ & & & & & & & & & & & \\
\hline \multirow[t]{4}{*}{ Oxy-carbide } & $(\mathrm{U}) \mathrm{CO}$ & $\mathrm{A}$ & & & & & & & $\mathrm{H}$ & & & & \\
\hline & $(\mathrm{Pu}) \mathrm{CO}$ & $\mathrm{A}$ & & & & & & & & & & & $\mathrm{Y}$ \\
\hline & $(\mathrm{U}, \mathrm{Pu}) \mathrm{CO}$ & $\mathrm{A}$ & & & & & & & $\mathrm{H}$ & & & & \\
\hline & $(\mathrm{U}, \mathrm{Th}) \mathrm{CO}$ & A & & & & & & & $\mathrm{H}$ & & & & \\
\hline Carbo-nitride & $(\mathrm{U}, \mathrm{Pu}) \mathrm{CN}$ & A & & & & & & & & & & & \\
\hline \multirow[t]{5}{*}{ Nitride } & $(\mathrm{U}) \mathrm{N}$ & A & & & & & $\mathrm{F}$ & & & & & & \\
\hline & $(\mathrm{Pu}) \mathrm{N}$ & A & & & & & $\mathrm{F}$ & & & & & & $\mathrm{Y}$ \\
\hline & $(\mathrm{Th}) \mathrm{N}$ & $\mathrm{A}$ & & & & & & & & & & & \\
\hline & $(\mathrm{U}, \mathrm{Pu}) \mathrm{N}$ & $\mathrm{A}$ & & & & & & & & & & & \\
\hline & (U,Th)N & A & & & & & & & & & & & \\
\hline
\end{tabular}




\begin{tabular}{|c|c|c|c|c|c|c|c|c|c|c|c|c|c|}
\hline \multirow[b]{2}{*}{ Subcategory } & \multirow[b]{2}{*}{ Example } & \multicolumn{11}{|c|}{ Fuel Form Designation } & \multirow{2}{*}{$\begin{array}{c}\text { Uranium } \\
\text { Free? }\end{array}$} \\
\hline & & $\mathrm{A}$ & $\mathrm{B}$ & $\mathrm{C}$ & $\mathrm{D}$ & $\mathrm{E}$ & $\mathrm{F}$ & $\mathrm{G}$ & $\mathrm{H}$ & $\mathrm{I}$ & $\mathrm{J}$ & $\mathrm{K}$ & \\
\hline & $(\mathrm{U}, \mathrm{Zr}) \mathrm{N}$ & $\mathrm{A}$ & & & & & & & & & & & \\
\hline & $(\mathrm{Pu}, \mathrm{Zr}) \mathrm{N}$ & & & & & & $\mathrm{F}$ & & & & & & $\mathrm{Y}$ \\
\hline & $(\mathrm{Pu}, \mathrm{MA}, \mathrm{Zr}) \mathrm{N}$ & & & & & & $\mathrm{F}$ & & & & & & $\mathrm{Y}$ \\
\hline \multirow[t]{2}{*}{ Oxy-nitride } & $(\mathrm{U}) \mathrm{NO}$ & A & & & & & & & & & & & \\
\hline & $(\mathrm{U}, \mathrm{Pu}) \mathrm{NO}$ & A & & & & & & & & & & & \\
\hline \multirow[t]{9}{*}{ Hydride } & (U)H & A & & & & & & & & & & & \\
\hline & $(\mathrm{Pu}) \mathrm{H}$ & A & & & & & & & & & & & $\mathrm{Y}$ \\
\hline & $(\mathrm{U}, \mathrm{Pu}) \mathrm{H}$ & A & & & & & & & & & & & \\
\hline & $(\mathrm{U}, \mathrm{Zr}) \mathrm{H}$ & $\mathrm{A}$ & & & & & & & & & & & \\
\hline & $(\mathrm{Pu}, \mathrm{Zr}) \mathrm{H}$ & $\mathrm{A}$ & & & & & & & & & & & $\mathrm{Y}$ \\
\hline & $(\mathrm{U}, \mathrm{Pu}, \mathrm{Zr}) \mathrm{H}$ & $\mathrm{A}$ & & & & & & & & & & & \\
\hline & $(\mathrm{Th}, \mathrm{U}, \mathrm{Zr}) \mathrm{H}$ & $\mathrm{A}$ & & & & & & & & & & & \\
\hline & $(\mathrm{Th}, \mathrm{Pu}, \mathrm{Zr}) \mathrm{H}$ & $\mathrm{A}$ & & & & & & & & & & & \\
\hline & $(\mathrm{Th}, \mathrm{Zr}) \mathrm{H}$ & $\mathrm{A}$ & & & & & & & & & & & \\
\hline \multirow[t]{2}{*}{ Silicide } & $(\mathrm{U}) \mathrm{Si}$ & $\mathrm{A}$ & & $\mathrm{C}$ & & & & & & & & & \\
\hline & $(\mathrm{U}, \mathrm{Al}) \mathrm{Si}$ & $\mathrm{A}$ & & $\mathrm{C}$ & & & & & & & & & \\
\hline
\end{tabular}

Table 5. Metallic Fuels

\begin{tabular}{|c|c|c|c|c|c|c|c|c|c|c|c|c|c|}
\hline \multirow[b]{2}{*}{ Subcategory } & \multirow[b]{2}{*}{ Example } & \multicolumn{11}{|c|}{ Fuel Type Designation } & \multirow{2}{*}{$\begin{array}{c}\text { Uranium } \\
\text { Free? }\end{array}$} \\
\hline & & $\mathrm{A}$ & $\mathrm{B}$ & $\mathrm{C}$ & $\mathrm{D}$ & $\mathrm{E}$ & $\mathrm{F}$ & $\mathrm{G}$ & $\mathrm{H}$ & $\mathrm{I}$ & $\mathrm{J}$ & $\mathrm{K}$ & \\
\hline \multirow[t]{2}{*}{ Pure } & $\mathrm{U}$ & & $\mathrm{B}$ & & & & & & & & & & \\
\hline & $\mathrm{Pu}$ & & $\mathrm{B}$ & & & & & & & & & & \\
\hline \multirow[t]{2}{*}{ Aluminum } & (U)Al & & & $\mathrm{C}$ & & & & & & & & & \\
\hline & $(\mathrm{Pu}) \mathrm{Al}$ & & & $\mathrm{C}$ & & & & & & & & & $\mathrm{Y}$ \\
\hline \multirow[t]{4}{*}{ Zirconium } & $(\mathrm{U}) \mathrm{Zr}$ & & $\mathrm{B}$ & & & & & & & & & & \\
\hline & $(\mathrm{Pu}) \mathrm{Zr}$ & & $\mathrm{B}$ & & & & & & & & & & $\mathrm{Y}$ \\
\hline & $(\mathrm{U}, \mathrm{Pu}) \mathrm{Zr}$ & & $\mathrm{B}$ & & & & & & & & & & \\
\hline & $(\mathrm{Pu}, \mathrm{MA}) \mathrm{Zr}$ & & $\mathrm{B}$ & & & & & & & & & & $\mathrm{Y}$ \\
\hline \multirow[t]{2}{*}{ Yttrium } & $(\mathrm{Pu}) \mathrm{Y}$ & & & $\mathrm{C}$ & & & & & & & & & $\mathrm{Y}$ \\
\hline & $(\mathrm{Pu}, \mathrm{MA}) \mathrm{Y}$ & & & $\mathrm{C}$ & & & & & & & & & $\mathrm{Y}$ \\
\hline Molybdenum & $(\mathrm{U}) \mathrm{Mo}$ & & & $\mathrm{C}$ & & & & & & & & & \\
\hline Iron & $(\mathrm{U}) \mathrm{Fe}$ & & & $\mathrm{C}$ & & & & & & & & & \\
\hline
\end{tabular}


Table 6. Halide Salt Fuels

\begin{tabular}{|c|c|c|c|c|c|c|c|c|c|c|c|c|c|}
\hline \multirow[b]{2}{*}{ Subcategory } & \multirow[b]{2}{*}{ Example } & \multicolumn{11}{|c|}{ Fuel Type Designation } & \multirow{2}{*}{$\begin{array}{c}\text { Uranium } \\
\text { Free? }\end{array}$} \\
\hline & & A & $\mathrm{B}$ & $\mathrm{C}$ & $\mathrm{D}$ & $\mathrm{E}$ & $\mathrm{F}$ & $\mathrm{G}$ & $\mathrm{H}$ & I & $\mathrm{J}$ & $\mathrm{K}$ & \\
\hline \multirow[t]{7}{*}{ Fluoride } & $(\mathrm{U}) \mathrm{F}$ & & & & & & & & & & $\mathrm{J}$ & & \\
\hline & $(\mathrm{Pu}) \mathrm{F}$ & & & & & & & & & & $\mathrm{J}$ & & $\mathrm{Y}$ \\
\hline & $(\mathrm{U}, \mathrm{Pu}) \mathrm{F}$ & & & & & & & & & & $\mathrm{J}$ & & \\
\hline & $(\mathrm{Th}) \mathrm{F}$ & & & & & & & & & & $\mathrm{J}$ & & \\
\hline & $(\mathrm{Th}, \mathrm{U}) \mathrm{F}$ & & & & & & & & & & $\mathrm{J}$ & & \\
\hline & $(\mathrm{Th}, \mathrm{Pu}) \mathrm{F}$ & & & & & & & & & & $\mathrm{J}$ & & \\
\hline & $(\mathrm{Th}, \mathrm{U}, \mathrm{Pu}) \mathrm{F}$ & & & & & & & & & & $\mathrm{J}$ & & \\
\hline \multirow[t]{3}{*}{ Chloride } & $(\mathrm{U}) \mathrm{Cl}$ & & & & & & & & & & & $\mathrm{K}$ & \\
\hline & $(\mathrm{Pu}) \mathrm{Cl}$ & & & & & & & & & & & $\mathrm{K}$ & $\mathrm{Y}$ \\
\hline & $(\mathrm{U}, \mathrm{Pu}) \mathrm{Cl}$ & & & & & & & & & & & $\mathrm{K}$ & \\
\hline
\end{tabular}

Table 7. Dispersion Matrices

\begin{tabular}{|c|c|c|}
\hline Designation & Matrix Category & Examples of Matrix Materials \\
\hline $\mathrm{A}$ & None & Used directly in ceramic form. \\
\hline $\mathrm{B}$ & None & Used directly in metallic or alloy form. \\
\hline $\mathrm{C}$ & Metal Matrix & $\mathrm{Al}, \mathrm{Zr}, \mathrm{Mo}, \mathrm{Mg}$, and stainless steel. \\
\hline $\mathrm{D}$ & Ceramic Oxide Matrix & $\mathrm{BeO}, \mathrm{MgO}, \mathrm{ZrO}_{2}$, and $\mathrm{CeO}_{2}$. \\
\hline $\mathrm{E}$ & Ceramic Carbide Matrix & $\mathrm{ZrC}$ and $\mathrm{SiC}$. \\
\hline $\mathrm{F}$ & Ceramic Nitride Matrix & TiN, $\mathrm{ZrN}, \mathrm{AlN}$, and $\mathrm{Si}_{3} \mathrm{~N}_{4}$. \\
\hline G & Ceramic Spinel Matrix & $\begin{array}{l}\mathrm{MgAl}_{2} \mathrm{O} 4, \mathrm{Y}_{3} \mathrm{Al}_{5} \mathrm{O}_{12} \text {, yttria-stabilized zirconia (YSZ), } \\
\text { with } \mathrm{Er}_{2} \mathrm{O}_{3}, \mathrm{Gd}_{2} \mathrm{O}_{3} \text {. }\end{array}$ \\
\hline $\mathrm{H}$ & Coated Particle & Porous carbon, pyrolytic carbon, $\mathrm{SiC}$, and $\mathrm{ZrC}$. \\
\hline $\mathrm{I}$ & Graphite Matrix & Graphite \\
\hline $\mathrm{J}$ & Fluoride Molten Salt & $\mathrm{LiF}, \mathrm{NaF}, \mathrm{ZrF}, \mathrm{KF}$, and $\mathrm{BeF}_{2}$. \\
\hline $\mathrm{K}$ & Chloride Molten Salt & $\mathrm{NaCl}, \mathrm{KCl}, \mathrm{LiCl}$, and $\mathrm{MgCl}_{2}$. \\
\hline
\end{tabular}

The information provided in Table 4 to Table 7 demonstrates the complexity and vast variety of fuel types and fuel forms that have been or are being considered for use in a multitude of nuclear reactor types. In many ways it is the detailed characterization of the spent fuel that is the starting point for selecting and designing an applicable reprocessing technology. From strictly an engineering perspective, it is always possible to envision a technical means of recovery and purification of fissile materials from any type of spent fuel. However, a viable process requires more than technical merit, it also requires economic justification, public acceptance, and political support. 


\subsection{Natural Uranium Oxide Fuel}

Why? The manufacture of natural uranium oxide fuel requires the least amount of processing. No uranium enrichment is required. Reactor grade NU oxide is pressed into dense cylinders and loaded into metal cladding. However, the reactors require heavy water or graphite for moderation.

CANDU reactors were developed in Canada for civilian energy production. These are pressurized, heavy water moderated, thermal spectrum reactors. Standard CANDU fuel is based on NU that is refined into high purity uranium oxide and manufactured into ceramic pellets. The pellets are loaded into Zircaloy fuel cladding and arranged into fuel bundles as shown in Figure 2.

High neutron economy and low fissile content requirement are salient features of the CANDU reactor. The reactor can operate with NU and slightly enriched uranium fuels. This feature can be exploited for several fuel cycle options opening the possibility to using spent LWR and mixed oxide (MOX) fuels as source materials for the fissile inventory. There are also concepts to use CANDU reactors to support $\mathrm{Pu}-\mathrm{Th}$ and $\mathrm{LEU}-\mathrm{Th}$ fuel cycles. ${ }^{51}$

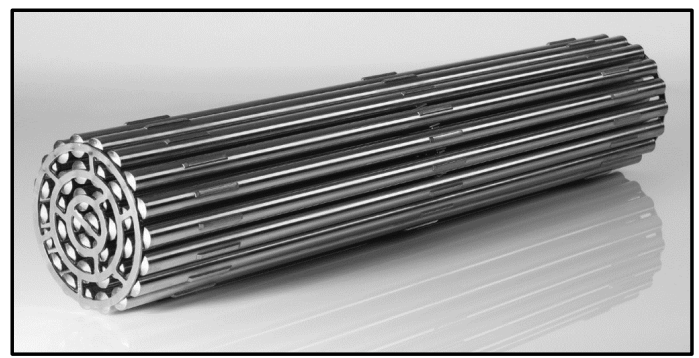

Figure 2. Photograph of CANDU reactor fuel bundle. ${ }^{52}$ A typical CANDU fuel bundle is about 0.1 -m-diameter and 0.5 -m-length, and weighs about $24 \mathrm{~kg}$. This bundle appears to contain 37 fuel elements in sequential layers of $18,12,6$, and 1 .

\subsection{Low Enriched Uranium Oxide Fuel}

Why? The manufacture of LEU oxide fuels requires a moderate degrees of uranium enrichment. Reactor grade LEU oxide is pressed into dense cylinders and loaded into metal cladding. However, these reactors require light water and graphite for moderation.

LWRs were developed in the U.S. for naval and civilian energy production. These are water-cooled, water moderated, thermal spectrum reactors. They are designed both as PWRs and BWRs. Standard LWR fuel is based on LEU uranium oxide fuel pellets clad in Zircaloy and arranged into fuel assemblies as shown in Figure 3. There are far more LWRs being used for civilian energy production than all other reactors for all other purposes combined.

Following the Fukushima Daiichi accident, research efforts have focused on development of accident tolerant fuels, which includes improving the safety performance of both the cladding and the fuel under abnormal conditions. ${ }^{53-58}$ 


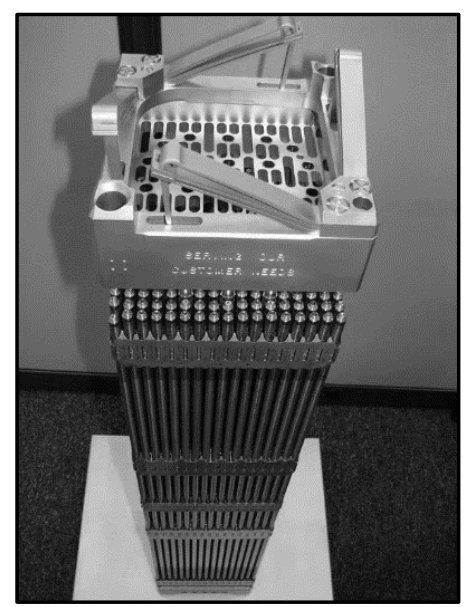

Figure 3. Photograph of PWR fuel assembly. ${ }^{59}$ Typical PWR and BWR grids are square and contain 14 to 18 and 8 to 10 fuel elements per row, respectively. The square dimensions range from about 0.14 to $0.23 \mathrm{~m}$, lengths from 3.9 to $4.8 \mathrm{~m}$, and weights from 500 to $700 \mathrm{~kg}$. Enrichment levels range up to about $5 \mathrm{wt} \%{ }^{235} \mathrm{U} .{ }^{60}$

\subsection{Mixed Oxide Fuel}

Why? There are over 2,000 MT of plutonium in the world, with the dominant inventories held by France, Japan, Russia, the United Kingdom, and the United States. MOX is a means of using these plutonium inventories for the production of civilian energy. MOX fuel does not require enriched uranium. MOX fuel is very versatile and can be used in a variety of reactor types.

MOX fuels are comprised of intimate mixtures of plutonium and uranium oxides. The MOX fuel is both manufactured as ceramic pellets and loaded into cladding much like LWR fuel and manufactured as powder and loaded directly into cladding. ${ }^{61,62}$ The uranium oxide in MOX fuels is typically made from DU or NU, but there are exceptions. The plutonium content in MOX fuels is typically in the range of 5 to $8 \mathrm{wt} \%$ but can be as high as $12 \mathrm{wt} \%{ }^{63}$

MOX fuels are used in a variety of reactor types. Sometimes the fuel loading in the reactor core is a mixture of uranium oxide and MOX fuel, and sometimes the entire core is MOX fuel. MOX is suitable for use in both thermal spectrum reactors (e.g., PWR and LWR) and SFRs.

Figure 4 shows fuel assemblies from the BN-800 reactor, which is an SFR. Figure 5 shows a fuel assembly from the Ohma reactor, which is an advanced boiling water reactor (ABWR). 


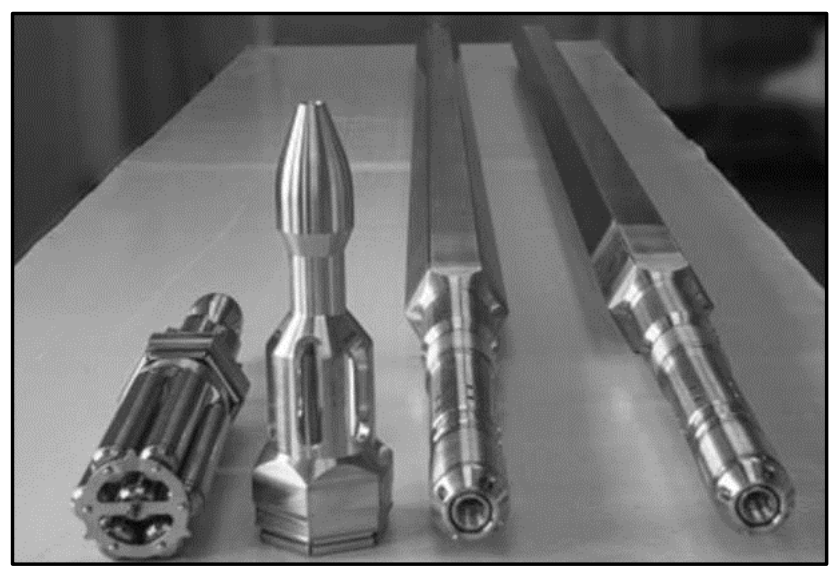

Figure 4. Photograph of BN-800 Reactor fuel assemblies, Beloyarsk Nuclear Power Station, Sverdlovsk Oblast, Russia. ${ }^{64}$ MOX fuel clad in stainless steel. The BN-800 reactor is an SFR.

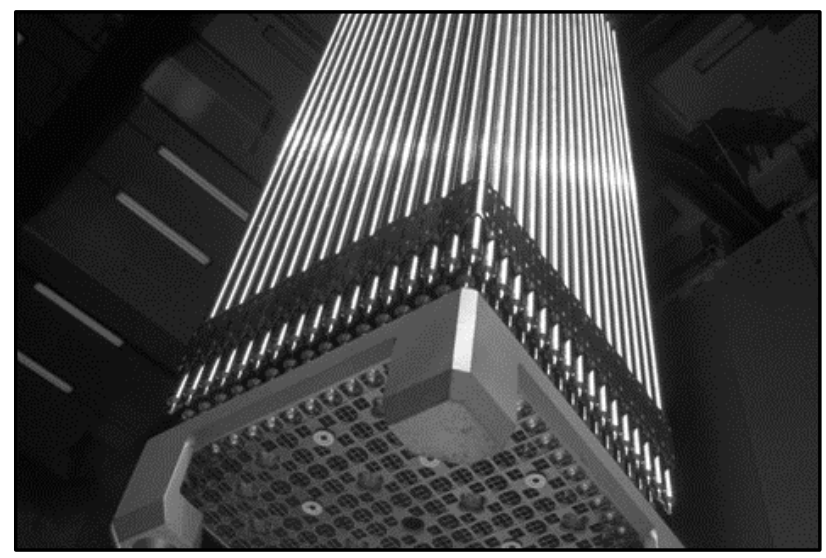

Figure 5. Photograph of Ohma Nuclear Power Plant fuel assembly, Aomori Prefecture, Japan. ${ }^{65}$ MOX fuel clad in zirconium alloy. The Ohma reactor is an ABWR.

\subsection{Natural Uranium Metal Fuel}

Why? The manufacture of NU metal fuel requires the second least amount of processing; with natural uranium oxide fuel requiring the least. No uranium enrichment is required. Reactor grade NU metal is formed into cylinders and/or tubes loaded into metal cladding. However, these reactors require graphite or heavy water for moderation. This was the preferred method of producing weapons grade plutonium.

Fueled with natural uranium metals, one reactor at $\mathrm{ORNL}^{\mathrm{d}}$, nine at $\mathrm{HS}^{\mathrm{e}}$, and five at $\mathrm{SRS}^{\mathrm{f}}$ were developed for plutonium and tritium production. ${ }^{66-68}$ The ORNL reactor was an early prototypic reactor. The two remaining families of reactors operated differently. The Hanford reactors were cooled by a combination of helium and water (single pass from the Columbia River) and moderated by graphite. The Savannah River reactors were cooled and moderated by heavy water, and the heavy water was, in turn,

d. The X-10 reactor. This was the second reactor to the Chicago Pile-1 reactor.

e. These were designated the $\mathrm{B}, \mathrm{D}, \mathrm{F}, \mathrm{H}, \mathrm{DR}, \mathrm{C}, \mathrm{KW}, \mathrm{KE}$, and $\mathrm{N}$ reactors.

f. These were designated the $\mathrm{R}, \mathrm{P}, \mathrm{L}, \mathrm{K}$, and $\mathrm{C}$ reactors. 
cooled by water from the Savannah River. A great deal of fuel development was performed at both sites, so the fuels described here are only representative. The majority of fuel was simply metallic NU fuel clad in aluminum. However, the N-Reactor at HS was unique in this fleet of reactors. It was the only reactor to serve the dual purpose of plutonium and electrical energy production, use zirconium alloy cladding, and use slightly enriched uranium $\left(1.25 \mathrm{wt} \%{ }^{235} \mathrm{U}\right)$. The N-Reactor was the last to be decommissioned. NReactor also produced civilian electricity. Many of these reactors also produced tritium via the transmutation of ${ }^{6} \mathrm{Li}$ targets. Some of these fuel designs were more complex and involved enriched uranium metal and lithium targets. The plutonium uranium reduction by extraction (PUREX) process, described later, was developed specifically to recover weapons grade plutonium from spent fuels discharged from these families of reactors. Hanford also pioneered the bismuth phosphate and reduction/oxidation (REDOX) reprocessing technologies. The use of enriched uranium fuels required engineering modifications to the PUREX process equipment to accommodate the change in criticality issues associated with the higher enrichments.

Similarly, MAGNOX reactors using metallic uranium as fuels were developed in the United Kingdom initially for plutonium production and were later adapted for civilian energy production. These were carbon dioxide $\left(\mathrm{CO}_{2}\right)$ cooled, graphite moderated, reactors. Metallic NU fuel was clad in magnesium alloy "fuel cans." Interestingly, the magnesium alloy developed for this application became the namesake of this family of reactors. The resulting alloy was called "MAGNOX AL80," which stands for "MAGnesium No OXidation ALuminum $80 \mathrm{wt} \%$." Among other factors, this aluminum alloy was compatible with the $\mathrm{CO}_{2}$ cooling gas, whereas aluminum alloys used at HS and Savannah River Site (SRS) were not.

Uranium naturel graphite gaz-cooled (UNGG) reactors were developed in France. These were similar to the MAGNOX reactors, but the metallic fuel was clad in a magnesium-zirconium alloy. Like the MAGNOX reactors, the UNGG reactors were initially used for plutonium production and were later adapted for civilian energy production.

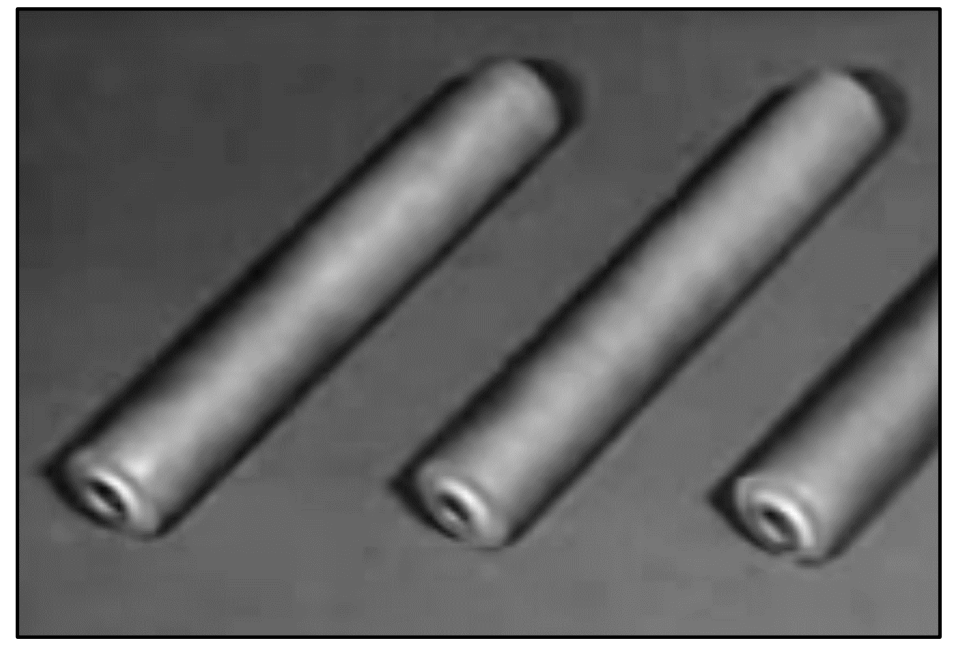

Figure 6. Photograph of typical Hanford Reactor fuel elements (single-pass-coolant reactor design). Single extruded tube of NU clad in aluminum alloy. 20 -cm-length, 2.5-cm-outside-diameter, weighing $4 \mathrm{~kg}$. 


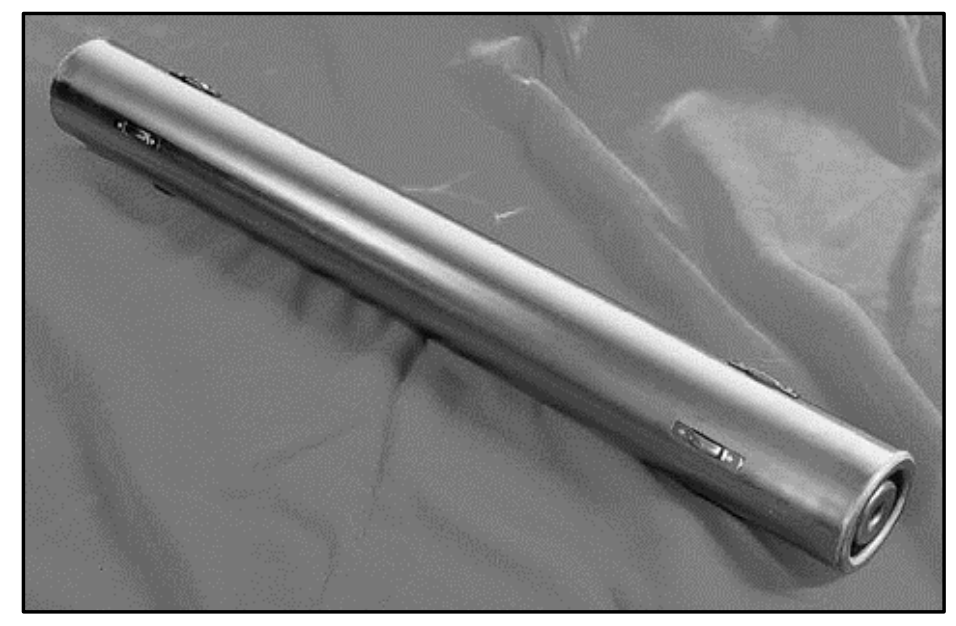

Figure 7. Photograph of Hanford N-Reactor fuel element (circulating-primary-coolant reactor design). Two coextruded concentric tubes (tube-in-tube design) of natural or slightly enriched $\left(1.25 \mathrm{wt} \%{ }^{235} \mathrm{U}\right)$ uranium clad in zirconium alloy. 66-cm-length, 5-cm-outside-diameter, weighing $24 \mathrm{~kg} .{ }^{69}$

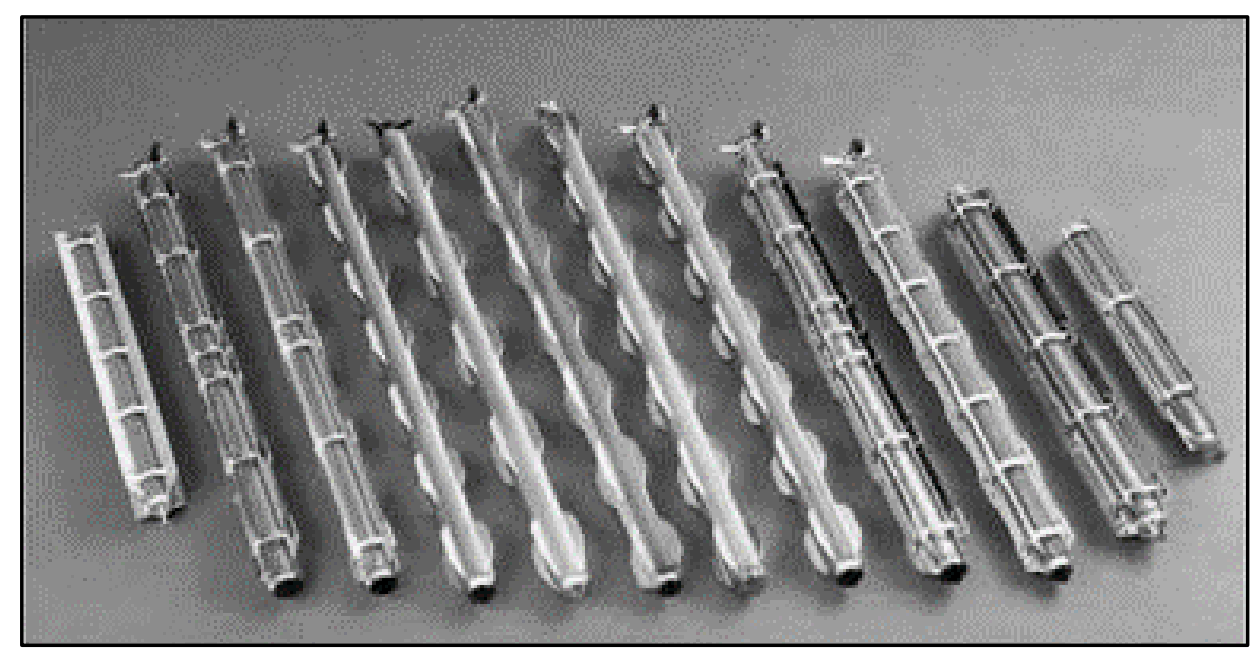

Figure 8. Photograph of examples of MAGNOX fuel cans. NU clad in magnesium alloy. ${ }^{70}$ MAGNOX fuel slugs ranged in size from about 50 to 90 -cm-length, weights 5 to $12 \mathrm{~kg}$, and all were close to $2.8-\mathrm{cm}$ diameter. ${ }^{71}$

Technical details are scarce for the plutonium production reactors used in Russia and China. ${ }^{\mathrm{g}}$ At least some of the thirteen (or so) Russian reactors were similar in principle to the U.S. production reactors, in that they were water-cooled, graphite moderated, and fueled with metallic NU clad in aluminum alloy. ${ }^{72-}$ ${ }^{74}$ However, these reactors were equipped with additional cooling channels for nitrogen, not helium, flow through the graphite core. Other Russian plutonium or tritium production reactors may have been quite different utilizing heavy water moderation. The two plutonium production reactors in China followed suit. $^{75-77}$

g. These include reactors at the Guangyuan Plutonium Production Complex, Sichuan Province, and the Jiuquan Atomic Energy Complex, Gansu Province. 
If the intent is to produce so called "weapons grade" plutonium, the goal is then to optimize operations with respect to ${ }^{239} \mathrm{Pu}$ production. This means that the NU fuel is "short cycled" in the reactor, having a residence time of about 30 days. The longer the fuel remains in the reactor, the greater the production of undesirable plutonium isotopes such as ${ }^{240} \mathrm{Pu}$ and ${ }^{241} \mathrm{Pu}$. If the intent is to produce electrical energy, such as with the Hanford N-Reactor and certain MAGNOX reactors, then the fuel remains in the reactor much longer and the resulting quality of the plutonium is diminished as it becomes so called "reactor grade" plutonium. Nevertheless, reactor grade plutonium is weaponizable, if not as desirable, for such applications. ${ }^{78}$ At the time of this writing, all the plutonium production reactors mentioned above are no longer operational.

As a result of these plutonium production efforts, there are now large stockpiles of weapons grade plutonium in Russia, the United Kingdom, and the United States. And, as a consequence of reprocessing LWR fuels, there are large stockpiles of reactor grade plutonium in France, Japan, and the United Kingdom. There are also vast quantities of reactor grade plutonium in the spent nuclear fuel inventories residing in any country that has operated, or is operating, nuclear reactors. How best to manage these plutonium inventories from environmental and security perspectives is a matter of international concern. Some of the reactor types described here are specifically intended to "burn" these plutonium reserves in reactors as a means of mitigating these concerns.

\subsection{Sodium-Bonded Metallic Fuel}

Why? Sodium-bonded metal fuels were developed for liquid-metal-cooled, fast breeder reactor applications. These metallic fuels included HEU-based alloys and DU-plutonium-based alloys. Metallic fuels lend themselves well to nonaqueous reprocessing technologies capable of recovering purified metallic products from spent metallic fuels. However, these are not the only types of fuels that can be used in this family of reactors. For example, MOX fuels and carbide fuels (to be discussed) are also applicable.

Sodium-bonded metallic fuels gained prominence during the U.S. Sodium-Cooled Fast Reactor Program which culminated in development of the Experimental Breeder Reactor II (EBR-II) at Argonne National Laboratory - West (ANL-W) (now the INL Materials and Fuels Complex) and the Fast Flux Test Facility (FFTF) at Hanford.

In this fuel design, metal fuel pins are clad in stainless steel fuel elements that are arranged in fuel assemblies. Photographs of an EBR-II driver fuel assembly is shown in Figure 9 in sections from the bottom (upper left photograph) to the top (lower right photograph). Sodium metal is added along with the fuel pin to improve the thermal conductivity between the fuel and the cladding. The MOX fuel assembly shown in Figure 5 looks very similar to the EBR-II diver fuel subassembly shown in Figure 9. Many different fuel alloys were tested in EBR-II and FFTF. The most prominent alloys capable of high burnups were binary fuel of HEU with $10 \mathrm{wt} \% \mathrm{Zr}$, and ternary fuel of DU with $20 \mathrm{wt} \% \mathrm{Pu}$ and $10 \mathrm{wt} \% \mathrm{Zr}$. A photograph of a U/Zr alloy fuel irradiated in FFTF is shown in Figure 10. 


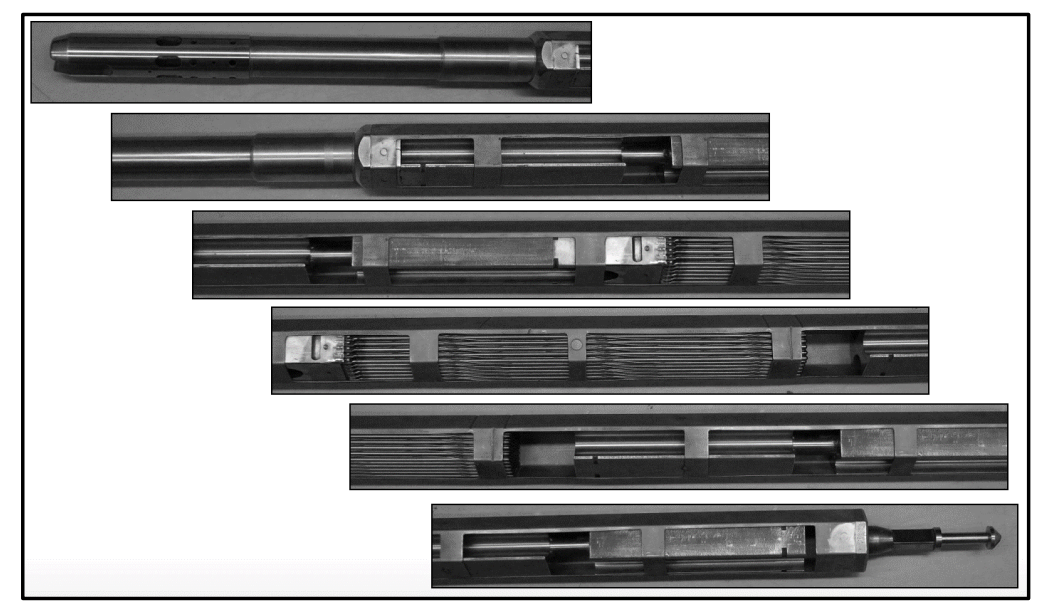

Figure 9. Photograph of a cut-away EBR-II driver fuel subassembly. (DOE photograph)

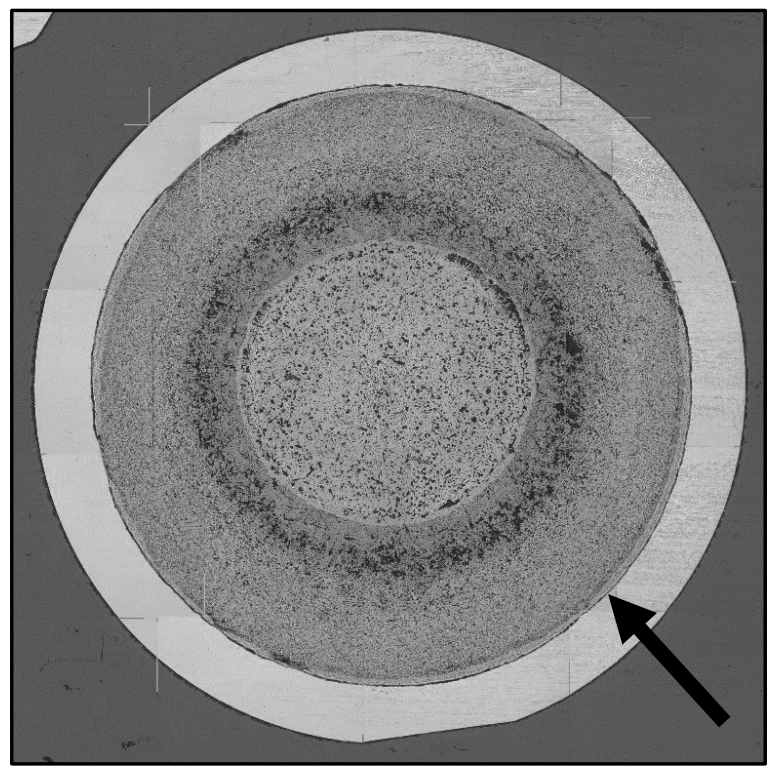

Figure 10. Mosaic microphotographs of a cross section of an EBR-II Mk-IIIA driver fuel element after $10 \%$ burnup. The outer grey ring is the stainless steel cladding that has an 0.23 -in.-OD. The arrows mark the ID of the cladding wall. The fuel has swelled and is touching the cladding wall. (Luca Capriotto, INL)

\subsection{Research Reactor Dispersion Fuel}

Why? Research reactors serve a wide variety of applications. Aluminum-clad plate-type fuel is the most common. However, the enrichment levels vary widely from LEU to HEU. Recent efforts to convert research reactor fuels to LEU have led to the development of "high-density" uranium compounds such as uranium silicides to replace the more common uranium aluminides.

The category "research reactor" encompasses a very wide variety of reactor types, sizes, and functions. The purpose here is not to impose a strict and arbitrary definition of what entails a research reactor. However, compared to commercial-scale electrical utility reactors, research reactors are much smaller and used for purposes other than electricity generation. Presently, there are about 220 operational research reactors worldwide, with hundreds $(>500)$ more in various states of decommissioning. ${ }^{79}$ Thermal power ratings range from less than $1 \mathrm{~kW}$ to greater than $200 \mathrm{MW}$, with facilities in over 50 countries. 
Providing neutrons is the one function that all research reactors share. Where they diversify is with the purpose of providing neutrons. Some of the many applications include the following:

- Education and Training

- Beamline Source

- Radiography and Tomography

- Isotope Production

- Materials Irradiation

- Nuclear Data

- Nuclear Fuels Testing

- Instrument Testing.

The status and disposition of research reactors are important topics because they operate on enriched uranium fuels spanning the full spectrum from LEU to HEU, including so called "weapons grade" uranium at $93 \mathrm{wt} \%{ }^{235} \mathrm{U}$. This means that the status of fresh and spent fuels from research reactors (that, remember, are spread globally) is a significant concern for the proliferations and safeguards of this material. In response, the U.S. Department of Energy (DOE) began the Global Threat Reduction Initiative (GTRI), which included the Reduced Enrichment for Research and Test Reactors (RERTR) Program and the U.S. Foreign Research Reactor Spend Nuclear Fuel (FRR SNF) Acceptance Program. The primary purposes of these programs are to convert research reactors from HEU to LEU fuels, and to return HEU fuels to the countries of origin. To accommodate these changes much research has been performed on new fuel designs with focus on increasing the uranium density and volume fraction to offset the undesirable performance characteristics of lower enriched fuels.

By far the most common dispersion fuel is the aluminum-clad plate-type. In this fuel design a uranium compound is formed into a thin plate and clad between two aluminum plates forming a fuel plate. Fuel and plate thicknesses are on the order of 0.5 to $1.5 \mathrm{~mm}$, respectively. Several fuel plates comprise a fuel assembly as depicted in Figure 11. Cooling is provided by air or water, and fuel temperatures remain low. There are many hundreds of fuel designs and configurations used in research reactors. Widely used uranium compounds include aluminides, silicides, hydrides, and molybdenides of uranium. The stoichiometries of these compounds vary according to application. And burnable poisons, such as boron and gadolinium, may be added to the fuel compositions. Conversion of a reactor from HEU to LEU often accompanies changing the uranium aluminide fuel to the newer uranium silicide or uranium molybdenide fuels for their increased fuel densities. 


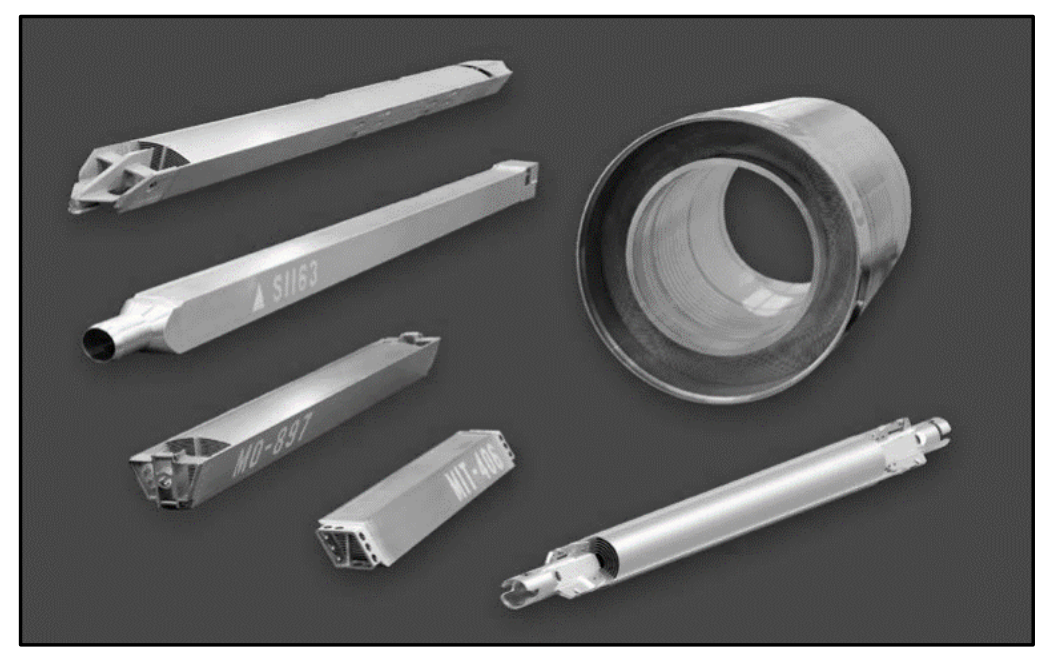

Figure 11. Photograph of typical research reactor plate fuel assemblies. (BWXT photograph)

The fuels described above are a type of "dispersion fuel." Dispersion fuels consist of fuel particles that are dispersed and suspended in a matrix. A wide variety of materials have been proposed to serve as fuel and matrix. The fundamental advantage of dispersion fuels over the monolithic fuels described earlier, is that the bulk of the matrix remains undamaged from radiation and fission product effects, allowing for higher burnups. ${ }^{80}$ There are a great number of dispersion fuel systems proposed. Of these, TRISO fuel has received the most attention, and it is designed for advanced high-temperature gas-cooled reactors.

\subsection{Coated-Particle Dispersion Fuel}

Why? Developed for high temperature reactor applications. Higher coolant outlet temperatures translate to improved thermal-to-mechanical energy conversion efficiencies. And higher temperature coolants can be put to more uses than lower temperature coolants. Therefore, reactors capable of achieving $1000^{\circ} \mathrm{C}$ or higher coolant temperatures are desirable.

TRISO fuels are significantly different from any of the fuels previously discussed. There are many variants of this fuel type. This fuel design was developed for high temperature reactor applications, such as the high-temperature gas-cooled reactor (HTGR), but it is not limited in that regard. The basic structural components as seen in Figure 12 are as follows:

- Inner spherical fuel kernel: The fuel kernel is on the order of 0.5-mm-diameter. Several materials are candidate fuels. The materials most studied include uranium oxide (as seen in the Figure 12), uranium carbide, and uranium oxy-carbide.

- Low-density pyrolytic carbon layer: The porosity in this layer provides space for the accumulation of fission product gases.

- First high-density isotropic pyrolytic carbon layer: This layer protects the fuel kernel during silicon carbide deposition and aids in fission gas retention.

- High-density silicon carbide layer: This layer provides the primary means of mechanical strength and containment of fission products.

- Second high-density isotropic pyrolytic carbon layer: This layer protects the silicon carbide layer and provides surface bonding to the dispersion matrix. 
- Together the various layers serve as the "cladding" surrounding the fuel kernel and barrier containing the fission products. And all layers must conduct the heat from the fuel kernel to the dispersion matrix.

- The dispersion matrix contains the TRISO particles and conducts the heat from the TRISO particles to the primary heat transfer fluid circulating through the core of the reactor.

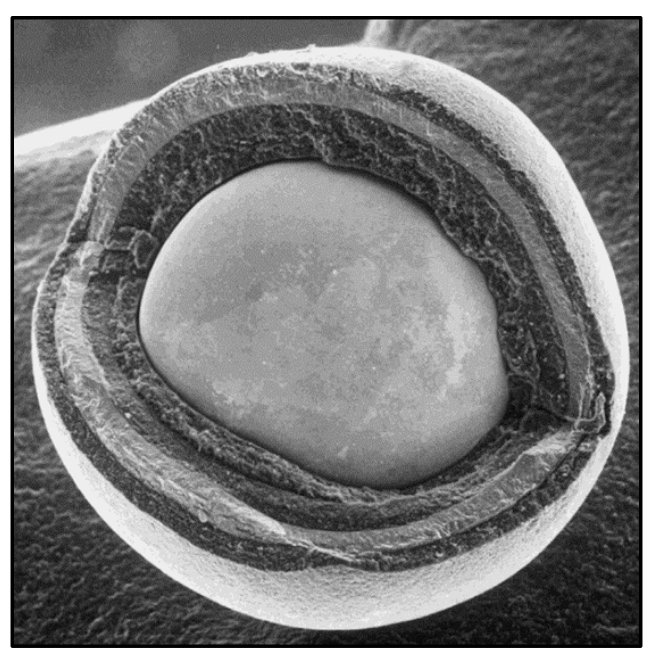

Figure 12. Photograph of breached TRISO fuel particle. The spherical uranium oxide kernel is encapsulated by successive layers of pyrolytic carbon and silicon carbide. (DOE photograph)

TRISO fuel particles dispersed in graphite cylinders, called "fuel compacts," are shown in Figure 13. These compacts measure 12.5-mm-diameter by $50-\mathrm{mm}$-length. These were designed for a prismatic-core HTGR where they are loaded into hexagonal graphite elements fitted with channels for cooling gas flow and fuel compacts.

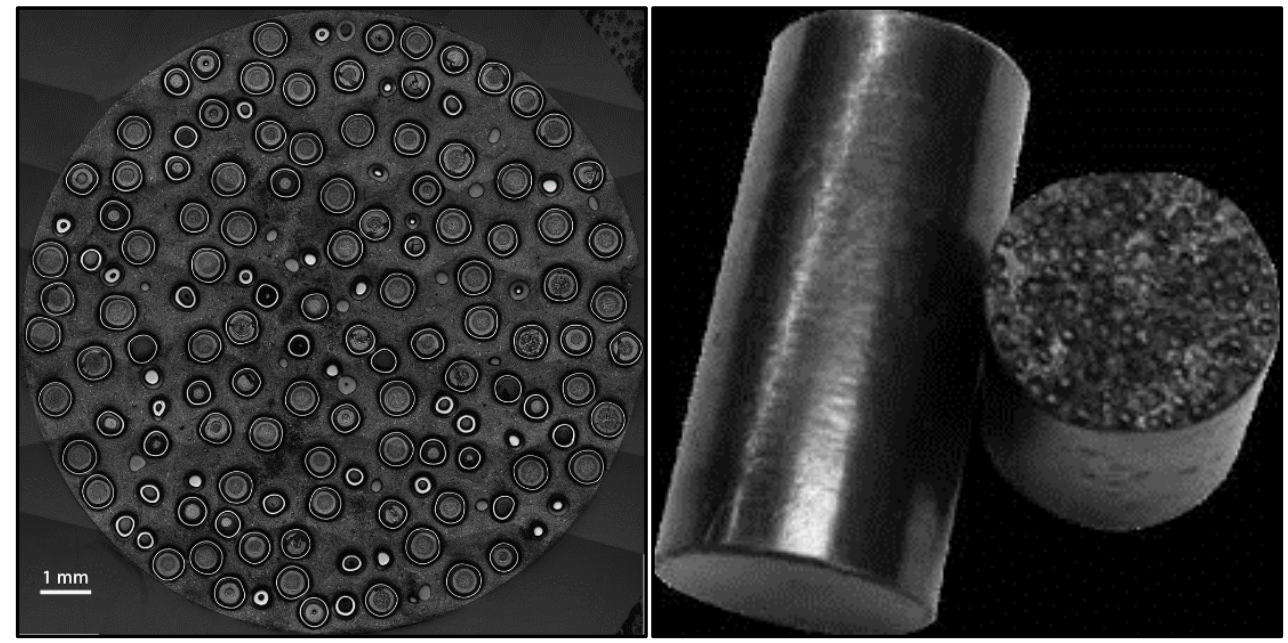

Figure 13. Photographs of graphite cylinder containing a dispersion of TRISO fuel particles. The image on the left is a cross section of the cylinder. (DOE photographs) 
TRISO fuel particles dispersed in graphite spheres, called "pebbles," are shown in Figure 14. These spheres measure 60-mm-diameter. The two-part design includes a 50-mm-diameter inner spherical fuel zone surrounded by 5-mm-thick fuel-free shell. These were designed for a pebble-bed HTGR.
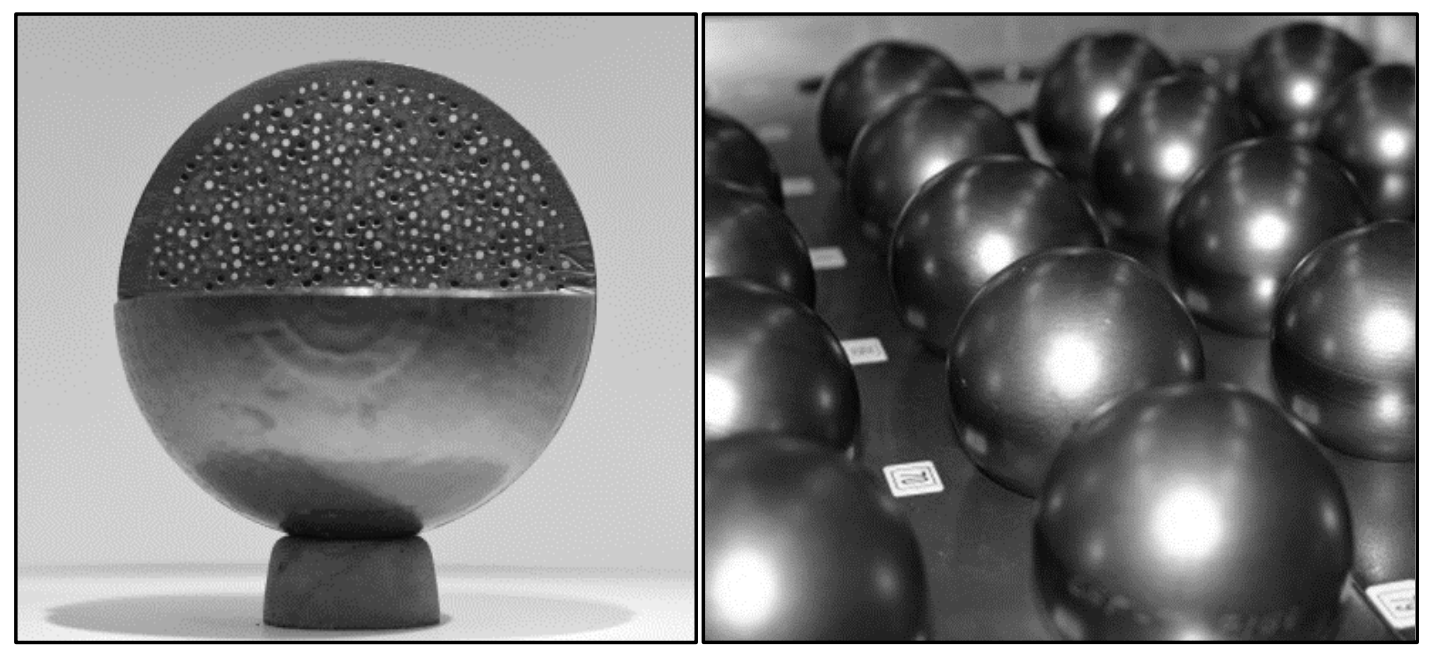

Figure 14. Photographs of a graphite sphere ("pebble") containing a dispersion of TRISO fuel particles. The image on the left is a partial cross section of a graphite sphere. (DOE photographs)

There are structural variants of these particles as well. The bi-structural isotropic (BISO) fuel, and the quad-structural isotropic (QUADRISO) fuel. The silicon carbide layer is absent in BISO fuel, which is exploited in a particular reprocessing scheme as described later. A burnable poison layer is present in QUADRISO fuel. A further distinction is made by the means of depositing the high-density isotropic pyrolytic carbon layer. For example, there is a distinction between LTI-TRISO and HTI-TRISO. Lowtemperature isotropic (LTI) pyrolytic carbon is derived from a mixture of propene and ethyne. Hightemperature isotropic (HTI) pyrolytic carbon is derived from methane.

The silicon carbide layer is formed by chemical vapor deposition (CVD) from methyltrichlorosilane. However, silicon carbide is not the only choice; work has been performed on zirconium carbide coated particles. ${ }^{81}$ There are many possible fuel combinations of DU, NU, LEU, HEU, and plutonium as oxides, carbides, and oxy-carbides. And it is also possible to combine fissile and fertile isotopes such as ${ }^{232} \mathrm{Th}^{82}$

\subsection{Naval Reactor Fuel}

Why? Refueling a reactor aboard a ship or submarine is a difficult task. Fuel technologies have advanced to where refueling is no longer require because the initial fueled reactor core is expected to last the lifetime of the vessel.

Nuclear reactors for service aboard ships and submarines have special requirements not encountered elsewhere. The following list is cited directly. ${ }^{83}$

- Compactness: Reactor must be small enough to fit within space and weight constraints of a warship while still being able to provide adequate power to drive at necessary speeds for engagement or rapid transit.

- Crew Protection: The crew lives and works very close to the reactor for extended amounts of time.

- Public Safety: U.S. Navy ships use various ports around the world; it is a necessity that the safety of the general public at these ports be guaranteed so that ships are continued to be welcomed.

- Reliability: The reactor must be able to continuously provide power and electricity to the ship to ensure a self-sufficient operational status in the most demanding environments. 
- Ruggedness: The reactors must be able to tolerate extreme conditions of being at sea as well as severe shocks during battle conditions.

- Maneuverability: The reactor must be able to provide rapid and frequent power changes to support the ships' tactical maneuvering.

- Endurance: It is crucial that the reactor to be able to operate for many years before refueling, the bestcase scenario is a lifetime core. This will maximize ship availability, minimize occupational exposure, minimize life-cycle cost, and minimize demand on the support infrastructure.

- Quietness: This is especially important for submarines so to minimize the threat of acoustic detection.

There is not much information available to the public on the designs of fuels and reactors for naval applications. Submarines are fitted with a single reactor, while larger surface vessels - such as aircraft carriers - may be fitted with several reactors. Most modern naval reactors are PWR-type reactor. Enrichment levels range from 93 to $97 \%{ }^{235} \mathrm{U} .{ }^{84}$ Therefore, spent naval reactor fuels could be an important source of HEU.

Other types of naval reactors were deployed in the past and are perhaps deployed presently. For example, the first two U.S. submarine reactors were water-cooled (designed by Westinghouse) and sodium-cooled (designed by General Electric). ${ }^{85}$ The S1W was the first water-cooled naval propulsion reactor. It was tested on land by Westinghouse at the National Reactor Testing Station near Arco, Idaho. This facility is now on the INL site. The S2W was the second water-cooled naval propulsion reactor and the first nuclear reactor to be used on a submarine. It was tested on the U.S.S. Nautilus (SSN-571) from January 21, 1954 to March 2, 1980. The S1G (a.k.a., SIR Mk-A) was the first sodium-cooled naval propulsion reactor. It was tested on land by General Electric at the Knolls Atomic Power Laboratory, Kesselring Site, in Niskayuna, NY. The reactor containment dome was a 225-ft-dia. sphere, made of 1in.-thick steel, weighing 3,850 ton; the dome itself was considered an engineering feat. ${ }^{86}$ The S2G (a.k.a SIR Mk-B) was the second sodium-cooled naval propulsion reactor and the second nuclear reactor to be used on a submarine. It was tested during sea trials on the U.S.S. Seawolf (SSN-575) submarine from July 21, 1955 to December 12, 1958, at which time it was replaced with a water-cooled S2Wa reactor. The S2G was also the final LMR tested by the Navy because PWR technologies were adopted for all future naval applications. ${ }^{87,88}$

Early Russian submarine reactors used uranium oxide fuel pellets clad in stainless steel and were cooled with a lead-bismuth alloy. ${ }^{89}$ Countries with military nuclear naval fleets include China, France, India, the United Kingdom, and the United States. Nuclear reactors have also been considered for civilian commercial vessels. ${ }^{90}$

\subsection{Inert Matrix Fuel}

Why? Inert matrix fuels do not contain uranium. The fissile inventory is completely comprised of transuranic elements. This fuel type is intended to consume transuranics as efficiently as possible. Eliminating uranium from the fuel prevents the formation of additional transuranics via the transmutation of uranium.

The purpose of inert matrix fuels (IMFs) is to "burn" plutonium as efficiently as possible. This is done by providing a uranium-free fuel, which eliminates completely the transmutation processes that generate additional transuranics in the core. IMFs have been proposed for every kind of civilian power reactor, including CANDUs and LWRs. In these core conversion scenarios, the core is often shared by a mixture of standard fuel assemblies along with IMF assemblies. 


\begin{abstract}
"A major disadvantage of removing ${ }^{238} U$ is the reduction or elimination of a prompt negative Doppler reactivity coefficient and a negative moderator temperature coefficient. A pure plutonium fuel type is not desirable in LWRS because of the low allowable mass loading per fuel rod (yielding short fuel cycles) and strong positive temperature coefficients. Any workable fuel composition must have a negative prompt temperature coefficient (i.e., reactor power decreases as temperature increases) for safety and control purposes. Plutonium cores in LWRs can have negative isothermal temperature coefficients if enough tungsten, erbium, or other resonance absorbers are added. The addition of burnable poison is also needed to hold down the core reactivity. "91
\end{abstract}

Resonance absorbers affect the neutron spectrum and provide negative reactivity by interacting preferentially with fast neutrons. This effect of resonance absorbers is termed Doppler reactivity feedback. Effective resonance absorbers include iron, niobium, tungsten, molybdenum, and the oxides of these metals that perform a similar function as ${ }^{238} \mathrm{U}$, which is absent in IMFs. But the options for resonance absorbers are not limited to these four elements. ${ }^{92-97}$

\title{
4.11 Molten Salt Fuel
}

Why? MSRs have several promising, yet unrealized, features that make them attractive. These include high coolant temperatures, low pressure molten salt cooling systems, enhanced intrinsic safety features, and greater thermal-tomechanical efficiencies than, for example, LWRs.

Molten salt fuels are significantly different from any of the fuels previously discussed. There are many variants of reactors designs that use molten salts, and many variants of the molten salt systems that can be used as fuel salts and cooling salts. There is a stark difference between molten salt fueled reactors and molten salt cooled reactors, even though both are MSRs. In most designs, MSRs have two molten salt loops: primary and secondary. The primary salt loop extracts heat from the core, and the secondary salt loop extracts heat from the primary salt loop. The most significant difference is the nature of the fuel. In a molten salt fueled reactor, the fissile inventory is contained in the primary molten salt. In a molten salt cooled reactor, the fissile inventory is stationary and contained in fuel elements in the core. Fluoride and, to a lesser extent, chloride salt systems have received the most attention. As discussed earlier, isotopic enrichment of lithium and chlorine may be necessary in order to preserve the neutron economy and to limit the formation of undesirable transmutation product such as ${ }^{3} \mathrm{H}$ and ${ }^{36} \mathrm{Cl}$, respectively.

There are several technical requirements placed on molten salt fuels and coolants. Certainly, the physical/chemical properties that are important to basic engineering design aspects include heat capacity, thermal conductivity, viscosity, vapor pressure, density, and radiation performance. The more subtle aspects are related to the chemical and electrochemical properties of the molten salts, particularly regarding the chemical compatibilities of the molten salts with the materials of construction of the reactor components. Even in the simplest applications, such as a secondary cooling loop residing entirely outside the reactor core, the chemical interactions between the salt and systems are quite complex. The systems include heat exchangers, piping, valves, and fluid pumps. For example, the cooling salt flowing between two heat exchangers results in a substantial temperature gradient. The solubilities in the molten salt of certain elements in the alloys used for materials of construction may be greater at higher temperature than at lower temperature. This effect establishes a mass transport mechanism from the higher temperature region to the lower temperature region. Also, two dissimilar metals in electrical contact and exposed to a common electrolyte will establish a Galvanic cell. A multiplicity of such cells will exist in these complex mechanical systems, which can lead to significant sources of corrosion. The existence of these mechanisms is unavoidable; the goal is to manage their effects. 
The situation with fuel salt is significantly more complex. All the same concerns addressed above apply, along with the additional complications associated with an ever changing and highly complex salt chemistry. Fuel salts contain the inventories of the fissile and fertile fuel components, as well as the fission and other transmutation products and radiolysis products. Metal fluorides and chlorides can be ranked according to their chemical stability relative to one another. Herein lies a concern. Many alloys considered for use in MSRs contain nickel and chromium. Fission product in the salt that are "more noble" than nickel and chromium - less stable in the salt than nickel or chromium - will form a redox couple with these alloy metals, if ionized. The noble metal fission products will be reduced from cations to metals, and the alloy metals will be oxidized from metals to cations. This mechanism is another form of unavoidable corrosion of the materials of construction. Furthermore, the plating of noble metals onto select surfaces of the materials of construction will establish additional mechanisms for Galvanic corrosion.

Research on MSRs began at ORNL in the late 1940s, with much attention focused on fluoride salts, and continued until the mid-1970s when these experimental programs were cancelled. Worldwide, only two MSRs have been operated. The Aircraft Reactor Experiment ${ }^{98}$ during November 3 to 12, 1954. And the MSRE $^{99}$ during two campaigns between June 1, 1965 and December 12, 1969. The purpose of the MSRE was to gain experience on the ${ }^{232} \mathrm{Th} /{ }^{233} \mathrm{U}$ MSBR fuel cycle. The nominal composition of the fuel salt was $\mathrm{LiF}-\mathrm{BeF}_{2}-\mathrm{UF}_{4}-\mathrm{ZrF}_{4}$ (65-29.2-0.8-5 mole \%). The first campaign used ${ }^{235} \mathrm{U}$ and the second campaign used ${ }^{233} \mathrm{U}$. ${ }^{232} \mathrm{Th}$ was never added to the fuel salts. Reviews of MSR technologies were performed previously. ${ }^{100,101,102}$ INL recently issued a report reviewing MSR technologies. ${ }^{103}$ 


\section{REPROCESSING}

Here reprocessing refers to any chemical process applied to the treatment of nuclear fuel, blanket material, or target material for the purpose of performing chemical separations. This is a broad interpretation of reprocessing that is meant to avoid the arbitrariness of a more exacting definition. Therefore, there are many diverse reasons why such materials would be reprocessed, which is an important realization. Selection of a specific reprocessing technology and, in finer resolution, selection of a specific reprocessing flowsheet requires answers to several key engineering and regulatory questions. All are classical engineering questions except the last two, which are unique to processes dealing with highly regulated materials including, but not limited to, materials such as these.

What are the characteristics of the materials to be reprocessed?

What chemical separations are required?

What separation efficiencies are required?

What recovery efficiencies are required?

What are the acceptance criteria of the recovered product materials?

What are the acceptance criteria of the recovered waste materials?

What are the environmental emissions standards?

What is the required reprocessing rate?

What is the required duration of operations?

What are the social requirements?

What are the economic requirements?

What are the materials control and accountancy requirements?

What are the safeguards requirements?

In a broad sense this all distills down to defining the task at hand. What follows are examples of reprocessing technologies that have been applied to, or conceived for, very specific applications both military and civilian. 


\subsection{Aqueous-Based Reprocessing Technologies}

Just as the first large-scale nuclear reactors were built to produce plutonium, the first large-scale reprocessing plants were built to recover plutonium from these spent fuels. The early plutonium separations processes such as the bismuth phosphate precipitation process and the REDOX process eventually led to the development of the PUREX process. All were developed for the purpose of recovering ${ }^{239} \mathrm{Pu}$ for weapons production.

Hanford Site ${ }^{104,105}$

- T Plant: Operated from 1944 to 1956 for plutonium recovery from spent fuels via the bismuth phosphate precipitation process. This was the world's first large-scale plutonium separation plant.

- B Plant: Operated from 1945 to 1957 for plutonium recovery from spent fuels via the bismuth phosphate precipitation process. Then, following modification from 1968 to 1985 for cesium and strontium recoveries from tank wastes.

- U Plant (a.k.a., TBP Plant): Constructed in 1945 for the same purpose as the T Plant and B Plant, but never operated in that capacity. Following modifications, it was operated from 1952 to 1958 for uranium recovery from uranium-bearing tank wastes from the $\mathrm{S}$ Plant. During this second mission it was named TBP Plant; but also went by Metal Recovery Plant and Uranium Recovery Plant. The process used at the TBP Plant to recovery uranium was a modification of the PUREX process. Tributyl phosphate (TBP) was used as the extractant, hence the name TBP Plant.

- S Plant (a.k.a., REDOX Plant): Operated from 1952 to 1967 for plutonium recovery from spent fuels via the REDOX process.

- A-Plant (a.k.a., PUREX Plant): Operated from 1956 to 1972, and 1983 to 1988, and for a brief period in 1990, for plutonium and uranium recovery from spent fuels via the PUREX process. The plant was also used to recover ${ }^{233} \mathrm{U}$ from irradiated thorium oxide blanket in 1965, 1966, and 1970. These PUREX operations are described in the literature. ${ }^{237} \mathrm{~Np}$ was also recovered as needed for production of ${ }^{238} \mathrm{Pu} .{ }^{106,107}$

- $\mathrm{UO}_{2}$ Plant: Operated on demand from 1956 to 1993 for the purpose of converting uranium nitrate hexahydrate from the U Plant to uranium oxide. The uranium oxide product was shipped to other locations for conversion to uranium hexafluoride and subsequent enrichment.

\section{Savannah River Site ${ }^{108}$}

- F Canyon: Operated from 1954 to 1957, shut down for upgrades, and 1959 to 2000, for plutonium and uranium recovery from spent fuels via the PUREX process.

- H Canyon: Operated from 1955 to 1959, shut down for three months for upgrades, and 1959 to present, for plutonium and uranium recovery from spent fuels via the PUREX process. Following the restart in 1959, the H Canyon used the "H-Modified" process, or simply the "HM" process, which was a modification to the PUREX process allowing for the processing of HEU fuels. The early PUREX processes were designed to process natural or DU fuels, not enriched uranium fuels. Modifications to the PUREX process equipment were needed to alleviate the criticality issues associated with enriched uranium. H Canyon has recently been used to downblend HEU research reactor fuels to LEU levels. ${ }^{109}$

- B-Lines: B-Lines were associated with both F Canyon and H Canyon. They were used to process the plutonium nitrate product from the PUREX process into plutonium metal.

- A-Lines: A-Lines were associated with both F Canyon and H Canyon. They were used to process the uranyl nitrate product from the PUREX process into uranium oxide. 
Idaho National Laboratory ${ }^{110}$

- Idaho Chemical Processing Plant (ICPP, aka Idaho Nuclear Technology Engineering Center (INTEC)): Operated from 1953 to 1992. Designed as a hybrid REDOX/PUREX process to treat a variety of HEU fuels. The ICPP and H Canyon were the two PUREX plants capable of reprocessing HEU fuels.

\section{U.S. Commercial Facilities ${ }^{111}$}

- Nuclear Fuel Services Company, West Valley, NY: Operated by W.R. Grace Company from 1966 to 1971. It was the only commercial PUREX plant to be operated in the U.S. The plant reprocessed fuels from commercial LWRs and the Hanford N-Reactor. The nominal design capacity was 300 MTHM per year. The plant was shut down in December 1971 for reconstruction to nearly triple its capacity. Work on this effort continued until 1976 when the company suspended operations.

- Midwest Fuel Recovery Plant, Morris, Illinois: Built by General Electric between 1970 and 1974 but never operated with irradiated fuels. Early testing revealed a flowsheet design flaw, and the plant was declared inoperable in 1975. Reprocessing was based on the Aquafluor process, which is a combination of solvent extraction coupled with uranium fluoride volatility. The nominal design capacity was 300 MTHM per year. ${ }^{112}$

- Barnwell Nuclear Fuel Plant, Barnwell, South Carolina: Built by Allied General Nuclear Services between 1970 and 1975 but never operated with irradiated fuels. Reprocessing was based on PUREX with a nominal design capacity of 1500 MTHM per year. ${ }^{13,114}$

- Exxon Nuclear Fuel Recovery and Recycling Center, Oak Ridge Reservation, Ok Ridge, Tennessee: Construction permit application submitted to the Nuclear Regulatory Commission (NRC) by the Exxon Nuclear Company, Inc., in 1976. The nominal design capacity was 2100 MTHM per year. The project never came to fruition. ${ }^{115}$ Getty Oil Company, Atlantic Richfield Company, and Allied-Gulf Corporation were developing similar plans to construct commercial reprocessing facilities at that time.

1976 saw the beginnings of a substantial policy shift that effectively ended commercial reprocessing in the U.S. This marked the beginning of the end to commercial reprocessing ventures in the U.S. Soon afterwards essentially all existing and planned projects were cancelled. It was an election year and President Ford was running against Mr. James Carter. In October 1976 during his campaign, President Ford announced,

"...the reprocessing and recycling of plutonium should not proceed unless there is sound reason to conclude that the world community can effectively overcome the associated risks of proliferation... that the United States should no longer regard reprocessing of used nuclear fuel to produce plutonium as a necessary and inevitable step in the nuclear fuel cycle, and that we should pursue reprocessing and recycling in the future only if they are found to be consistent with our international objectives. "116

And after the election, in April 1977, President Carter announced,

"We will defer indefinitely the commercial reprocessing and recycling of plutonium produced in the U.S. nuclear power programs." And later... "The plant at Barnwell, South Carolina, will receive neither federal encouragement nor funding for its completion as a reprocessing facility. ""116

Other countries did not follow the U.S. lead, and instead developed vast infrastructures for commercial reprocessing of nuclear fuels since the 1970s. A summary of major international reprocessing facilities is given in Table 8. China and India are the only countries actively researching and expanding their reprocessing capabilities. Russia is faced with cold war legacy nuclear waste issues that are on par 
with, or worse than, those in the U.S. However, Russia is modernizing its reprocessing infrastructure and actively engaged in demonstrating new reprocessing technologies. Japan is modernizing its infrastructure with the construction of Rokkasho, which is expected to open in 2022 after significant delays. France continues to reprocess nuclear fuels for its own domestic needs and under contract to other countries. And the United Kingdom has recently terminated its reprocessing activities after a long history of nuclear development. Early on Germany chose not to develop its own reprocessing capabilities, and instead contracted with France and the United Kingdom to reprocess its spent LWR fuels up until 2005.

Table 8. Summary of Major International Reprocessing Facilities.

\begin{tabular}{|c|c|c|c|c|}
\hline Country & Facility Name & $\begin{array}{l}\text { Dates of } \\
\text { Operation }\end{array}$ & Production Scale & Fuels Reprocessed \\
\hline \multirow[t]{3}{*}{ China } & $\begin{array}{l}\text { Lanzhou Nuclear } \\
\text { Fuel Complex. }\end{array}$ & 2010 to present. & $\begin{array}{l}\text { Pilot Plant } 10 \text { to } \\
20 \mathrm{MT} / \mathrm{y} \text {. }\end{array}$ & \\
\hline & $\begin{array}{l}\text { Gansu Nuclear } \\
\text { Technology } \\
\text { Industrial Park. }\end{array}$ & $\begin{array}{l}\text { Under } \\
\text { development. }\end{array}$ & $200 \mathrm{MT} / \mathrm{y}$. & \\
\hline & $\begin{array}{l}\text { Reprocessing Plant. } \\
\text { Based on Orano } \\
\text { technology. Site } \\
\text { location TBD. }\end{array}$ & $\begin{array}{l}\text { Under } \\
\text { development. } \\
\text { Target early } \\
\text { 2030s. }\end{array}$ & $800 \mathrm{MT} / \mathrm{y}$. & LWR fuels. \\
\hline \multirow[t]{7}{*}{ France } & Marcoule UP1. & 1958 to 1976. & $\begin{array}{l}900 \mathrm{MT} / \mathrm{y} \\
\text { Military. }\end{array}$ & GGR. \\
\hline & & 1976 to 1993. & $\begin{array}{l}\text { Military and } \\
\text { civilian. }\end{array}$ & \\
\hline & & 1993 to 1997. & Civilian. & \\
\hline & LaHague UP2. & 1966 to 1976. & $800 \mathrm{MT} / \mathrm{y}$. & GGR. \\
\hline & LaHague UP2-400. & 1976 to 2004 . & $400 \mathrm{MT} / \mathrm{y}$. & LWR and GGR. \\
\hline & LaHague UP2-800. & 1994 to present. & $800 \mathrm{MT} / \mathrm{y}$. & LWR. \\
\hline & LaHague UP3. & 1989 to present. & $800 \mathrm{MT} / \mathrm{y}$. & LWR, MOX, RR. \\
\hline \multirow[t]{2}{*}{ Germany } & $\begin{array}{l}\text { Karlsruhe } \\
\text { Reprocessing Plant. }\end{array}$ & 1971 to 1990. & $\begin{array}{l}\text { Pilot Plant } 35 \\
\text { MT/y. }\end{array}$ & LWR. \\
\hline & $\begin{array}{l}\text { Wackersdorf Nuclear } \\
\text { Reprocessing Plant. }\end{array}$ & $\begin{array}{l}\text { Under } \\
\text { development } \\
1982 \text { to } 1988 . \\
\text { Abandoned. }\end{array}$ & $350 \mathrm{MT} / \mathrm{y}$. & LWR. \\
\hline \multirow{3}{*}{$\begin{array}{l}\text { India, Trombay, } \\
\text { Bhabha Atomic } \\
\text { Research Centre } \\
\text { (BARC) }\end{array}$} & $\begin{array}{l}\text { Uranium Thorium } \\
\text { Separation Facility } \\
\text { (UTSF). }\end{array}$ & 2002 to present. & $\begin{array}{l}\text { THOREX Pilot } \\
\text { Plant. }\end{array}$ & $\begin{array}{l}\text { ThO2 irradiated in } \\
\text { CIRUS reactor. }\end{array}$ \\
\hline & $\begin{array}{l}\text { Power Reactor } \\
\text { Thoria Reprocessing } \\
\text { Facility (PRTRF). }\end{array}$ & 2015 to present. & $\begin{array}{l}\text { THOREX Pilot } \\
\text { Plant. }\end{array}$ & $\begin{array}{l}\text { ThO2 irradiated in } \\
\text { Dhruva PHWR } \\
\text { reactor. }\end{array}$ \\
\hline & $\begin{array}{l}\text { Plutonium } \\
\text { Reprocessing Plant } \\
\text { (PRP). }\end{array}$ & 1964 to 1973 . & $\begin{array}{l}\text { PUREX } 30 \\
\mathrm{MT} / \mathrm{y} .\end{array}$ & $\begin{array}{l}\text { CIRUS reactor } \\
\text { fuel. Al-clad } \\
\text { metallic NU. }\end{array}$ \\
\hline
\end{tabular}




\begin{tabular}{|c|c|c|c|c|}
\hline Country & Facility Name & $\begin{array}{l}\text { Dates of } \\
\text { Operation }\end{array}$ & Production Scale & Fuels Reprocessed \\
\hline & PRP (refurbished). & 1983 to present. & $\begin{array}{l}\text { PUREX } 60 \\
\mathrm{MT} / \mathrm{y} .\end{array}$ & $\begin{array}{l}\text { Dhruva PHWR } \\
\text { fuel. Al-clad } \\
\text { metallic NU. }\end{array}$ \\
\hline \multirow{6}{*}{$\begin{array}{l}\text { India, } \\
\text { Kalpakkam, } \\
\text { Indira Gandhi } \\
\text { Centre for } \\
\text { Atomic Research } \\
\text { (IGCAR) }\end{array}$} & $\begin{array}{l}\text { Kalpakkam Atomic } \\
\text { Reprocessing Plant } \\
\text { (KARP). }\end{array}$ & $\begin{array}{l}1996 \text { to } 2003 \\
2009 \text { to present. }\end{array}$ & $\begin{array}{l}\text { PUREX } 100 \\
\mathrm{MT} / \mathrm{y} .\end{array}$ & $\begin{array}{l}\text { Madras Atomic } \\
\text { Power Station } \\
\text { (MAPS) PHWR } \\
\text { fuel. }\end{array}$ \\
\hline & $\begin{array}{l}\text { KARP Expansion } \\
\text { Project PReFRe-3A. }\end{array}$ & $\begin{array}{l}\text { Under } \\
\text { development. }\end{array}$ & PUREX. & \\
\hline & $\begin{array}{l}\text { Lead Mini Cell } \\
\text { Facility. }\end{array}$ & 2002 to present. & Pilot Plant. & $\begin{array}{l}\text { Fast Breeder Test } \\
\text { Reactor (FBTR) } \\
\text { U/Pu carbide fuel. }\end{array}$ \\
\hline & $\begin{array}{l}\text { Compact } \\
\text { Reprocessing Facility } \\
\text { for Advanced Fuels } \\
\text { (CORAL). }\end{array}$ & 2003 to present. & $\begin{array}{l}\text { Pilot Plant } 12 \\
\mathrm{~kg} / \mathrm{y} \text {. }\end{array}$ & $\begin{array}{l}\text { FBTR U/Pu } \\
\text { carbide fuel. }\end{array}$ \\
\hline & $\begin{array}{l}\text { Demonstration Fast } \\
\text { Reactor Plant } \\
\text { (DFRP). }\end{array}$ & $\begin{array}{l}\text { Under } \\
\text { development. }\end{array}$ & $\begin{array}{l}\text { Demonstration } \\
\text { Plant } 100 \text { to } 500 \\
\mathrm{~kg} / \mathrm{y} .\end{array}$ & $\begin{array}{l}\text { FBTR and } \\
\text { Prototype Fast } \\
\text { Breeder Reactor } \\
\text { (PFBR) fuels. }\end{array}$ \\
\hline & $\begin{array}{l}\text { Fast Reactor Fuel } \\
\text { Reprocessing Plant } \\
\text { (FRFRP). }\end{array}$ & $\begin{array}{l}\text { Under } \\
\text { development. }\end{array}$ & $14 \mathrm{MT} / \mathrm{y}$ & PFBR fuels. \\
\hline \multirow{5}{*}{$\begin{array}{l}\text { India, Tarapur, } \\
\text { Bhabha Atomic } \\
\text { Research Centre } \\
\text { (BARC) }\end{array}$} & $\begin{array}{l}\text { Tarapur Plutonium } \\
\text { Pant. }\end{array}$ & 1964 to 1974 . & $\begin{array}{l}\text { PUREX } 30 \\
\text { MT/y. }\end{array}$ & $\begin{array}{l}\text { CIRUS reactor } \\
\text { fuel. Al-clad } \\
\text { metallic NU. }\end{array}$ \\
\hline & $\begin{array}{l}\text { Tarapur Plutonium } \\
\text { Pant (Refurbished). }\end{array}$ & 1984 to 1997. & $\begin{array}{l}\text { PUREX } 50 \\
\mathrm{MT} / \mathrm{y} .\end{array}$ & $\begin{array}{l}\text { CIRUS and } \\
\text { Dhruva reactor } \\
\text { fuels. Al-clad } \\
\text { metallic NU. }\end{array}$ \\
\hline & $\begin{array}{l}\text { Power Reactor Fuel } \\
\text { Reprocessing Plant - } \\
1 \text { (PReFRe-1). }\end{array}$ & 1979 to present. & $100 \mathrm{MT} / \mathrm{y}$. & $\begin{array}{l}\text { MAPS and } \\
\text { Rajasthan Atomic } \\
\text { Power Station } \\
\text { (RAPS) PHWR } \\
\text { fuels. }\end{array}$ \\
\hline & $\begin{array}{l}\text { Power Reactor Fuel } \\
\text { Reprocessing Plant - } \\
2 \text { (PReFRe-2). }\end{array}$ & 2011 to present. & $100 \mathrm{MT} / \mathrm{y}$. & $\begin{array}{l}\text { MAPS and RAPS } \\
\text { PHWR fuels. }\end{array}$ \\
\hline & $\begin{array}{l}\text { Integrated Nuclear } \\
\text { Recycle Plant (IP-1). }\end{array}$ & $\begin{array}{l}\text { Under } \\
\text { development. }\end{array}$ & $600 \mathrm{MT} / \mathrm{y}$. & \\
\hline
\end{tabular}




\begin{tabular}{|c|c|c|c|c|}
\hline Country & Facility Name & $\begin{array}{c}\text { Dates of } \\
\text { Operation }\end{array}$ & Production Scale & Fuels Reprocessed \\
\hline \multirow[t]{2}{*}{ Japan } & $\begin{array}{l}\text { Tokai Reprocessing } \\
\text { Plant. }\end{array}$ & 1977 to 2009. & $100 \mathrm{MT} / \mathrm{y}$. & LWR, MOX. \\
\hline & $\begin{array}{l}\text { Rokkasho Nuclear } \\
\text { Fuel Cycle Facility. }\end{array}$ & Target 2021. & $800 \mathrm{MT} / \mathrm{y}$. & LWR, MOX. \\
\hline \multirow{4}{*}{$\begin{array}{l}\text { Russia, } \\
\text { Production } \\
\text { Association } \\
\text { Mayak (PO } \\
\text { Mayak), Ozersk } \\
\text { (Formerly } \\
\text { Chelyabinsk-65) }\end{array}$} & $\begin{array}{l}\text { Defense } \\
\text { Radiochemical } \\
\text { Facility, Plant B } \\
\text { (a.k.a., Plant 24). }\end{array}$ & $\begin{array}{l}1948 \text { to early } \\
1960 \text { s (Shutdown } \\
\text { as Plant BB was } \\
\text { brought online.). }\end{array}$ & & $\begin{array}{l}\text { Spent fuels from } \\
\text { plutonium } \\
\text { production } \\
\text { reactors. }\end{array}$ \\
\hline & $\begin{array}{l}\text { Defense } \\
\text { Radiochemical } \\
\text { Facility, Plant BB } \\
\text { (a.k.a., Plant 35). }\end{array}$ & 1959 to 1987. & & $\begin{array}{l}\text { Spent fuels from } \\
\text { plutonium } \\
\text { production } \\
\text { reactors. }\end{array}$ \\
\hline & $\begin{array}{l}\text { RT-1 Reprocessing } \\
\text { Facility } \\
\text { (Incorporating parts } \\
\text { of Plant B). }\end{array}$ & 1977 to 2016. & $400 \mathrm{MT} / \mathrm{y}$. & $\begin{array}{l}\text { VVER-440, BN, } \\
\text { and Naval fuels. }\end{array}$ \\
\hline & $\begin{array}{l}\text { RT-1 Reprocessing } \\
\text { Facility } \\
\text { (Refurbished). }\end{array}$ & $\begin{array}{l}2016 \text { to early } \\
2030 \text { s (To be shut } \\
\text { down as RT-2 } \\
\text { comes online.). }\end{array}$ & $400 \mathrm{MT} / \mathrm{y}$. & $\begin{array}{l}\text { VVER, RBMK, } \\
\text { BN, and Naval } \\
\text { fuels. }\end{array}$ \\
\hline \multirow{2}{*}{$\begin{array}{l}\text { Russia, Siberia } \\
\text { Chemical } \\
\text { Enterprise } \\
\text { (SCE), Seversk, } \\
\text { (Formerly } \\
\text { Tomsk-7) }\end{array}$} & $\begin{array}{l}\text { Radiochemical } \\
\text { Works (RCW) Unit } \\
15 \text { (Contained two } \\
\text { reprocessing lines.). }\end{array}$ & $\begin{array}{l}1961 \text { to } 1994 \\
1962 \text { to } 1994 .\end{array}$ & 6,000 MT/y. & $\begin{array}{l}\text { Spent fuels from } \\
\text { plutonium } \\
\text { production } \\
\text { reactors. }\end{array}$ \\
\hline & $\begin{array}{l}\text { Pilot Demonstration } \\
\text { Power Complex } \\
\text { (PDPC) Nitride Fuel } \\
\text { Plant KEU-2. }\end{array}$ & $\begin{array}{l}\text { Under } \\
\text { development. } \\
\text { Target } 2024 .\end{array}$ & $5 \mathrm{MT} / \mathrm{y}$ & $\begin{array}{l}\text { BREST-300 } \\
\text { mixed nitride } \\
\text { fuels. }\end{array}$ \\
\hline \multirow[t]{3}{*}{$\begin{array}{l}\text { Russia, } \\
\text { Zheleznogorsk } \\
\text { (Formerly } \\
\text { Krasnoyarsk-26) }\end{array}$} & $\begin{array}{l}\text { Defense } \\
\text { Radiochemical } \\
\text { Facility. }\end{array}$ & 1953 to 1995 . & 3,000 MT/y. & $\begin{array}{l}\text { Spent fuels from } \\
\text { plutonium } \\
\text { production } \\
\text { reactors. }\end{array}$ \\
\hline & $\begin{array}{l}\text { RT-2 Reprocessing } \\
\text { Facility. }\end{array}$ & $\begin{array}{l}\text { Under } \\
\text { development. } \\
\text { Target } 2025 . \\
\end{array}$ & $\begin{array}{l}1,000 \text { to } 1,500 \\
\mathrm{MT} / \mathrm{y} .\end{array}$ & $\begin{array}{l}\text { VVER, RBMK, } \\
\text { BN and fuels. }\end{array}$ \\
\hline & $\begin{array}{l}\text { Pilot Demonstration } \\
\text { Centre (PDC). }\end{array}$ & 2015 to present. & $\begin{array}{l}10 \text { to } 250 \mathrm{MT} / \mathrm{y} \\
\text { as capacity is } \\
\text { increased. }\end{array}$ & $\begin{array}{l}\text { VVER and BN } \\
\text { fuels. }\end{array}$ \\
\hline
\end{tabular}




\begin{tabular}{|c|c|c|c|c|}
\hline Country & Facility Name & $\begin{array}{c}\text { Dates of } \\
\text { Operation }\end{array}$ & Production Scale & Fuels Reprocessed \\
\hline \multirow[t]{4}{*}{$\begin{array}{l}\text { United Kingdom, } \\
\text { Sellafield }\end{array}$} & $\begin{array}{l}\text { B204 Reprocessing } \\
\text { Plant. }\end{array}$ & 1952 to 1964 . & 300 to $750 \mathrm{MT} / \mathrm{y}$. & $\begin{array}{l}\text { Windscale Pile, } \\
\text { MAGNOX. }\end{array}$ \\
\hline & $\begin{array}{l}\text { B204 Head-End } \\
\text { Plant (Head-end to } \\
\text { B205.). }\end{array}$ & 1969 to 1972 . & & LWR. \\
\hline & $\begin{array}{l}\text { B205 (aka } \\
\text { MAGNOX) } \\
\text { Reprocessing Plant. }\end{array}$ & 1964 to 2020 . & $\begin{array}{l}\text { Military and } \\
\text { civilian. } 1,500 \\
\text { MT/y. }\end{array}$ & MAGNOX. \\
\hline & $\begin{array}{l}\text { Thermal Oxide } \\
\text { Reprocessing Plant } \\
\text { (THORP). }\end{array}$ & 1994 to 2018 . & 1,200 MT/y. & AGR, LWR. \\
\hline
\end{tabular}

From the preceding discussions it is evident that aqueous reprocessing technologies are mature and have a long history of being used at massive industrial scales for both military and commercial applications. No other reprocessing technologies come close to these levels of development and deployment. There are a great many variants of aqueous reprocessing technologies as described in contemporary literature. ${ }^{117-125}$

A universal feature of all aqueous reprocessing technologies is that uranium, plutonium, and minor actinides are, after separations and calcination, recovered as oxide materials. If any forms other than oxides are needed for fuel fabrication, then additional chemical conversions are necessary. It is predominantly this feature that provides opportunities for other non-aqueous reprocessing technologies to compete with aqueous technologies.

\subsection{Non-aqueous Reprocessing Technologies}

If the PUREX process is used as the benchmark of aqueous reprocessing technologies, against which non-aqueous reprocessing technologies are to be compared, then the following attributes have been offered as potential benefits of the latter over the former.

1. Metallic products: Non-aqueous reprocessing technologies can recover actinides as refined metals from both metallic and non-metallic spent fuels, thereby eliminating the need for subsequent oxideto-metal chemical conversion.

2. Hotter fuels: Non-aqueous reprocessing technologies can process spent fuels directly from reactor operations without the need for interim storage and cooling. Non-aqueous separations media are not subject to radiation damage as are aqueous and organic separations media.

3. Decreased criticality susceptibility: Aqueous and organic media always acts as neutron moderators, whereas certain non-aqueous systems do not. Non-aqueous reprocessing technologies generally eliminate moderator materials, allowing for greater concentrations of actinides in the process fluids.

4. Smaller footprint: Due to the abilities to process fuels more quickly from the reactor and maintain higher actinide concentrations in process fluids, the footprint of a non-aqueous reprocessing facility is less than that of an equivalent-scale aqueous reprocessing facility.

5. Less process waste volume: Due to the higher actinide concentrations in process fluids and, in some cases, reduced number of flowsheet unit operations, a non-aqueous reprocessing facility will generate less waste volume than that of an equivalent-scale aqueous reprocessing facility. 
What follows is an attempt to categorize and describe the major non-aqueous reprocessing technologies that have been researched and, in some limited capacities, used to reprocess or treat spent fuels. The order in which the information is presented is not chronological and the focus is on U.S. history.

\subsubsection{Treatment Technologies Developed to Support EBR-II}

Historically, eleven LMRs have been operated in the U.S. between 1949 and 1994 as shown chronologically in Figure 15. Since the 1940's, many other LMR concepts were proposed and advanced to various rigor levels of design without ever being built and operated. Of these, four additional reactors (LAMPRE-II, CRBRP, SAFR, and PRISM) are included in Figure 15 (grey arrows) because of their significance. Although never completed and operated, these four reactors underwent significant development before their projects were terminated. PRISM remains a viable contender for future LMFBR development as its design is actively updated and improved.

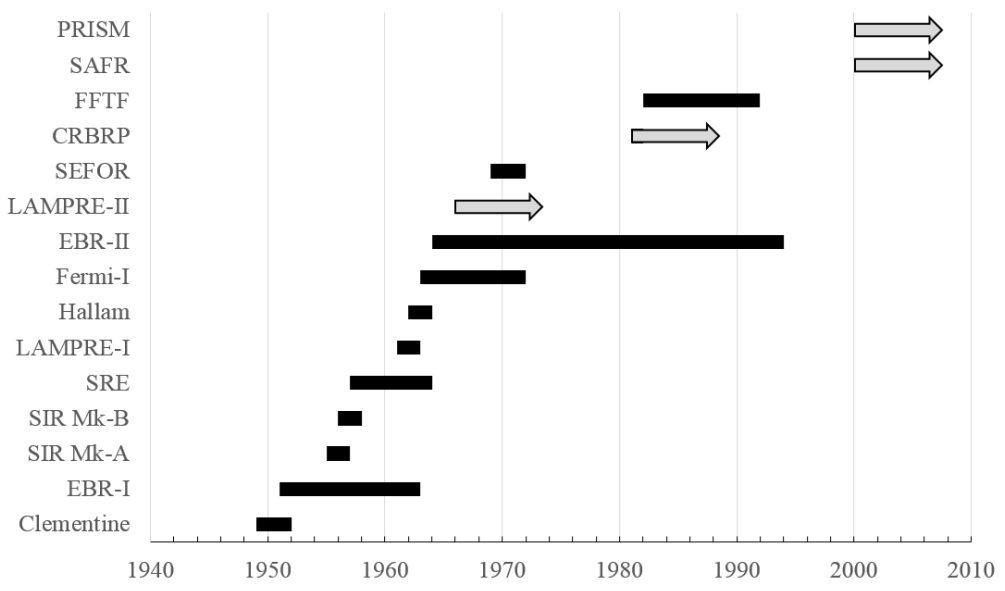

Figure 15. Operational chronology of U.S. LMRs.

Brief descriptions of the 15 LMRs presented in Figure 14 are presented below. And some technical specifications are given in Table 9.

- Clementine was the first fast-spectrum reactor. Its purpose was to study the viability of plutoniumbased reactor fuels and provide basic nuclear physics data for the atomic weapons program. It was fueled by molten plutonium and cooled by liquid mercury. ${ }^{126,127,128}$

- Experimental Breeder Reactor I (EBR-I) was the first LMFBR to simultaneously breed plutonium and produce electrical power. Its purpose was to demonstrate the principle of breeding ${ }^{239} \mathrm{Pu}$ from ${ }^{238} \mathrm{U}$ and the feasibility of operating a LMFBR for future civilian power production. It also provided information on fast neutron physics and radiation-induced metallurgical damage that was useful in the design and development of Fermi-I and EBR-II. The HEU fuel region was cooled by NaK and the DU blanket region was cooled by air. ${ }^{129-}$

- SIR Mk-A (a.k.a. S1G) was the first sodium-cooled naval propulsion reactor. It was tested on land by General Electric at the Knolls Atomic Power Laboratory, Kesselring Site, in Niskayuna, NY. ${ }^{137,138}$

- $\quad$ SIR Mk-B (a.k.a. S2G) was the second sodium-cooled naval propulsion reactor. It was tested during sea trials on the U.S.S. Seawolf (SSN-575) submarine. ${ }^{139,140}$

- $\quad$ Sodium Reactor Experiment (SRE) was the first LMR designed for civilian power production. Its purpose was to demonstrate the technical and economic feasibility of a SGBR for this application. Engineering and physics data gained from the SRE were used to support the design of the Hallam Nuclear Power Facility (HNPF) reactor. It was operated by Atomics International at the Santa Susana Field Laboratory near Simi Valley, CA. ${ }^{141-143}$ 
- Los Alamos Moten Plutonium Reactor Experiment-I (LAMPRE-I) was used to test fast reactor fuels and materials. The engineering and physics data gained from LAMPRE-I was used to support the design of LAMPRE-II. ${ }^{144-148}$

- Hallam Nuclear Power Facility (HNPF) was the first LMR commercial venture. It was part of the Atomic Energy Commission's (AEC's) Power Demonstration Reactor Program. The project was managed by the AEC, Consumers Public Powers District (CPPD), Atomics International, and Bechtel Corporation. ${ }^{149-154}$

- Fermi-I (a.k.a., Enrico Fermi Fast Breeder Reactor (EFFBR)) was the first LMFBR commercial venture. It was operated under the Power Reactor Development Company, a consortium of more than thirty private companies. Its purpose was to demonstrate the operation of a LMFBR in the environment of a commercial utility power company. ${ }^{155-159}$

- EBR-II was the first LMFBR to simultaneously breed plutonium, produce electrical power, and operate on reprocessed fuel taken from its core. Its purpose was to demonstrate a closed fuel cycle on an operating LMFBR. Engineering and physics data gained from EBR-II were used to support the design of the FFTF reactor. ${ }^{160-}{ }^{170}$ EBR-II was located at ANL-W and operated from 1963 to 1994. It was a sodium-cooled fast breeder reactor with driver and blanket regions. The driver fuel was sodium-bonded metallic HEU alloyed primarily with fissium (HEU-5Fs) or zirconium (HEU-10Zr), and the blanket was sodium-bonded metallic DU. EBR-II is important in the present context because it has served as one of the primary focal points for the development of non-aqueous reprocessing technologies in the U.S.

- Los Alamos Moten Plutonium Reactor Experiment-II (LAMPRE-II) was to be a higher energy version of LAMPRE-I. However, this reactor was never built.

- Southwest Experimental Fast Oxide Reactor (SEFOR) was a research reactor operated under a consortium that included the U.S. AEC, General Electric, and several electric power companies. Its purpose was to study the nuclear physics and safety of MOX cores. One way it achieved this was to demonstrate the ability of the Doppler coefficient to terminate a transient, which has to do with the relationship between absorption characteristics and temperature of fissile atoms. ${ }^{171-173}$

- Clinch River Breeder Reactor Project (CRBRP) was intended to be a LMFBR demonstration reactor to assess the economics of breeder reactor technology and attain experience and engineering data to design a larger cost competitive LMFBR commercial reactor. The project was managed by AEC, Tennessee Valley Authority (TVA), Commonwealth Edison, and Project Management Corporation. The project was authorized by congress in 1972, terminated by the Carter Administration in 1977, and resumed by the Reagan Administration in 1980. After expenditures exceeded $\$ 1 \mathrm{~B}$, and the cost of completion estimated to be an additional $\$ 2.5 \mathrm{~B}$, the project lost congressional support as was terminated in October 1983. ${ }^{174-}{ }^{183}$

- Fast Flux Test Facility (FFTF) reactor was used as a testbed for LMFBR development. It was used for irradiation testing of fuels and materials under a fast-spectrum, and to develop procedures, components, and systems used to design future commercial LMFBRs. ${ }^{184-}{ }^{190}$

- Sodium Advanced Fast Reactor (SAFR) was a design study performed by Rockwell International, Bechtel Corporation, and Combustion Engineering under the DOE Advanced Liquid Metal Reactor (ALMR) program. Development work on SAFR was terminated in 1988 when the DOE selected Power Reactor Innovative Small Module (PRISM) for further consideration as a demonstration reactor. ${ }^{191-193}$

- Power Reactor Innovative Small Module (PRISM) was a design study performed by General Electric under the DOE ALMR program. The PRISM design has undergone several iterations since its conception in 1981 and the termination of the ALMR program in 1994. ${ }^{194-201}$ 
Table 9. Summary Technical Specifications and References of U.S. LMRs.

\begin{tabular}{|c|c|c|c|}
\hline Reactor Name & Clementine & EBR-I & $\begin{array}{l}\text { SIR Mk-A } \\
\text { Prototype }\end{array}$ \\
\hline Reactor Type & LMFR & LMFBR & SGR \\
\hline Coolant & Mercury & Sodium/Potassium & Sodium \\
\hline Design Type & Loop & Loop & Loop \\
\hline Fuel Type & Molten Plutonium & Metallic HEU Alloy & Oxide HEU \\
\hline Blanket Type & - & Metallic DU & - \\
\hline Moderator & - & - & Graphite \\
\hline Thermal Power, MW & 0.025 & 1.2 & - \\
\hline Electrical Power, MW & Zero & 0.2 & - \\
\hline Start Date & 1949 & $12 / 1951$ & 1955 \\
\hline End Date & 1952 & $12 / 1963$ & 1957 \\
\hline Location & LANL Site, NM & INL Site, ID & Niskayuna, NY \\
\hline Reactor Name & SIR Mk-B & SRE & LAMPRE-I \\
\hline Reactor Type & SGR & SGBR & LMFR \\
\hline Coolant & Sodium & Sodium & Sodium \\
\hline Design Type & Loop & Loop & Loop \\
\hline Fuel Type & Oxide HEU & Metallic LEU Alloy & Molten Plutonium \\
\hline Blanket Type & - & Thorium & - \\
\hline Moderator & Beryllium & Beryllium & - \\
\hline Thermal Power, MW & - & 20 & 1 \\
\hline Electrical Power, MW & - & 6 & Zero \\
\hline Start Date & 1956 & 1957 & 1961 \\
\hline End Date & 1958 & 1964 & 1963 \\
\hline Location & $\begin{array}{c}\text { U.S.S. Seawolf } \\
(\text { SSN-575) }\end{array}$ & $\begin{array}{c}\text { SSFL Site, } \\
\text { Semi Valley, CA }\end{array}$ & LANL Site, NM \\
\hline Reactor Name & HNPF & Fermi-I & EBR-II \\
\hline Reactor Type & SGR & LMFBR & LMFBR \\
\hline Coolant & Sodium & Sodium & Sodium \\
\hline Design Type & Loop & Loop & Pool \\
\hline Fuel Type & Metallic LEU Alloys & Metallic LEU Alloys & $\begin{array}{l}\text { Metallic HEU Alloys } \\
\text { (Some MOX) }\end{array}$ \\
\hline Blanket Type & - & Metallic DU & Metallic DU \\
\hline Moderator & Graphite & - & - \\
\hline Thermal Power, MW & 254 & $\begin{array}{l}430 \text { Design, } \\
200 \text { Achieved }\end{array}$ & 62.5 \\
\hline Electrical Power, MW & 76 & $\begin{array}{l}125 \text { Design, } \\
66 \text { Achieved }\end{array}$ & 20 \\
\hline Start Date & 1962 & $8 / 1963$ & $7 / 1964$ \\
\hline End Date & 1964 & $9 / 1972$ & $10 / 1994$ \\
\hline Location & Lancaster County, NE & Monroe County, MI & INL Site, ID \\
\hline
\end{tabular}




\begin{tabular}{|c|c|c|c|}
\hline Reactor Name & LAMPRE-II & SEFOR & CRBRP \\
\hline Reactor Type & LMFR & LMFR & LMFBR \\
\hline Coolant & Sodium & Sodium & Sodium \\
\hline Design Type & Loop & Loop & Pool \\
\hline Fuel Type & Molten Plutonium & MOX & MOX \\
\hline Blanket Type & - & - & DU Oxide \\
\hline Moderator & - & - & - \\
\hline Thermal Power, MW & 20 & 20 & 975 \\
\hline Electrical Power, MW & Zero & Zero & 350 \\
\hline Start Date & 1966 Proposed & 1969 & 1972 Proposed \\
\hline End Date & - & 1972 & - \\
\hline Location & LANL Site, NM & Washington County, AR & Roane County, TN \\
\hline Reactor Name & FFTF & SAFR & PRISM \\
\hline Reactor Type & LMFBR & LMFBR & LMFBR \\
\hline Coolant & Sodium & Sodium & Sodium \\
\hline Design Type & Loop & Pool & Pool \\
\hline Fuel Type & $\begin{array}{c}\text { MOX } \\
\text { (Some Metallic HEU) }\end{array}$ & Metallic U/Pu/Zr Alloy & Metallic U/Pu/Zr Alloy \\
\hline Blanket Type & DU Oxide & Metallic U/Zr Alloy & Metallic U/Zr Alloy \\
\hline Moderator & - & - & - \\
\hline Thermal Power, MW & 400 & 900 & 471 \\
\hline Electrical Power, MW & Zero & 350 & 155 \\
\hline Start Date & $4 / 1982$ & - & - \\
\hline End Date & $4 / 1992$ & - & - \\
\hline Location & Hanford Site, WA & $\begin{array}{c}\text { Rockwell/ } \\
\text { Westinghouse }\end{array}$ & General Electric \\
\hline
\end{tabular}

\subsubsection{Melt Refining and Skull Reclamation Processes}

Why? Fast breeder reactor technologies were a U.S. priority at the time EBR-II was commissioned. The melt refining process offered a simple process flowsheet for reprocessing metallic HEU fuels remotely. The skull reclamation process was developed to recover actinides from the disposable process crucibles used during melt refining.

From the very first days of operation, the EBR-II reactor was co-located with a hot cell reprocessing facility called the Fuel Cycle Facility (FCF). Spent driver fuels from EBR-II were reprocessed in FCF from 1964 to 1968 using the melt refining process. More than 400 subassemblies (34,000 fuel elements) were remotely fabricated from spent EBR-II driver fuels and recycled back to the reactor core. The melt refining process was intended to be minimalistic in terms of the number of process steps to facilitate remote hot cell operation. The EBR-II HEU-5Fs fuel elements were mechanically de-clad to liberate the fuel pins, which were loaded into one-time-use zirconia crucibles and melted. Separations partitioned materials to various locations based on volatility and reactivity with the crucible materials. The majority (90 to $95 \%$ ) of the actinides and noble metal fission products (the fissium alloy elements) reported to the consolidated metal ingot product. Metals capable of reacting with zirconia formed a "skull" within the zirconia crucible. The balance of metals ( 5 to $10 \%$ ) not reporting to the metal ingot product, reported to the skull along with some of the more reactive fission product metals. 
The purpose of the skull reclamation process was to recover uranium losses to the skull. Unfortunately, the skull reclamation process was more complex and involved several steps of oxidation, salt fluxing, additions of zinc and magnesium, and decanting. And the process only recovered uranium from the skulls; it did not recover transuranics. The skull reclamation process was developed to pilot scale, but it was never installed and implemented in FCF before the end of the reprocessing campaign. Since that time, the complexity of the process and the unacceptable losses of actinides to the skull materials have rendered the melt refining and skull reclamation processes obsolete. ${ }^{202-} \quad 229$

\subsubsection{Early Conceptual Integral Fast Reactor Pyroprocessing}

Why? The IFR pyroprocessing flowsheet was meant to improve upon the deficiencies of the melt refining and skull reclamation processes. The electrorefining process would produce a higher purity HEU product and provide an improved means of transuranic recovery.

A goal of the Integral Fast Reactor (IFR) program was to demonstrate a closed fuel cycle around EBR-II that was more efficient than the earlier melt refining and skull reclamation processes of the 1960s. The IFR program required a new driver fuel capable of higher burnup levels, and one that was also compatible with the new reprocessing technologies. In preparation for the IFR program, the EBR-II core was converted from HEU-5Fs to HEU-10Zr. And the intention was that once reprocessing operations began, the core would be converted to a DU-20Pu-10Zr fuel as plutonium was recycled from the driver and blanket. ANL researchers began proposing IFR pyroprocessing flowsheets around 1984. These early flowsheets included unit operations of fuel chopping, uranium electrorefining with liquid cadmium anode, halide slagging, cathode processing, casting furnace, and fuel fabrication.

The purpose of fuel chopping was to cut the fuel elements into smaller pieces to expose the metallic fuel to the solvent cadmium and molten salt electrolyte. The mechanical de-cladding used for the earlier melt refining process was not adopted for the IFR program for two reasons: i) the higher burnup levels achieved during the IFR program resulted in greater metallurgical interactions between the fuel and cladding rendering mechanical de-cladding difficult, and ii) there was no longer a need to de-clad because the fuel could be effectively dissolved or oxidized away from the stainless steel cladding.

Electrorefining was the primary means of chemical separations and was a significant improvement over the former melt refining and skull reclamation processes in terms of both separation and recovery efficiencies of actinides and overall waste reduction. The electrorefining operations transported uranium from an impure metal anode to a purified metal cathode through a high-temperature molten salt. The salt system used was the $\mathrm{LiCl}-\mathrm{KCl}$ eutectic with a nominal concentration of $\mathrm{UCl}_{3}$. Electrorefining in the presence of a trichloride provided excellent separations. Metals more electronegative than uranium remained with the anode, while metals more electropositive than uranium accumulated in the salt. Cathode processing was a vacuum retort furnace used to treat the dendritic electrorefined uranium. It was designed to accommodate both salt distillation and uranium metal consolidation into an ingot. The purified HEU would then be processed and cast into fuel pins in the casting furnace for fabrication of new fuel elements. ${ }^{230-} 241$

During these early stages of process development, the liquid cadmium anode was thought necessary as a means of dissolving the metallic fuel into a molten metal pool beneath the electrolyte. Uranium and plutonium would be oxidized from the cadmium pool into the salt, while metals more noble would remain in the cadmium pool as a sludge. In the next iteration of this technology, the liquid cadmium anode deep enough to accommodate a chopped fuel basket was replaced by a shallow liquid cadmium pool beneath the chopped fuel basket suspended in the electrolyte. 
Halide slagging, like the skull reclamation process, was another unit operation that was proposed but never deployed during the EBR-II mission. It was originally proposed by ANL researchers as an improvement to the melt refining and skull reclamation processes for processing high plutonium containing fuels. During those early days of EBR-II operations, the intention was to convert the core from HEU-Fs fuel to DU-Pu-Fs fuel. Halide slagging was thought to be an improved process for purifying these future fuel types. However, the reprocessing mission was cancelled before the conversion was attempted. And much later, halide slagging was proposed for the IFR mission as a means of recovering plutonium from EBR-II blanket materials as plutonium chloride to be advanced to the electrorefiner.

\subsubsection{Later Conceptual Integral Fast Reactor Pyroprocessing}

Why? As research on an electrorefining based flowsheet continued, it was determined that a liquid cadmium anode and halide slagging were not necessary. The separations processes of the finalized IFR flowsheet included electrorefining and cathode processing to produce a HEU-Zr alloy ingot for fuel fabrication. And the liquid cadmium cathode technology was developed to recover plutonium from the electrorefiner salt.

The finalized IFR pyroprocessing flowsheet developed by ANL researchers between 1986 and 1994 included the unit operations of fuel chopping, uranium electrorefining, liquid cadmium cathode, cathode processing, casting furnace, and fuel fabrication. The liquid cadmium cathode was a means of cocollecting uranium and plutonium from the electrorefiner salt for use in fuel fabrication. It was again the intent to convert the EBR-II core from HEU fuel to plutonium alloy fuel during the reprocessing mission. ${ }^{242-} \quad 297$

Research was also underway on how to adapt the IFR pyroprocessing technologies developed for EBR-II metallic fuels, to the recovery of plutonium from LWR oxide fuels. ${ }^{298-300}$

Much work was performed readying FCF to accept this mission. For example, the hot cells were decontaminated to permit human entry into the cells. This facilitated refurbishment of the infrastructure and installation of the process equipment. However, the IFR was not to be realized.

\subsubsection{EBR-II Spent Fuel Treatment}

Why? On September 30, 1994, EBR-II was shut down. Subsequently, the driver and blanket fuels were removed from the reactor and the sodium-coolants drained from the system. ${ }^{301,302}$ On October 1, 1994, the IFR program was terminated by the DOE by order of the U.S. Congress. ${ }^{303}$ The mission at ANL-W changed from one of reprocessing spent EBR-II fuel for fuel recycle research (the IFR program) to one of treating spent EBR-II fuel for disposition (the Spent Fuel Treatment Program).

When EBR-II was shut down, the Yuca Mountain Nuclear Waste Repository was under development and thought to become the destination for EBR-II spent fuels and other high-level nuclear wastes. However, because EBR-II fuels and blankets contained bond-sodium, and because sodium metal is highly reactive with water liberating both heat and hydrogen, untreated these materials were not candidates for direct disposal to the Yuca Mountain repository. To meet the acceptance criteria of Yuca Mountain, it was necessary to neutralize the reactivity of the bond-sodium. The EBR-II spent fuel treatment (SFT) process was developed to meet these criteria in three distinct phases, which can be called process selection, process demonstration, and process operation.

Process selection proceeded from 1995 to 2000. The National Research Council issued a series of reports evaluating electrometallurgical techniques for treating the inventory of EBR-II sodium-bonded spent fuel and blanket materials. ${ }^{304-} 311$ And the DOE issued a series of reports evaluating the

environmental impacts of managing and treating the sodium-bonded spent fuel inventories in Idaho. ${ }^{312-}$ 324 
Process demonstration proceeded from 1996 to 1999 as the EBR-II Spent Nuclear Fuel Treatment Demonstration Project. Once electrometallurgical fuel treatment was selected as the disposition technology, select technologies developed for the IFR program were adapted to meet the requirements of this new mission. ${ }^{325-} \quad{ }^{378}$ There are several key differences between electrometallurgical processing as intended for the IFR program and electrometallurgical processing used for SFT.

- The IFR program was intended to process EBR-II driver fuels by electrochemical means, and to process EBR-II blanket materials by halide slagging. The SFT program processes both driver fuels and blanket materials by electrochemical means in two electrorefiners; one designed for driver fuels and one designed for blanket materials.

- The IFR program would recover plutonium from both driver fuels and blanket materials for the manufacture of U-Pu-Zr alloy fuels. The disposition path for plutonium in the SFT program is to leave the plutonium in the electrorefiner salts, which are converted into a salt waste form.

- The IFR program used the casting furnace to cast fuel alloy pins for the manufacture of new fuel elements. The SFT program uses the casting furnace to cast a single sample pin used to verify the uranium enrichment level of the final electrorefined uranium product.

- The IFR program included fuel fabrication equipment. The SFT program does not utilize such equipment.

Process operations proceeded from 1999 to January 2005 as ANL researchers continued to perform process improvements and treat spent nuclear fuel in FCF. In January 2005 there was change in contractor management. ANL-W that was managed by the University of Chicago became INL Materials and Fuels Complex managed by Battelle Energy Alliance. From that time forward the SFT program has been overseen by INL researchers who continue to perform process improvements. ${ }^{379-}$

\subsection{ORNL MSBR Salt Processing}

Why? The ORNL MSBR concept required stringent ${ }^{233} \mathrm{~Pa}$ management in the fuel salt. This was performed by treating a slipstream of salt in a chemical processing plant to recover and isolate ${ }^{233} \mathrm{~Pa}$ until it decayed to ${ }^{233} \mathrm{U}$. The resulting ${ }^{233} \mathrm{U}$ was harvested. A portion could be returned to the reactor and excess could be used to fuel other reactors. The ability to effectively manage this strategy was never fully demonstrated and remains conceptual.

MSR development began under the Aircraft Nuclear Propulsion Program (1946 to 1961), after which MSR development continued for civilian power production (1961 to 1976). A significant portion of this large body of work is related to the ${ }^{232} \mathrm{Th}-{ }^{233} \mathrm{U}$ fuel cycle MSBR concept developed at ORNL. The MSBR concept being proposed required continuous chemical processing of molten fluoride fuel salt to control the breeding ratio via management of the ${ }^{233} \mathrm{~Pa}$ inventory. Major unit operations for processing the salt include fluorination, hydrofluorination, vacuum distillation, reductive extraction, metal transfer process, electrolytic oxidizer/reducer, and others. This history was recently summarized in a report. ${ }^{487}$ 


\title{
5.4 Chloride Volatility Processes
}

\author{
Why? These processes exploit the high vapor pressures of zirconium chloride \\ and aluminum chloride to affect separations. Chlorination processes are \\ proposed to volatilize zirconium cladding from oxide fuels and volatilize the \\ zirconium from zirconium matrix dispersion fuels. Similarly, chlorination \\ processes are proposed to volatilize the aluminum from aluminum matrix \\ dispersion fuels.
}

The ZIRCEX process is proposed as a head-end process to aqueous as well as non-aqueous reprocessing. It is discussed in this section because, after all, it is a high-temperature non-aqueous process. The ZIRCEX process has been proposed as a means of de-cladding Zircaloy-clad oxide fuels, volatilizing the bulk of the aluminum and zirconium from Training, Research, Isotopes, General Atomics (TRIGA) reactor fuels, and volatilizing the bulk of aluminum from research reactor plate fuels. The process exploits the differences in vapor pressures of metal chloride species to affect separations. The fuel is chlorinated in an atmosphere of chlorine, $\mathrm{Cl}_{2}(\mathrm{~g})$, hydrogen chloride, $\mathrm{HCl}(\mathrm{g})$, or carbon tetrachloride $\mathrm{CCl}_{4}(\mathrm{~g})$. Metals such as aluminum and zirconium form chlorides that have much higher vapor pressures than uranium chloride, allowing aluminum and zirconium to be separated from the uranium. These bulk separations significantly reduce the mass of fuel materials that are required to be dissolved into caustic or acidic solutions for aqueous reprocessing. And reducing the mass of material to the dissolvers reduces the volume of solution to be treated by the aqueous process and the volume of waste generated by the aqueous process. ${ }^{488-497}$

\subsection{Fluoride Volatility Processes}

Why? These processes exploit the high vapor pressure of uranium hexafluoride to affect separations. Fluorination processes are widely used during uranium enrichment to convert purified uranium oxide to uranium hexafluoride prior to enrichment by diffusion or centrifuge technologies. And fluorination processes were proposed by ORNL for processing MSBR fuels for ${ }^{233} \mathrm{~Pa}$ management.

Fluoride volatility processes have been proposed for several different applications. Only select applications are described here. The Aquafluor process was developed by General Electric for its Midwest Fuel Recovery Plant in Morris, Illinois. However, as discussed earlier, the plant never came to fruition. The Aquafluor process was predominantly a PUREX-based separations process designed to separate, recover, and purify uranium, neptunium, and plutonium from spent LWR fuels. A unique feature of this process was the conversion of uranium oxide (the calcined product of uranyl nitrate hexahydrate) to uranium hexafluoride in a fluidized bed reactor. Additional processing steps purified the uranium hexafluoride, which was intended to be packaged and transported to enrichment facilities. ${ }^{12,493,498}$

The FLUOREX process was proposed by Hitachi-GE as a means of reprocessing a variety of oxide fuels, over an extended period, as the reactor fleet transitions from LWRs to FBRs utilizing MOX fuels. Like the Aquafluor process, the FLUOREX process is a hybrid process using both aqueous and nonaqueous technologies. The Aquafluor process included fluoride volatility of uranium at the back end, to produce uranium hexafluoride for re-enrichment. The FLUOREX process includes fluoride volatility at the head-end for two purposes: to control the $\mathrm{Pu}: \mathrm{U}$ ratio of the materials entering the PUREX process, and to produce purified uranium hexafluoride for re-enrichment or other disposition. ${ }^{499-503}$ 
The Nitrofluor process was an entirely non-aqueous reprocess technology proposed by Brookhaven National Laboratory. The process was claimed to be applicable to variety of fuel types. The fuel was dissolved in a mixture of anhydrous nitrogen dioxide and HF at moderate temperatures between 100 and $200^{\circ} \mathrm{C}$. The primary separation stage is based on which metals form soluble fluorides in the solvent, and which for insoluble oxides and oxy-nitrides. Subsequently, the solvent is decanted from the solids. Uranium and plutonium form soluble species and report with the solvent. Selective fluorination of the solvent will volatilize uranium as uranium hexafluoride (by the action of bromine fluoride) and plutonium as plutonium hexafluoride (by the action of fluorine gas). These two product streams would be purified further. ${ }^{493,498,504-506}$

The ORNL ${ }^{232} \mathrm{Th}-{ }^{233} \mathrm{U}$ fuel cycle MSBR concepts required processing of the fuel salts to manage the ${ }^{233} \mathrm{~Pa}$ inventories and removing fission products. This subject was discussed earlier. In the fuel salt processing flowsheets proposed by ORNL, fluorination and hydrofluorination were major unit operations used primarily to volatilize uranium from the salts. There were two application for this operation. To remove the bulk of the uranium from the salt stream entering the chemical process ahead of ${ }^{233} \mathrm{~Pa}$ extraction, and to recover ${ }^{233} \mathrm{U}$ from the process salt kept in storage while ${ }^{233} \mathrm{~Pa}$ decayed to ${ }^{233} \mathrm{U}$.

Fluoride volatility has been proposed for several other fuel reprocessing schemes. For metal fuel processing, there is a significant distinction between fluoride volatility and chloride volatility routes. In metal dispersion fuels, chloride volatility is proposed to volatilize the zirconium or aluminum matrix away from the uranium and plutonium. By contrast, the fluoride volatility is proposed to volatilize the uranium and plutonium away from the matrix metals. ${ }^{507-510}$ And similar fluoride volatility concepts have been proposed for graphite matrix fuels. ${ }^{511}$ Fluoride volatility processes have also been proposed for reprocessing LWR and FR oxide fuels with the absence of aqueous separations. ${ }^{512-514}$

\title{
5.6 Fluoride Salt Electrowinning (Hall-Héroult Analog)
}

\author{
Why? The Hall- Héroult process has been effective for over a century in \\ manufacturing primary aluminum. Research was performed on adapting a \\ similar process for reducing uranium oxide to uranium metal. Most of the \\ research was focused on primary uranium production, but it has also been \\ proposed as a reprocessing technology for spent fuels.
}

The process of "Bomb reduction" is the standard method of producing uranium metal via the thermal reduction of uranium tetrafluoride by magnesium metal in batch operations. The reduction reaction is highly exothermic resulting in a temperature and pressure spike in the reaction vessel, hence the expression "bomb reduction." This process necessitates the conversion of uranium oxide to uranium tetrafluoride and produces significant quantities of process wastes. The electrowinning process was initially conceived as a means of continuous production of uranium metal from uranium oxide, which was attractive from a production perspective. At the time, large tonnages of uranium metal were needed to fuel the U.S. plutonium production reactor fleet. Later the concept was proposed as a reprocessing technology for uranium oxide fuel.

In this process uranium oxide is dissolved in a fluoride salt that has a solubility for uranium oxide and is suitable for operations above the melting temperature of uranium metal. The dissolved uranium is reduced on the surface of a molten pool of uranium metal, and the dissolved oxygen forms $\mathrm{CO}(\mathrm{g})$ and $\mathrm{CO}_{2}(\mathrm{~g})$ on the surface of a graphite anode. ${ }^{515-} 527$ 


\subsection{Mercury Amalgamation Processes}

Why? Mercury has a low melting temperature and forms an amalgam with many other metals. These properties were exploited to affect the reduction of uranium oxide fuels to metal and affect separations and purifications of both uranium and plutonium metallic fuels.

The METALLEX process was proposed as a means of reprocessing uranium oxide fuels. The uranium oxide is exposed to mercury containing a reductant such as magnesium. The magnesium reports to an oxide slag, along with other impurities, and the uranium reports to the mercury as an amalgam. The mercury amalgam is purified further by subsequent washing and filtering steps. The purified amalgam is oxidized with steam to form uranium oxide. The uranium oxide and mercury are separated in a retort furnace and the hydrogen partial pressure is controlled to produce a purified $\mathrm{UO}_{2}$ product.

The HERMEX process was proposed as a means of purifying uranium and plutonium metals, either as unirradiated materials or as irradiated fuels. The HERMEX process is simpler than the METALLEX process because oxide reduction and reoxidation are not necessary. Variations of these processes can be used to convert and purify oxide-to-metal, and metal to oxide. ${ }^{528-} 543$

\subsection{Salt Cycle Process}

Why? Much attention was focused on breeder reactor technologies during the period of early development in the U.S. because uranium reserves were thought to be much scarcer than they were later determined to be. A molten salt process for reprocessing MOX fuel to support FBRs was developed at Hanford. Because $M O X$ reactors were not greatly pursued in the U.S. for civilian power production yielding to LWR technologies, research into this reprocessing technology was short lived. However, Russia continues active research in this area in support of their MOX reactor fleet.

The Salt Cycle Process was "conceived by a Hanford chemist in 1959." ${ }^{544}$ Development of the process culminated in the United States in 1966 with a demonstration using irradiated MOX fuel. ${ }^{545} \mathrm{~A}$ few years later a comprehensive summary of the process was published in the open literature. ${ }^{546}$

As development of the Salt Cycle Process ended in the United States in the mid-1960s, development began in Russia in the late-1960s at a research facility in Sverdlovsk (now Ekaterinberg) ${ }^{547}$ Today, Russian development continues at the Research Institute of Atomic Reactors (RIAR) in Dimitrovgrad where the process is called the Dimitrovgrad Dry Process or the Russian Institute of Atomic Reactors (RIAR) Dry Process. The U.S. "Salt Cycle Process" and the Russian "Dry Process" are essentially the same process, albeit with minor variations. Here the process will be called the Salt Cycle Process (SCP).

There are different variants of the process, each using a different set, or different configuration, of unit operations. The three primary variants are the MOX to $\mathrm{MOX}, \mathrm{PuO}_{2}$ and $\mathrm{UO}_{2}$ to $\mathrm{MOX}$, and $\mathrm{MOX}$ to $\mathrm{PuO}_{2}$ and $\mathrm{UO}_{2}$. The first variant represents the reprocessing of spent $\mathrm{MOX}$ fuel without the separations and recoveries of uranium and plutonium oxides. The second variant represents the utilization of plutonium and uranium oxide reserves to produce MOX fuel. For example, the utilization of weapons plutonium for the production of MOX fuel. And the third variant indicates that the process can be used to recover purified plutonium and uranium oxide from spent MOX fuel.

The first step of the process is chlorination of the feed oxides into a molten salt. The chlorine and oxygen chemical potentials within the salt, and the salt temperature, are controlled to affect the formation of chlorides, oxychlorides, and oxides in the salt. This control makes it possible to selectively deposit mixed oxides onto a graphite cathode (an electrochemical process utilizing a chlorine gas evolving anode) or to precipitate oxides from the salt. The purified oxide products are washed in water to remove the salt, thermally processed to affect the desired oxide stoichiometry, and blended to the desired MOX 
compositions. Fission product impurities are recovered by similar processes, but separately from the uranium and plutonium oxides. ${ }^{548-} \quad 599$

\subsection{Salt Transport Process}

Why? The salt transport process was another attempt at a reprocessing technology for MOX fuels. However, where the Salt Cycle Process was designed

to produce a purified oxide product, the salt transport process was designed to produce a purified metal product.

The salt transport process was proposed by ANL researchers as a means of reprocessing stainlesssteel-clad LMFBR MOX fuels. There are several discreet steps in the process. The cladding is dissolved in a pool of liquid zinc at $850^{\circ} \mathrm{C}$, which does not affect the oxide fuel. The bulk of the zinc solution is transferred away, and the residual zinc is removed by vacuum distillation leaving behind the oxide fuel and some residual stainless steel. During oxide reduction, the oxide fuel is contacted with salt and a calcium-containing alloy. The calcium reports to the salt as dissolved calcium oxide, while the reduced fuel reports to the alloy phase as metals. The salt from oxide reduction is a waste product and the metal alloy are advanced in the process. Plutonium and uranium are purified by successive transfers of these metals between different salt and metal phases. The final recovery of the purified metal products is achieved by distillation. ${ }^{600-}{ }^{617}$ The salt transport process has similarities to the halide slagging process and the ORNL metal transfer process.

\subsection{Two Phase Exchange Processes}

Why? Many processes have been proposed that exploit chemical separations across the interfaces between two high-temperature liquid phases. Examples are metal/salt and metal/oxide slag. These processes are usually proposed as one of several unit operations within a flowsheet, as opposed to being proposed as a stand-alone reprocessing technology.

Two phase exchange processes are a reoccurring theme in both aqueous and non-aqueous reprocessing schemes. They exploit the relative stabilities of species between the two phases to affect the desired separations. Halide slagging was discussed earlier as a unit operation proposed during the early development of the IFR program. The process exploits separations between metal/salt interfaces. Halide slagging has also been proposed as a means of purifying liquid metal plutonium fuels such as $\mathrm{Pu}-\mathrm{Fe}$ alloys. ${ }^{618-621}$ Other types of slagging operations include oxide slagging and carbide slagging. ${ }^{622}$ Generally, these terms imply that a molten metal phase is equilibrated with an oxide phase or a carbide phase. Oxide slagging was used in the EBR-II melt refining process described earlier.

The lithium reduction process is the reduction of oxide fuel to metal by the action of lithium metal. This is another form of a two phase exchange process. The process is based on the greater stability of lithium oxide compared to that of uranium and plutonium oxides. ${ }^{623-627}$ This lithium-based chemical oxide reduction process is similar in principle to lithium-based electrochemical oxide reduction process cited earlier. In the former process, lithium metal is directly introduced as the reducing agent. In the latter process, lithium metal is electrochemically produced on the surface of the oxide fuel in a $\mathrm{LiCl}-\mathrm{LiO}_{2}$ molten salt medium. And in the latter process, the electrochemical reduction of the uranium and plutonium oxides is a contributing factor not experienced in the former process. 


\subsection{Processes Applied to TRISO-Type Fuels}

Why? TRISO-type fuels are highly refractory materials, meaning it is difficult to penetrate the coating materials to chemically access the fuel kernels. However, once the fuel kernels are liberated from the silicon carbide and pyrolytic carbon layers, various reprocessing routes can be applied. Therefore, the feature that most distinguishes these coated particle fuels from other fuel types is the headend processing required to prepare the fuels for chemical reprocessing.

Many varieties of TRISO-type fuel particles have been under consideration and many avenues for reprocessing these spent fuels have been proposed. Reprocessing technologies face major challenges. For example, in the ${ }^{232} \mathrm{Th}-{ }^{233} \mathrm{U}$ fuel cycle application, the fertile materials are encapsulated in BISO particles, and the fissile materials are encapsulated in TRISO particles. These two particles' types are intimately mixed within the graphite fuel matrices. As a head-end to chemical separations, these BISO and TRISO fuel particles must be liberated from the matrix and separated from each other. The particles are liberated from the matrix by burning (oxidation of the graphite), and then separated from each other by physical classification based on the size distribution. In one proposed application, the fertile-BISO particles have greater than $355-\mu \mathrm{m}$-diameter and the fissile-TRISO particles have less than 355 - $\mu \mathrm{m}$-diameter. Separations of the two families of particles is accomplished by screening at 45 U.S. sieve size.

Another challenge common to any TRISO fuel application is liberating the fuel kernels from the encapsulating layers of silicon carbide. Once the fuel kernels are exposed, then both aqueous and nonaqueous means may be applied to extracting and recovering the fissile materials. Methods of breaching the silicon carbide lays include mechanical comminution, chemical conversion (e.g., chloride and fluoride volatility), and thermal shock. Once the fuel kernels are exposed, methods of extracting the fissile materials include traditional aqueous digestion, supercritical $\mathrm{CO}_{2}$ solvent extraction (as the carrier for an appropriate extractant), and molten salt dissolution. ${ }^{628-638}$

\subsection{Weapons Plutonium Refining}

Why? The first applications of nuclear technologies in the U.S., as well as several other countries, were weapons production. The first large-scale nuclear reactors were operated to produce plutonium and the first large-scale reprocessing plants were operated to recover that plutonium. Several metallurgical processes are needed to manage and use the stockpiles of metallic plutonium for weapons applications.

The primary sources of weapons plutonium are the plutonium production reactors described earlier. These reactors are designed and operated to produce weapons grade plutonium, which means maximizing the yield of ${ }^{239} \mathrm{Pu}$ and minimizing the yield of other plutonium isotopes, which generally requires that the ${ }^{238} \mathrm{U}$ target has a relatively short residence time within the reactor. This contrasts with reactor grade plutonium. For example, all uranium-based fuels and blankets produce plutonium by transmutation. However, if the reactor is designed and operated for electrical power production then, typically, the residence time of fuel within the reactor is maximized. Spent fuel produced under these conditions will contain plutonium, but the plutonium will contain significant quantities of isotopes in addition to ${ }^{239} \mathrm{Pu}$ making it undesirable for weapons use. However, this is not to imply that reactor grade plutonium is not weaponizable. 
As described earlier, the PUREX and other separations processes are used to recover plutonium from the spent fuel. Purified plutonium oxide is converted to metallic plutonium via two primary methods. By fluorination to plutonium tetrafluoride followed by magnesium-thermal-reduction to plutonium metal in a magnesium fluoride-based salt, and by direct calcium-thermal-reduction to plutonium metal in a calcium chloride-calcium oxide-based salt. The latter process is called direct oxide reduction and eliminates the fluorination step. The resulting plutonium metal may or may not require additional purification prior to alloying and casting operations.

The desired plutonium isotope for use in weapons is ${ }^{239} \mathrm{Pu} .{ }^{240} \mathrm{Pu}$ is undesirable because it has a significant rate of spontaneous fission that can interfere with weapons physics. ${ }^{241} \mathrm{Pu}$ is undesirable because it has a relatively short half-life and decays to ${ }^{241} \mathrm{Am}$, which decays to ${ }^{237} \mathrm{~Np}$ by alpha and gamma emissions that cause detrimental effects within weapons.

- $\quad{ }^{241} \mathrm{Pu}(\beta-) 14.35 \mathrm{y}={ }^{241} \mathrm{Am}$

- $\quad{ }^{241} \mathrm{Am}\left({ }^{4} \mathrm{He}, \gamma\right) 432.2 \mathrm{y}={ }^{237} \mathrm{~Np}$

There are no means of chemically separating the isotopes of plutonium from each other, and plutonium is not subject to isotopic enrichment processes on large scales like uranium and some of the other metals discussed earlier. However, when the growth of ${ }^{241} \mathrm{Am}$ reaches a threshold, the ${ }^{241} \mathrm{Am}$ can be chemically separated from the plutonium. Americium separation from plutonium is performed by chlorination of the metallic americium from molten plutonium, which is a molten salt extraction process. Chlorination is performed by exchange reactions with magnesium chloride. The reduced magnesium reports to the molten plutonium; but is later separated from the plutonium during vacuum casting operations. Americium can also be removed by sparging the molten plutonium with chlorine gas to preferentially form americium chloride.

Purified plutonium metal has six allotropes (crystallographic phases) between ambient temperature and its melting temperature. These allotropes exhibit significant density variations. Alloying elements are added to plutonium to stabilize these phase-transition effects over the temperature ranges encountered during operations such as plutonium machining and weapons deployment. Gallium is an example of an alloying element used to stabilize plutonium for weapons production. Small amounts of gallium will stabilize the high-temperature plutonium $\delta$-phase (normally stable between 310 and $415^{\circ} \mathrm{C}$ in purified plutonium) down to ambient temperatures.

Purified plutonium metal can be produced by electrorefining impure plutonium metal. The process is performed in a chloride salt at temperatures well above the melting temperature of plutonium metal. The process is performed in small batches, a few kilograms, and low amperages. Plutonium is oxidized from the impure phase and reduced to metal on a tantalum cathode. The molten plutonium drips from the cathode into a pool of purified plutonium metal.

Since the 1960s, researchers at LANL, Rocky Flats Plant (RFP), and Lawrence Livermore National Laboratory (LLNL) have been developing molten salt technologies to reduce plutonium oxide derived from the PUREX process to metal, and to subsequently electro-refine plutonium metal for purification and americium control. ${ }^{639-}$ 


\section{EFFECT OF REPROCESSING EFFICIENCY}

The consequences of reprocessing efficiencies on the utilization of fissile materials in a fuel cycle scenario is profound. Two highly abstracted models of an integrated fuel reprocessing scheme are presented here that illustrate the importance of maximizing the retention of fissile materials, and maximizing the rejection of fission products, during reprocessing. The integrated fuel reprocessing scheme is illustrated in Figure 16.

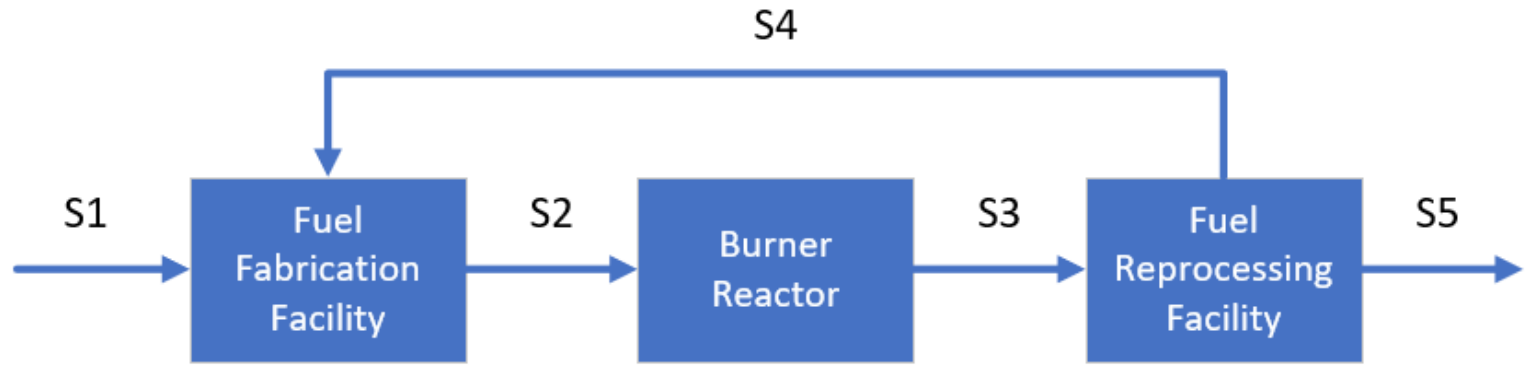

Figure 16. Illustration of the Integrated Fuel Reprocessing Scheme

The process streams shown in Figure 16 are identified as follows. As is the case with an integrated recycle system, the composition of any process stream is affected, to one degree or another, by the performances and efficiencies of all of the integrated processes.

S1: $\quad$ Adjustment stream to fuel fabrication. This stream is needed to maintain the fuel cycle. It could, for example, contain plutonium from weapons stockpiles or the fissile materials recovered from LWR fuels. It is also possible this stream could be net negative for fissile materials if the reactor is a breeder reactor generating more fissile inventory than its input.

S2: $\quad$ Fresh fuel stream from fuel fabrication to the reactor. This is the "new" fuel (i.e., preprocessed, or reconstituted fuel) entering the burner reactor. It will contain a complex mixture of plutonium, minor actinides, and fission products.

S3: $\quad$ Spent fuel stream from the reactor to reprocessing. This is the "spent" fuel entering the reprocessing facility. It will contain the post irradiation fissile and fission product inventories. Fissile inventory can be larger than its input, in the case of a breeder reactor. A burner reactor will generate lower fissile inventory as an output than its input. Fission product inventory output is always larger than its input.

S4: $\quad$ Recovered stream from reprocessing to fuel fabrication. This stream contains the fissile materials and fission products that are retained in the fuel cycle.

S5: Discharged stream from reprocessing to waste. This stream contains the fissile materials and fission products that are rejected from the fuel cycle to the waste streams.

In general terms, the goals of nuclear fuel reprocessing are to maximize the retention of fissile materials, and minimize the retention of fission products, in the fuel cycle process. However, the separations sciences embedded within these two goals do not behave independently of each other. For example, those technologies which are deployed to maximize the retention of fissile materials will, at the same time, tend to increase the retention of fission products. In other words, if the primary goal is to meet some established target threshold for the retention of fissile materials (e.g., $99.5 \mathrm{wt} \%$ of the fissile materials must be retained in the fuel cycle), then the secondary goal becomes optimization of rejection of fission products while meeting that target. This is only one of many ways in which this engineering challenge can be expressed. 


\subsection{The Importance of Maximizing the Retention of Fissile Materials}

The integrated fuel reprocessing scheme illustrated in Figure 17 is considered here in regard to the retention of fissile materials in the fuel cycle. A simple process efficiency model for fissile material retention is illustrated in Figure 17.

(c1c2)

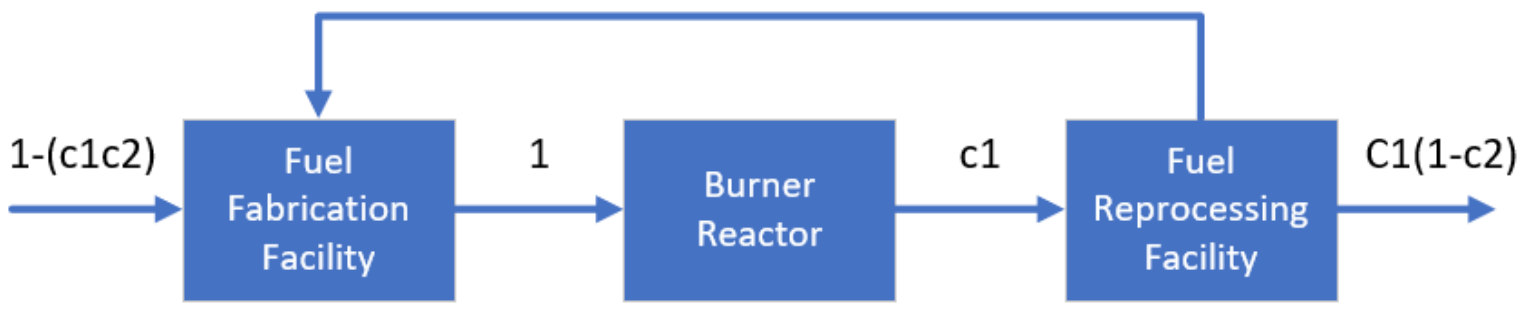

Figure 17. Process Model for Fissile Material Retention.

The mass distribution parameters shown in Figure 17 are identified as follows.

1: Mass of Fissile Materials in Stream $\mathbf{S}_{2}$. This value is normalized to 1, which means that the "new" fuel stream contains one arbitrary mass unit of fissile materials. In engineering units, this value would equal the fissile materials demand of the reactor.

$\mathbf{c}_{1}$ : $\quad$ Mass of Fissile Materials in Stream $\mathbf{S}_{3}$. This value is the mass of fissile materials in the "spent" fuel stream, expressed as a fraction of the mass of fissile materials in the "new" fuel stream. For a burner, $\mathrm{c} 1$ is less than 1 and for a breeder $\mathrm{c} 1$ is larger than 1.

$\mathbf{c}_{2}$ : $\quad$ Reprocessing Efficiency. This is the efficiency of the reprocessing facility to retain fissile materials in the fuel cycle and $\mathrm{c} 2$ is between 0 to 1 in that 1 means full retention of fissile materials while 0 means no retention of fissile materials.

1-c 1 Reactor Efficiency. This is the efficiency of the reactor to burn fissile materials. This value is in terms only of comparison of the fissile materials loadings of the "new" and "spent" fuel streams. This is not a rigorous definition of burn-up efficiency. For the case of a breeder, $1-c_{1}$ is negative value implying that more fission materials are generated than burned.

$\mathbf{c}_{1} \mathbf{c}_{2}$ : Mass of Fissile Materials in Stream $\mathbf{S}_{\mathbf{4}}$. This value is the mass of fissile materials in the recycle stream, expressed as a fraction of the mass of fissile materials in the "new" fuel stream.

$\mathbf{c}_{1}\left(\mathbf{1}-\mathbf{c}_{2}\right)$ : Mass of Fissile Materials in Stream $\mathbf{S}_{5}$. This value is the mass of fissile materials in the waste stream, expressed as a fraction of the mass of fissile materials in the "new" fuel stream.

1-( $\left(\mathbf{c}_{1} \mathbf{c}_{2}\right)$ : Mass of Fissile Materials in Stream $\mathbf{S}_{\mathbf{1}}$. This value is the mass of fissile materials needed to complement the mass of fissile materials in the recycle stream, in order to meet the demand of the reactor. For a breeder reactor $(\mathrm{c} 1>1)$ and high retention reprocessing scheme for fissile materials ( $2 \approx 1$ ), this term can be negative meaning surplus fissile inventory needs to be discharged from the system.

Results of the model are presented in Table 10. The loss of fissile materials to the waste stream $\left(c_{1}\left(1-c_{2}\right)\right)$ from the reprocessing facility is shown as a percentage of the fresh fissile materials adjustment $\left(1-\left(c_{1} c_{2}\right)\right)$ to the fuel fabrication, for various values of $c_{1}$ and $c_{2}$. This relationship is expressed in the following equation. 


$$
\text { Fissile Material Loss }(\%)=\frac{c_{1}\left(1-c_{2}\right)}{1-\left(c_{1} c_{2}\right)} \times 100
$$

Typical prototype burner reactor designs give fissile materials burn-up efficiencies ranging between 0.10 and 0.15 . Considering this range as an achievable "near term" performance from a burner reactor, demonstrating fissile materials recycling efficiency better than $0.99(>99 \%)$ is crucial to justifying the integrated burner/reprocessing cycle as an effective means of burning and minimizing fissile materials discharges to a long-term geological repository.

Table 10. Fissile Material Loss Results of Fissile Material Model.

\begin{tabular}{c|c|c|c}
\hline \multirow{2}{*}{$\begin{array}{c}\text { Reactor } \\
\text { Efficiency } \\
\text { (1-c1) }\end{array}$} & \multicolumn{3}{|c}{$\begin{array}{c}\text { Reprocessing } \\
\text { Efficiency } \\
\text { (c2) }\end{array}$} \\
\cline { 2 - 4 } & 0.9 & 0.99 & 0.999 \\
\hline 0.05 & 65.52 & 15.97 & 1.86 \\
\hline 0.10 & 47.37 & 8.26 & 0.89 \\
\hline 0.15 & 36.17 & 5.36 & 0.56 \\
\hline 0.20 & 28.57 & 3.85 & 0.40 \\
\hline 0.25 & 23.08 & 2.91 & 0.30 \\
\hline 0.30 & 18.92 & 2.28 & 0.23 \\
\hline 0.35 & 15.66 & 1.82 & 0.19 \\
\hline 0.40 & 13.04 & 1.48 & 0.15 \\
\hline
\end{tabular}

Referring to Table 10, for the case in which the reactor efficiency is $0.10^{\mathrm{h}}$ and the reprocessing efficiency is $0.99,{ }^{\mathrm{i}} 8.26 \mathrm{wt} \%$ of the fissile materials in Stream S1 are channeled to waste via Stream S5.

\subsection{The Importance of Maximizing the Rejection of Fission Products}

The integrated fuel reprocessing scheme illustrated in Figure 16 is considered here in regard to the rejection of fission products from the fuel cycle. An abstracted process efficiency model for fission product rejection is illustrated in Figure 18.

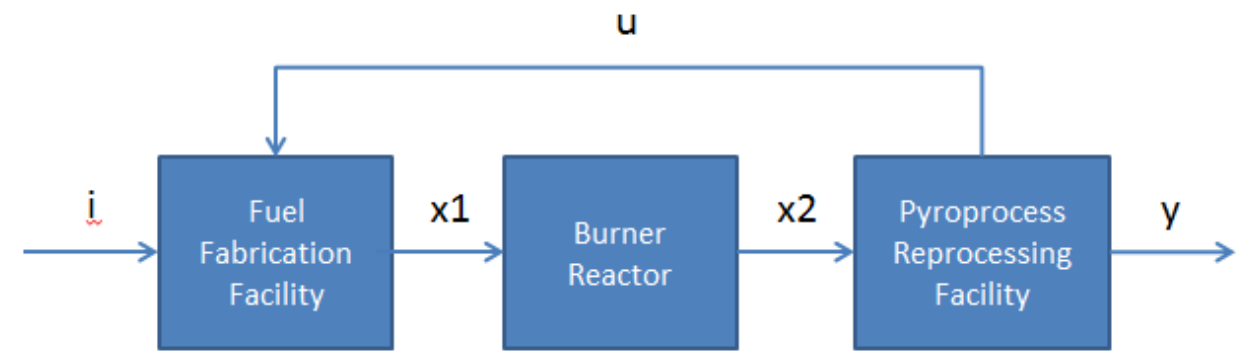

Figure 18. Process Model for Fission Product Rejection.

h. There is a net $10 \%$ reduction of the fissile materials inventory of the reactor fuel as a result of irradiation.

i. The reprocessing facility retains a net $99 \%$ of the fissile materials in the fuel cycle. 
The mass distribution parameters shown in Figure 18 are identified as follows.

i: $\quad$ Mass of Fission Products in Stream $\mathbf{S}_{\mathbf{1}}$. This value considers the condition in which Stream S1 contains some mass fraction of fission products. For example, this could be the case if the source of burnable fissile materials is preprocessed LWR fuel. For the case of a breeder where some fissile materials are to be discharged from the system due to surplus of fissile inventory in the system, the term $i$ can be negative as part of inseparable fission products from the recycled fissile materials shall be discharged along with fissile materials.

$\mathbf{x}_{1}$ : Mass of Fission Products in Stream $\mathbf{S}_{2}$. This value is the mass of fission products in the "new" fuel stream.

$\mathbf{x}_{2}$ : $\quad$ Mass of Fission Products in Stream $\mathbf{S}_{2}$. This value is the mass of fission products in the "spent" fuel stream.

u: Mass of Fission Products in Stream $\mathbf{S}_{\mathbf{4}}$. This value is the mass of fission products in the recycle stream.

y: Mass of Fission Products in Stream $\mathbf{S}_{5}$. This value is the mass of fission products in the waste stream.

The following equations describe the model.

$$
\begin{gathered}
x_{1, n}=u_{n-1}+i_{n} \\
x_{2, n}=x_{1, n}+b_{n} \\
y_{n}=c\left(x_{1, n}\right) \\
u_{n}=(1-c)\left(x_{2, n}\right) \\
x_{2, n}=\frac{(i+b)\left(1-(1-c)^{n-1}\right)}{c}
\end{gathered}
$$

In the equations above, $i_{n}$ is an impurity related constant associated with $\mathrm{Stream} \mathrm{S}_{1}, b_{n}$ is a burn-up related constant associated with the reactor, and $c$ is the rejection efficiency of fission products from the reprocessing facility. The involved mass terms reach steady states as the number of cycles (n) approaches infinity.

$$
\begin{gathered}
\lim _{n \rightarrow \infty} x_{2, n}=\frac{i+b}{c} \\
\lim _{n \rightarrow \infty} x_{1, n}=\frac{i+b}{c-b} \\
\lim _{n \rightarrow \infty} y_{n}=i+b \\
\lim _{n \rightarrow \infty} u_{n}=\frac{(1-c)(i+b)}{c}
\end{gathered}
$$

Results of the model are presented in Table 11. This set of results reflects a case in which a burner reactor may be used, and no fission products are present in Stream $\mathrm{S}_{1}$; which is to say that $i=0$. 
Table 11. Results of Fission Product Model.

\begin{tabular}{|c|c|c|c|c|}
\hline \multirow{2}{*}{$\begin{array}{l}\text { Relative } \\
\text { Burn-Up in } \\
\text { Reactor } \\
\end{array}$} & $\begin{array}{c}\text { Fission Product } \\
\text { Generation in the } \\
\text { Reactor } \\
\text { (wt } \% \text { of total fuel) }\end{array}$ & $\begin{array}{l}\text { Fission Product } \\
\text { Rejection Fraction } \\
\text { from Reprocessing }\end{array}$ & $\begin{array}{l}\text { Fission Product to } \\
\text { Fuel Fabrication } \\
\text { (wt } \% \text { of total fuel) }\end{array}$ & $\begin{array}{l}\text { Fission Product to } \\
\text { Reprocessing } \\
\text { (wt } \% \text { of total fuel) }\end{array}$ \\
\hline & $\left(\mathrm{x}_{2}-\mathrm{x}_{1}\right)$ & $\mathrm{y} / \mathrm{x}_{2}$ & $\mathrm{u}$ & $\mathrm{x}_{2}$ \\
\hline \multirow{4}{*}{ Low } & 2 & 0.9 & 0.22 & 2.22 \\
\hline & 2 & 0.8 & 0.50 & 2.50 \\
\hline & 2 & 0.7 & 0.86 & 2.86 \\
\hline & 2 & 0.5 & 2.00 & 4.00 \\
\hline \multirow{4}{*}{ Medium } & 4 & 0.9 & 0.44 & 4.44 \\
\hline & 4 & 0.8 & 1.00 & 5.00 \\
\hline & 4 & 0.7 & 1.71 & 5.71 \\
\hline & 4 & 0.5 & 4.00 & 8.00 \\
\hline \multirow{4}{*}{ High } & 8 & 0.9 & 0.89 & 8.89 \\
\hline & 8 & 0.8 & 2.00 & 10.00 \\
\hline & 8 & 0.7 & 3.43 & 11.43 \\
\hline & 8 & 0.5 & 8.00 & 16.00 \\
\hline
\end{tabular}

Table 11 is divided into three sections representing low, medium, and high burn-up of fuel in the reactor. This particular comparison is completely subjective, but for these purposes "low" burn-up converts $2 \mathrm{wt} \%$ of the incoming fissile materials mass to fission products; "medium" burn-up, $4 \mathrm{wt} \%$; and "high" burn-up, 8 wt $\%$.

For each of the three levels of burn-up, the table considered four values of reprocessing efficiencies: $0.9,0.8,0.7$, and 0.5. A value of 0.9 means that $90 \mathrm{wt} \%$ of the fission products in Stream $\mathrm{S} 3$ are rejected to Stream S5.

Referring to Table 11, for the case in which the reactor is operated at a "medium" burn-up, and the reprocessing efficiency is $80 \%$, the "new" fuel to the reactor will contain $1 \mathrm{wt} \%$ fission products (as a result of $1 \mathrm{wt} \%$ fission product returned to fuel fabrication in Stream S4) and the "spent" fuel from the reactor will contain $5 \mathrm{wt} \%$ fission products (as a result of an additional $4 \mathrm{wt} \%$ fission products generated in the reactor).

\subsection{Remarks on the Abstracted Fuel Cycle Models}

The fissile materials retention and fission products rejection models presented here are highly abstracted, but they reflect the consequences associated with these process effects concisely. What is not addressed in this development is the relationship between fissile materials retention and fission products rejection with regards to the engineering design and operations of the reactor and reprocessing facility. The exact nature of these relationships is very complex.

However, what can be stated with certainty is that fissile materials retention and fission products reject are not independent considerations. In general, there should be a tradeoff between fissile materials retention and fission product rejections. That is, as we seek to increase fissile materials retention, fission products rejection will decrease. The degree of this tradeoff should depend on the considered reprocessing technology.

Nevertheless, much information can be gleamed from the data in Table 10 and Table 11. The following are some of the observed relationships. 
- Higher burn-up improves the consumption of fissile materials.

- Increased fissile materials retention improves the consumption of fissile materials.

- If burn-up is a limitation, then improved fissile materials retention can allow for higher consumption of fissile materials.

- Increased fission products rejection decreases fission products loading of the fuel.

- Higher burn-up increases the fission products loading of the fuel.

- If fissile materials loading of the fuel is a limitation, then improved fission products rejection can allow for higher burn-up.

- Improved purity of the fissile materials source material decreases the fission products loading of the fuel.

\subsection{The Considerations of Fundamental Complexities}

The abstracted model addresses the behaviors of fissile materials and fission products in only the broadest of terms. However, each category is comprised of a family of elements with unique separations behaviors. The consequences of these "uniquenesses" is that each fissile material will have an independent retention efficiency, and each fission product will have an independent rejection efficiency. And, as is already understood, there will be some degree of overlap between the separation behaviors of the two families.

For example, if, categorically, $99.9 \%$ is the minimum retention efficiency for any single fissile materials element during reprocessing, then there will be corresponding lower (i.e., lower than the mean) rejection efficiencies for those fission products that have separations characteristic similar to some of the minor actinides. A consequence of this dilemma is that the composition of the steady state loading of fission products in the fuel cycle will be shifted toward these particular fission products.

In general terms, the composition of the retained/rejected fissile materials (Streams $\mathrm{S}_{4}$ and $\mathrm{S}_{5}$ ) will not exactly reflect the composition of the bulk fissile materials (Stream $\mathrm{S}_{3}$ ). And similarly, the composition of the rejected/retained fission products ( Stream $\mathrm{S}_{5}$ and $\mathrm{S}_{4}$ ) will not exactly reflect the composition of the bulk fission products (Stream $\mathrm{S}_{3}$ ). 


\section{CONCLUSIONS}

Many different types of nuclear reactors using many different types of nuclear fuels serving many different applications are possible. The varieties of reactor and fuel types are seemingly endless. Consequently, the selection of reprocessing technologies and strategies are highly application specific. And in addition to these technical challenges, the engineering considerations are also influenced by economic, social, and political objectives.

A great amount of historical work has been performed on the study of reprocessing technologies, both aqueous and non-aqueous. This report provides a high-level summary of that body of work. Aqueous reprocessing technologies have been used at massive scales for plutonium production and civilian power production. Non-aqueous reprocessing technologies have not seen the same level of use as aqueous technologies, but there are certain fuel cycle scenarios that are better served by non-aqueous methods. These may include, for example, many of the fuel cycle concepts adapted to the production of metallic fuels and molten salt fuels. 


\section{REFERENCES}

1. Ronen, Y., "The Common Properties of the "Fertile" Isotopes," Nuclear Science and Engineering, 156 (2007): 408-409.

2. Palko, A. A., "Separation of Boron Isotopes in the Bench-Scale Boron Fluoride-Anisole Unit," Industrial and Engineering Chemistry, 51, 2 (1959): 121-124.

3. Merritt, R. C., "The Extractive Metallurgy of Uranium," Colorado School of Mines Research Institute, 1971.

4. "Production of Yellow Cake and Uranium Fluorides," Proceeding of an Advisory Group Meeting Organized by the International Atomic Energy Agency, Paris, France, June 5-8, 1979.

5. Edwards, C. R., A. J. Oliver, "Uranium Processing: A Review of Current Methods and Technology," Journal of Metals (JOM), (September 2000): 12-20.

6. Singh, H., C. K. Gupta, "Solvent Extraction in Production and Processing of Uranium and Thorium," Mineral Processing and Extractive Metallurgy Review, 21 (2000): 307-349.

7. Benedict, M., T. H. Pigford, H. W. Levi, "Nuclear Chemical Engineering, Second Edition," McGraw-Hill, ISBN 0-07-004531-3, 1981.

8. Kim, L. K., "Uranium Mining and Milling,” Lawrence Livermore National Laboratory, LLNL-TR-747582, March 8, 2018.

9. Kim, J., J. W. Eerkens, M. H. Yang, C. K. Rhee, W. W. Kim, "Current Status of the MLIS Uranium Enrichment Process," Transactions of the Korean Nuclear Society Spring Meeting, Jeju, Korea, (2009): 455-456.

10. Aalbergsjo, S. G., "Uranium Enrichment Technologies,” Norwegian Defense Research Establishment, FFI-Rapport 2008/02376, 2009.

11. Makhijani, A., L. Chalmers, B. Smith, "Uranium Enrichment: Just Plain Facts to Fuel an Informed Debate on Nuclear Proliferation and Nuclear Power," Institute for Energy and Environmental Research, October 2004.

12. Shaffer, J. H., "Preparation and Handling of Salt Mixtures for the Molten Salt Reactor Experiment," Oak Ridge National Laboratory, ORNL-4616, January 1971.

13. Symons, E. A., "Lithium Isotope Separation: A Review of Possible Techniques," Separations Science and Technology, 20 (1985) 633-651.

14. "Mercury Releases from Lithium Enrichment at the Oak Ridge Y-12 Plant - A Reconstruction of Historical Releases and Off-Site Doses and Health Risks," ChemRisk, Report of the Oak Ridge Dose Reconstruction, Vol. 2, July 1999.

15. Begun, G. M., L. L. Brown, L. B. Yeatts, N. C. Bradley, E. F. Joseph, "Chemical and Isotopic Studies of the NITROX System for N15 Enrichment," Oak Ridge National Laboratory, ORNL-2291, June 1957.

16. Ishida, T., Y. Ono, "Early History of Chemical Exchange Isotope Enrichment and Lessons We Learn," Journal of Nuclear Science and Technology, 43, 4, (2006): 391-399.

17. Ding, X. C., T. Kaneshiki, M. Arima, M. Nomura, T. Suzuki, Y. Fujii, "High Enrichment of ${ }^{15}$ N Isotope by Ion Exchange for Nitride Fuel Development," Progress in Nuclear Energy, 50 (2008): 504-509. 
18. Murphy, G. M., H. C. Urey, I. Kirshenbaum, Editors, "Production of Heavy Water: National Nuclear Energy Series,” McGraw-Hill, New York, 1955.

19. Miller, A. I., "Heavy Water: A Manufacturers' Guide for the Hydrogen Century," Canadian Nuclear Society Bulletin, 22, 1 (2001).

20. Waltham, C., “An Early History of Heavy Water,” Department of Physics and Astronomy, University of British Columbia, 2011.

21. Compere, E. L., S. H. Freid, C. W. Nestor, "Distribution and Release of Tritium in HighTemperature Gas-Cooled Reactors as a Function of Design, Operational, and Material Parameters," Oak Ridge National Laboratory, ORNL-TM-4303, June 1974.

22. Phillips, J. E., C. E. Easterly, "Sources of Tritium,” Oak Ridge National Laboratory, ORNL/TM-6402, December 1980.

23. Kramer, D., "DOE Prepares Major Upgrade of Its Lithium-6 Operations," Physics Today, 71, 5 (2018): 29-31.

24. Lamarsh, J. R., A. J. Baratta, "Introduction to Nuclear Engineering, Third Edition," Prentice Hall, ISBN 0-201-82498-1, 2001.

25. Renier, J. A., M. L. Grossbeck, "Development of Improved Burnable Poisons for Commercial Nuclear Power Reactors,” Oak Ridge National Laboratory, ORNL/TM-2001/238, October 2001.

26. Tomberlin, T. A., "Beryllium - A Unique Material in Nuclear Applications," Idaho National Engineering and Environmental Laboratory, INEEL/CON-04-01869, November 2004.

27. "Advanced Applications of Water Cooled Nuclear Power Plants," International Atomic Energy Agency, IAEA-TECDOC-1585, July 2007.

28. "Liquid Metal Coolants for Fast Reactors Cooled by Sodium, Lead, and Lead-Bismuth Eutectic," International Atomic Energy Agency, Nuclear Energy Series No. NP-T-1.6, 2012.

29. "Gas-Cooled Reactors and Their Applications," Proceedings of a Technical Committee Meeting, International Atomic Energy Agency, Julich, Germany, October 20-23, 1986.

30. Dolan, T. J., ed., "Molten Salt Reactors and Thorium Energy," Woodhead Publishing, ISBN 978-0-08-101126-3, 2017.

31. "Technology and Applied R\&D Needs for Molten Salt Chemistry," Molten Salt Chemistry Workshop, Oak Ridge National Laboratory, April 10-12, 2017.

32. Cowan, R., "Nuclear Power Reactors: A Study in Technological Lock-In," Cambridge University Press, The Journal of Economic History, Vol. 50, No. 5, (1990): 541-567.

33. Stacy, S. M., "Proving the Principle: A History of the Idaho National Engineering and Environmental Laboratory 1949-1999," Idaho Operations Office of the Department of Energy, DOE/ID-10799, ISBN 0-16-059185-6, 2000.

34. Steunenberg, R. K., L. Burris, "From Test Tube to Pilot Plant: A 50 Year History of the Chemical Technology Division at Argonne National Laboratory," ANL-00/16, ISBN 0-9679168-1-X, August 2000.

35. "Nuclear Heritage: Idaho's 52 Reactors," Idaho National Laboratory, Fact Sheet 08-GA50044-23R3, 2008. 
36. "The History of Reactor Operations," Argonne National Laboratory, https://www.ne.anl.gov/About/reactors/History-of-Argonne-Reactor-Operations.pdf.

37. Lerner, L., "Argonne Marks $70^{\text {th }}$ Anniversary of First Man-Made Nuclear Chain Reaction," Argonne National Laboratory, https://www.anl.gov/article/argonne-marks-70th-anniversary-offirst-manmade-nuclear-chain-reaction, December 2, 2012.

38. Rosenthal, M. W., "An Account of Oak Ridge National Laboratory's Thirteen Nuclear Reactors," Oak Ridge National Laboratory, ORNL/TM-2009/181, August 2009 (Revised March 2010).

39. Bunker, M. E., "Early Reactors: From Fermi's Water Boiler to Novel Power Prototypes," Los Alamos Science, (Winter/Spring 1983): 124-131.

40. "Ultra High Temperature Reactor Experiment (UHTREX) Facility Description and Safety Analysis Report," Los Alamos Scientific Laboratory of the University of California, LA-3556 Revised, February 1967.

41. Salazar, M., J. Elder, "Decommissioning the UHTREX Reactor Facility at Los Alamos, New Mexico," Los Alamos National Laboratory, LA-12356, 1992.

42. Harvey, D., "History of the Hanford Site: 1943-1990," Pacific Northwest National Laboratory, 1990.

43. Gerber, M. S., "The Hanford Site: An Anthology of Early Histories," Westinghouse Hanford Company, WHC-MR-0435, October 1993.

44. "Plutonium: The First 50 Years. United States Plutonium Production, Acquisition, and Utilization from 1944 through 1994,” U.S. Department of Energy, DOE/DP-0137, February 1996.

45. Gerber, M. S., "Hanford's Historic Reactors: Constant Change in the Early Years," Columbia Magazine, Vol. 9, No. 1, 1995.

46. Gerber, M. S., "The Plutonium Production Story at the Hanford Site: Processes and Facilities History," Westinghouse Hanford Company, WHC-MR-0521, June 1996.

47. "Closing the Circle on the Splitting of the Atom: The Environmental Legacy of Nuclear Weapons Production in the United States and What the Department of Energy is Doing About It," U.S. Department of Energy, DOE/EM-0266, January 1996.

48. "Nuclear Reactors Built, Being Built, or Planned in the United Sates as of June 30, 1959," United States Atomic Energy Commission, TID-8200, 1959.

49. “Nuclear Reactors Built, Being Built, or Planned 1996," U.S. Department of Energy, TID-8200 (60 ${ }^{\text {th }}$ Revision), 1996.

50. Lane, J. A., H. G. MacPherson, F. Maslan, editors, "Fluid Fuel Reactors," Addison-Wesley Publishing Company, 1958.

51. "Fuel Cycle Options for Light Water Reactors and Heavy Water Reactors," International Atomic Energy Agency, IAEA-TECDOC-1122, November 1999.

52. "Enhanced CANDU 6 Technical Summary," SNC Lavalin Nuclear Office, Mississauga, Ontario, 2004.

53. “Accident Tolerant Fuel Concepts for Light Water Reactors," International Atomic Energy Association, IAEA-TECDOC-1797, October 2014. 
54. Zinkle, S. J., K. A. Terrani, J. C. Gehin, L. J. Ott, L. L. Snead, “Accident Tolerant Fuels for LWRs: A Perspective," Journal of Nuclear Materials, 448 (2014): 374-379.

55. Bragg-Sitton, S., "Development of Advanced Accident-tolerant Fuels for Commercial LWRs," Nuclear News, (March 2014): 83-91.

56. Kim, H. G., J. H. Yang, W. J. Kim, Y. H. Koo, "Development Status of Accident-tolerant Fuel for Light Water Reactors in Korea," Nuclear Engineering and Technology, 48 (2016): 1-15.

57. Bragg-Sitton, S. M., M. Todosow, R. Montgomery, C. R. Stanek, R. Montgomery, W. J. Carmack, "Metrics for the Technical Performance Evaluation of Light Water Reactor Accident-Tolerant Fuel," Nuclear Technology, 195 (2016): 111-123.

58. Terrani, K. A., "Accident Tolerant Fuel Cladding Development: Promise, Status, and Challenges," Journal of Nuclear Materials, 501 (2018): 19-30.

59. Carrilho, L. A., "Experimental and Computational Study of Roughened Surface for PWR Rod Bundles," Ph.D. Thesis, College of Engineering and Computing, University of South Carolina, 2012.

60. Weihermiller, W. B., G. S. Allison, "LWR Nuclear Fuel Bundle Data for Use in Fuel Bundle Handling: Topical Report,” Battelle Pacific Northwest Laboratory, PNL-2575, September 1979.

61. "Status and Advances in MOX Fuel Technology," International Atomic Energy Agency, Technical Report Series No. 415, 2003.

62. Gratchyov, A. F., et al., "Demonstration Experiment of BN-600 MOX Vibropac FAs Irradiation for the Excess Weapons Plutonium Disposal," Journal of Nuclear Science and Technology, 44, 3 (2007): 504-510.

63. Trellue, H. R., "Safety and neutronics: A comparison of $\mathrm{MOX}$ and $\mathrm{UO}_{2}$ Fuel," Progress in Nuclear Energy, 48 (2006): 135-145.

64. "Russia Starts Batch Production of MOX Fuel Assemblies," World Nuclear News, December 2018.

65. "MOX Fuel for Ohma," World Nuclear News, April 2009.

66. Gerber, M. S., "The Plutonium Production Story at the Hanford Site: Processes and Facilities History,” Westinghouse Hanford Company, WHC-MR-0521, June 1996.

67. "Closing the Circle on the Splitting of the Atom: The Environmental Legacy of Nuclear Weapons Production in the United States and What the Department of Energy is Doing About It," U.S. Department of Energy, DOE/EM-0266, January 1996.

68. "Bringing It to Form: A Thematic Study of Savannah River Site's Separations Processes, F and H Areas. Savanna River Site Cold War Historic Property Documentation, Volume 1, Narrative and Photography," New South Associates, Technical Report No. 2202, July 19, 2013.

69. "Improving the Scientific Basis for Managing DOE's Excess Nuclear Materials and Spent Nuclear Fuel,” The National Academic Press, Washington, DC, 2003.

70. Curwen, I., "Decommissioning the World's First Commercial Nuclear Power Station," https://nda.blog.gov.uk/2019/09/03/decommissioning-the-worlds-first-commercial-nuclear-powerstation/.

71. Stewart, J. C. C., "Development and Manufacture of MAGNOX Fuel," Proceedings of the Institution of Mechanical Engineers, 178, 9 (1963-64): 227-240. 
72. Bukharin, O., T. B. Cochran, R. S. Norris, "Nuclear Weapons Databook, New Perspectives on Russia's Ten Secret Cities," Natural Resources Defense Council, Washington, D.C., Nuclear Program, October 1999.

73. von Hippel, F. N., M. Bunn, "Saga of the Siberian Plutonium Production Reactors," Federation of American Scientists, Public Interest Report, 53, 6, 2000.

74. Diakov, A., "The History of Plutonium Production in Russia," Science \& Global Security, 19 (2011): 28-45.

75. Zhang, Z., "China's HEU and Plutonium Production and Stockpiles," Science \& Global Security, 19 (2011): 68-89.

76. Zhang, H., "China's Fissile Material Production and Stockpile," International Panel of Fissile Materials, Research Report No. 17, 2017.

77. Zhang, H., "The History of Fissile-Material Production in China," The Nonproliferation Review, 25, 5-6 (2019): 1-23.

78. Lovins, A. B., "Nuclear Weapons and Power-Reactor Plutonium," Nature, 283, 5750 (1980): 817-823.

79. International Atomic Energy Agency, Research Reactor Database, Available at https://www.iaea.org/.

80. Hofman, G. L., Y. S. Kim, “Dispersion Fuels,” Materials and Science, Whiley- VCH Verlag GmbH \& Co., 2015.

81. Porter, I. E., T. W. Knight, M. C. Dulude, E. Roberts, J. Hobbs, "Design and Fabrication of an Advanced TRISO Fuel with ZrC Coating," Nuclear Engineering and Design, 259 (2013): 181-186.

82. Verfondern, K., H. Nabielek, M. J. Kania, H. J. Allelein, "High-Quality Thorium TRISO Fuel Performance in HTGRs," Schriffen des Forschungszentrums Julich, Energy \& Environment, Vol. 174, 2013.

83. "Report on Use of Low Enriched Uranium in Naval Nuclear Propulsion," Prepared by the Director of Naval Nuclear Propulsion, June 1995.

84. "Low-Enriched Uranium for Potential Naval Nuclear Propulsion Applications," JASON, The MITRE Corporations, JSR-16-Task-013, November 2016.

85. Hewlett, R. G., F. Duncan, "Nuclear Navy: 1946-1962," The University of Chicago Press, ISBN 0-226-33219-5, 1974.

86. "Civilian Power Reactor Program, Part III, Status Report on Sodium Graphite Reactors as of 1959," U.S. Atomic Energy Commission, TID-8518(6), Book 6, 1969.

87. Cowan, R., "Nuclear Power Reactors: A Study in Technological Lock-In," Cambridge University Press, The Journal of Economic History, Vol. 50, No. 5, (1990): 541-567.

88. Stacy, S. M., "Proving the Principle: A History of the Idaho National Engineering and Environmental Laboratory 1949-1999," Idaho Operations Office of the Department of Energy, DOE/ID-10799, ISBN 0-16-059185-6, 2000.

89. Zrodnikov, A. V., V. I. Chitaykin, B. F. Gromov, O. G. Grigoryv, A. V. Dedoul, G. I. Toshinsky, Y. D. Dragunov, V. S. Stepanov, "Use of Russian Technology of Ship Reactors with Lead-Bismuth Collant in Nuclear Power," International Atomic Energy Agency, IAEA-TECDOC-1172, 2000. 
90. Peakman, A., H. Owen, T. Aram, "The Core Design of a Small Nodular Pressurized Water Reactor for Commercial Marine Propulsion,” Progress in Nuclear Energy, 113 (2019): 175-185.

91. Ryskamp, J. M., et al., "Weapons-Grade Plutonium Dispositioning Volume 3: A New Reactor Concept Without Uranium or Thorium for Burning Weapons-Grade Plutonium," US Department of Energy, DOE/ID-10422, 1993.

92. "Unconventional Options for Plutonium Disposition," International Atomic Energy Agency, IAEA-TECDOC-840, 1994.

93. Burghartz, M., Hj. Matzke, C. Leger, G. Vambenepe, M. Rome, "Inert Matrices for the Transmutation of Actinides: Fabrication, Thermal Properties and Radiation Stability of Ceramic Materials," Journal of Alloys and Compounds, 271-273 (1998): 544-548.

94. Chawla, R., R. J. M. Konings, "Categorization and Priorities for Future Research on Inert Matrix Fuels: An Extended Synthesis of the Panel Discussions," Progress in Nuclear Energy, 38, 3-4 (2001): 455-458.

95. Carmack, W., R. Fielding, P. Medvedev, M. Meyer, M. Todosow, H. B. Hamilton, J. Nino, S. Philpot, J. Tulenko, "AECL/US INERI - Development of Inert Matrix Fuels for Plutonium and Minor Actinide Management in Power Reactors - Fuel Requirements and Down-Select Report," Idaho National Laboratory, INL/EXT-05-00436, June 2005.

96. "Viability of Inert Matrix Fuel in Reducing Plutonium Amounts in Reactors," International Atomic Energy Agency, IAEA-TECDOC-1516, August 2006.

97. Mittag, S., S. Kliem, "Burning Plutonium and Minimizing Radioactive Waste in Existing PWRs," Annals of Nuclear Energy, 38 (2011): 98-102.

98. Cottrell, W. B., H. E. Hungerford, J. K. Leslie, J. L. Meem, "Operation of the Aircraft Reactor Experiment,” Oak Ridge National Laboratory, ORNL-1845, 1955.

99. Roberts, R. C., "MSRE Design and Operations Report, Part 1, Description of Reactor Design," Oak Ridge National Laboratory, ORNL-TM-728, 1965.

100. Serp, J., M. Allibert, O. Benes, S. Delpech, O. Feynberg, V. Ghetta, D. Heuer, D. Holcomb, V. Ignatiev, J. L. Kloosterman, L. Luzzi, E. M. Lucotte, J. Uhlier, R. Yoshioka, D. Zhimin, "The Molten Salt Reactor (MSR) in Genration IV: Overview and Perspectives," Progress in Nuclear Energy, 77 (2014): 308-319.

101. Rosenthal, M. W., P. R. Kasten, R. B. Briggs, "Molten Salt Reactors - History, Status, and Potential," Nuclear Applications and Technologies, 8 (2017): 107-117.

102. Zhang, D., L. Liu, M. Liu, R. Xu, C. Gong, J. Zhang, C. Wang, S. Qiu, G. Su, "Review of Conceptual Design and Fundamental Research of Molten Salt Reactors in China," International Journal of Energy Research, 42 (2018): 1834-1848.

103. Fredrickson, G. L., G. Cao, R. Gakhar, and T.-S. Yoo, "Molten Salt Reactor Salt Processing Technology Status,” Idaho National Laboratory, INL/EXT-18-51033, 2018.

104. Gerber, M. S., "A Brief History of the PUREX and UO3 Facilities," Westinghouse Hanford Company, WHC-MR-0437, November 1993.

105. Gerber, M. S., "The Plutonium Production Story at the Hanford Site: Processes and Facilities History,” Westinghouse Hanford Company, WHC-MR-0521, June 1996. 
106. Duckworth, J. P., L. R. Michels, "New Neptunium Recovery Facility at the Hanford PUREX Plant," I\&EC Process Design and Development, 3 (1964): 302-306.

107. Duckworth, J. P., J. R. Lariviere, "New Neptunium Recovery Facility at the Hanford PUREX Plant,” I\&EC Process Design and Development, 3 (1964): 306-308.

108. "Bringing it to Form: A Thematic Study of Savannah River Site's Separations Processes, F and H Areas," New South Associates Technical Report No. 2202, 2013.

109. Magoulas, V. E., "Savannah River Site's H-Canyon Facility: Recovery and Down Blend Uranium for Beneficial Use,” INMM 54 Annual Meeting, Palm Desert, CA, July 15-18, 2013.

110. Pace, B., J. Braun, H. Gilbert, "Idaho National Laboratory Reprocessing Complex Historic American Engineering Record Report - ID-3-H,” Idaho National Laboratory, INL/EXT-06-11969, 2006.

111. Mellinger, P. J., K. M. Harmon, L. T. Lakey, "A Summary of Nuclear Fuel Reprocessing Activities Around the World," Pacific Northwest Laboratory, PNL-4981, November 1984.

112. Reas, W. H., "The Aquafluor Process," Kjeller Report, Reprocessing of Fuel from Present and Future Power Reactors, Advanced Course Organized by the Netherland's - Norwegian Reactor School, Institutt for Atomenergi, KR-126, (September 1967): 361-384.

113. Carr, W. H., W. B. Summer, L. L. Thomas, "Transuranic Waste from Reprocessing of Nuclear Fuel," Nuclear and Chemical Waste Management, 4, (1983): 25-33.

114. Brooksbank, R. E., R. O. Sandberg, "Operability and Maintainability of the Barnwell Nuclear Fuel Plant: A Key Issue,” Nuclear Technology, 63, (1983): 244-253.

115. Ritter, G. L., "The Exxon Nuclear Fuel Recovery and Recycling Center: Process Description," Nuclear Technology, 43 (1979): 194-202.

116. "CRS Report to Congress, Nuclear Fuel Reprocessing: U.S. Policy Development," Congressional Research Service, Order Code RS22542, March 27, 2008.

117. Slansky, C. M., "A Survey of Headend Processes for nuclear Fuel Reprocessing," Journal of Metals, (January 1964): 25-32.

118. Selvaduray, G., M. K. Goldtein, R. N. Anderson, "Survey of Nuclear Fuel Reprocessing Technologies," Conservation and Recycling, 3, (1979): 93-134.

119. Choppin, G. R., M. Kh. Khankhasayev, editors, "Chemical Separation Technologies and Related Methods of Nuclear Waste Management,” Springer, ISBN 978-94-011-4546-0, 1999.

120. "Nuclear Separations Technologies Workshop Report," U.S. Department of Energy, Bethesda, Maryland, July 27-28, 2011.

121. Nash, K. L., G. J. Lumetta, editors, “Advanced Separation Techniques for Nuclear Fuel Reprocessing and Radioactive Waste Treatment," Woodhead Publishing, ISBN 978-08-101723-4, 2011.

122. Taylor, R., editor, "Reprocessing and Recycling of Spent Nuclear Fuel," Woodhead Publishing, ISBN 978-1-78242-212-9, 2015.

123. Todd, T. A., "Chemical Separations for the Nuclear Fuel Cycle," Idaho National Laboratory, INL/CON-18-51361, 2018. 
124. "State-of-the-Art Report on the Progress of Nuclear Fuel Cycle Chemistry," Nuclear Energy Agency, Organization for Economic Co-Operation and Development, NEA No. 7267, 2018.

125. Peterson, R. A., editor, "Engineering Separations Unit Operations for Nuclear Reprocessing," CRC Press, ISBN 978-1-138-60582-4, 2020.

126. "ORNL Metal Recovery Plant Processing Clementine Reactor Fuel Elements: Terminal Report," Oak Ridge National Laboratory, ORNL-1941, September 7, 1955.

127. Bunker, M. E., "Early Reactors: From Fermi’s Water Boiler to Novel Power Prototypes," Los Alamos Science, Winter/Spring, (1983): 124-131.

128. "Historical Context of the Omega Reactor Facility, Technical Area 2. Historical Building Report No. 234," Los Alamos National Laboratory, LA-UR-04-6681, September 2004

129. Zinn, W. H., "Basic Problems in Central-Station Nuclear Power," Nucleonics, Vol. 10, No. 9 , (1952): 8-14.

130. Lichtenberger, H. V., F. W. Thalgott, W. Y. Kato, M. Novick, "Operating Experience and Experimental Results Obtained from an NaK-Cooled Fast Reactor," Proceedings of the International Conference on the Peaceful Uses of Atomic Energy, Volume 3, Power Reactors, United Nations, Geneva, August 8 - 20, 1955.

131. Raseman, C. J., L. Green, "Commercial Power Reactors Cooled with Sodium, Heavy Water, or Organic Liquids," Leonard E. Link, ed., Reactor Technology Selected Reviews - 1964, (1964): 71130.

132. E. W. Kendall, D. K. Wang, "Decontamination and Decommissioning of the EBR-I: Complex Final Report," Aerojet Nuclear Company, Idaho National Engineering Laboratory," American Society of Mechanical Engineers, June 15, 1979, ANCR-1242, July 1975.

133. Michal, R., "Fifty Years Ago in December: Atomic Reactor EBR-I Produced First Electricity," Nuclear News, pp. 28-29, November 2001.

134. "A National Historic Mechanical Engineering Landmark: Experimental Breeder Reactor I: Idaho National Engineering Laboratory,” American Society of Mechanical Engineers, June 15, 1979.

135. R. Haroldson, "The Story of the Borax Nuclear Reactor and the EBR-I Meltdown," Copyright Ray Haroldson, Idaho Falls, ID, 2008.

136. L. J. Koch, “Koch: Remembering the EBR-I,” Nuclear News, (November 2001): 30-35.

137. "Civilian Power Reactor Program, Part III, Status Report on Sodium Graphite Reactors as of 1959," U.S. Atomic Energy Commission, TID-8518(6), Book 6, 1969.

138. Hewlett, R. G., Francis Duncan, "Nuclear Navy: 1946-1962," The University of Chicago Press, ISBN 0-226-33219-5, 1974.

139. Cowan R., "Nuclear Power Reactors: A Study in Technological Lock-In," Cambridge University Press, The Journal of Economic History, Vol. 50, No. 5, (1990): 541-567.

140. Stacy, S. M., "Proving the Principle: A History of the Idaho National Engineering and Environmental Laboratory 1949-1999," Idaho Operations Office of the Department of Energy, DOE/ID-10799, ISBN 0-16-059185-6, 2000.

141. Beeley, R. J., E. G. Lowell, H. Polak, J. Renard, “The Sodium Graphite Reactor: Tomorrow's Power Plant,” Atomics International, NAA-SR-MEMO-5114, April 1960. 
142. Beeley, R. J., J. E. Mahlmeister, "Operating Experience with the Sodium Reactor Experiment and Its Application to the Hallam Nuclear Power Facility," Atomics International, NAA-SR-MEMO546, 1959.

143. Carroll, J. W., C. C. Conners, J. M. Harris, J. M. Marzex, B. F. Ureda, "Sodium Reactor Experiment Decommissioning: Final Report," Rockwell International, ESG-DOE-13403, August 1983.

144. Swickard, E. O., ed., "Los Alamos Molten Plutonium Reactor Experiment (LAMPRE) Hazard Report," Los Alamos National Laboratory, LA-2327, December 1959.

145. Anderson, J. W., W. D. McNeese, C. C. Burwell, J. A. Leary, "Preparation and Fabrication of Plutonium Fuel Alloy for Los Alamos Plutonium Reactor Experiment No. 1," Nuclear Science and Engineering, Vol. 11, (1961): 434-440.

146. “LAMPRE-I Final Design Status Report,” Los Alamos National Laboratory, LA-2833, March 1963.

147. Peterson, R. E., R. L. Cubitt, "Operation of the Plutonium-Fueled Fast Reactor LAMPRE," American Nuclear Society, Fast Reactors National Topical Meetings, San Francisco, CA, April 1967.

148. Harper, J. R., R. Garde, "Decommissioning the Los Alamos Molten Plutonium Reactor Experiment (LAMPRE-I)," Los Alamos National Laboratory, LA-9052-MS, November 1981.

149. Weisner, E. F., W. M. Sybert, “A Sodium-Graphite Reactor Steam-Electric Station for 75 Megawatts Net Generation,” North American Aviation, Inc., NAA-SR-1300, March 22, 1955.

150. Gronemeyer, F. C., J. W. Merryman, “75,000 Kilowatts of Electricity by Nuclear Fission at the Hallam Nuclear Power Facility," Atomics International, AI-5272, Presented at the ASCE Convention, Reno, Nevada, June 23, 1960.

151. Dickinson, R. W., R. C. Gerber, C. L. Larson, "Hallam Nuclear Power Facility Prototype for Advanced Sodium-Cooled Power Stations," IEEE Transactions on Power Apparatus and Systems, Vol. 80, No. 3, (May 1961): 1008-1011.

152. Cochran, J. D., J. E. Owens, "Initial Operation of the Sodium Graphite Reactor at the Hallam Nuclear Power Facility," American Power Conference 26th Annual Meeting, Chicago, Illinois, April 14-16, 1964.

153. "Hallam Nuclear Power Facility Retirement Plan", Atomics International, NAA-SR-MEMO-12340 (Revised 5-20-67), February 24, 1967.

154. Huntsman, L. K., R. H. Meservey, "Sodium Removal from Hallam Reactor Components," EG\&G Idaho, Inc., TREE-1368, August 1979.

155. "Report on the Fuel Melting Incident in the Enrico Fermi Atomic Power Plant on October 5, 1966," Atomic Power Development Associates, Inc., APDA-233, December 15, 1968.

156. "Enrico Fermi Atomic Power Plant, Unit 1, Operating Experience Through 200 MWT," Atomic Power Development Associates, Inc., EFAPP-200-1, August 1971.

157. Alexanderson, E. P., H. A. Wagner, "Fermi-I: New Age for Nuclear Power: A History of the Enrico Fermi Atomic Power Project," American Nuclear Society, LaGrange Park, Ill, ISBN 0894480170, 1979. 
158. "Finding Aid for Enrico Fermi Atomic Power Plant Records, 1952-1975, Accession 75.2," Benson Ford Research Center, Dearborn, MI, January 2011.

159. Ragheb, M., "Fermi-I Fuel Meltdown Incident," Copyright M. Ragheb, November 20, 2014.

160. “EBR-II: Sixteen Years of Operation,” Argonne National Laboratory - West, Idaho Falls, Idaho, May 1980.

161. Perry, W. H., G. L. Lentz, W. J. Richardson, G. C. Walz, "Seventeen Years of LMFBR Experience: Experimental Breeder Reactor II (EBR-II)," American Power Conference, Chicago, IL, April 2628, 1982.

162. Lentz, G. L., H. W. Buschman, R. N. Smith, "EBR-II: Twenty Years of Operating Experience", International Symposium on Fast Breeder Reactors: Experience and Future Trends," Lyon, France, July 22-26, 1985.

163. Stevenson, C. E., “The EBR-II Fuel Cycle Story, American Nuclear Society,” ISBN 0-89448-0316, 1987.

164. "Bibliography of Publications on Experimental Breeder Reactor No. II (EBR-II): 1955 - August 1992,” Argonne National Laboratory, ANL/EBR-133 (Rev. 5), August 1992.

165. Sackett, J. I., "Operating and Test Experience With EBR-II, The IFR Prototype", Progress in Nuclear Energy, Vol. 31, No. 1/2, (1997): 111-129.

166. Michelbacher, J. A., C. E. Baily, D. K. Baird, S. P. Henslee, C. J. Knight, K. E. Rosenberg, "Shutdown and Closure of the Experimental Breeder Reactor - II," Proceedings of the 10th International Conference on Nuclear Engineering (ICONE 10), Arlington, VA, April 14-18, 2002.

167. Westfall, C., "Civilian Nuclear Power on the Drawing Board: The Development of Experimental Breeder Reactor - II,” Argonne National Laboratory, INL/HIST-1-03/6, 2003.

168. Westphal, C., "Vision and Reality: The EBR-II Story," Nuclear News, Vol. 47, No. 2, (February 2004): 25-32.

169. Michelbacher, J. A., S. P. Henslee, C. J. Knight, S. R. Sherman, "Decommissioning of Experimental Breeder Reactor-II Complex, Post Sodium Draining," IAEA Technical Meeting: The Decommissioning of Fast Reactors after Sodium Draining, Centre d'Etudes de Cadarache, France, September 26-30, 2005.

170. Koch, L. J., "Experimental Breeder Reactor - II (EBR-II): An Integrated Experimental Fast Reactor Nuclear Power Station," Authorized by Argonne National Laboratory, Published by the American Nuclear Society, 2008.

171. "Southwest Experimental Fast Oxide Reactor Development Program: Thirty-First and Final Report, November 1971 - January 1972,” General Electric, GEAP-10010-31, February 1972.

172. Hixson, J. D., "SEFOR Plant Operating Experience," General Electric, GEAP-13924, December 1972.

173. Hazama, T., J. Tommasi, "Re-Evaluation of SEFOR Doppler Experiments and Analyses with JNC and ERANOS Systems," The Physics of Fuel Cycles and Advanced Nuclear Systems: Global Developments (PHYSOR 2004), Chicago, IL, April 25-29, 2004.

174. Jacobi, W. M., Y. S. Tang, "The Clinch River Breeder Reactor - A Combined Power and Fuel Source," National Meeting of the American Institute of Chemical Engineers, Pittsburgh, PA, June $5,1974$. 
175. Dickson, P. W., "Design and Status of the Clinch River Breeder Reactor Plant," Frontiers of Power Technology Conference, Stillwater, Oklahoma, October 9, 1974.

176. Hardigg, G. W., "Clinch River Breeder Reactor Plant,” Intersociety of Energy Conversion Engineering Conference, Newark, Delaware, August 17, 1975.

177. “Clinch River Breeder Reactor Plant, Technical Review, Summer 1977,” E. H. Hill ed., Project Management Corporation, CRBRP-PMC-77-03, 1977.

178. "Report of the Comptroller General of the United States: Problems with Publications Related to the Clinch River Breeder Reactor Project,” US Government Accounting Office, EMD-77-74. January 6, 1978.

179. "Clinch River Breeder Reactor Plant Project: Summary Edition 1980 Technical Progress Report (October 1979 Through September 1980)," Westinghouse Electric, CRBRP-ARD-0270 (SUMM.), 1980 .

180. "Breeder Basics: The Clinch River Breeder Reactor Plant Project (2nd ed.)," Breeder Reactor Corporation, Oak Ridge, TN, 1980.

181. Boudreau, J., "The American Breeder Reactor Gets a Second Chance," Los Alamos Science, Vol. 2, No. 2, 1981.

182. "The Breeder Reactor Project," Environmental Science and Technology, Vol. 17, No. 9, (1983): 406A-412A.

183. "Final Report: The Clinch River Breeder Reactor Plant Project," Breeder Reactor Corporation, Oak Ridge, TN, January 1985.

184. "Fast Flux Test Facility Program, Atomic Energy Commission," U.S. General Accounting Office Staff Study, 097121, January 1975.

185. “The Fast Flux Test Facility: Built on Safety,” Hanford, HEDL-7658, 1989.

186. "Fast Flux Test Facility Transition Project Plan," Westinghouse Hanford Company, WHC-SD-FFSSP-004 (Revision 1), November 1994.

187. "Environmental Assessment: Shutdown of the Fast Flux Test Facility, Hanford Site, Richland, Washington," U.S. Department of Energy, DOE/EA-0993, May 1995.

188. "Medical Isotopes Production at the Fast Flux Test Facility: A Technical and Economic Assessment," Hanford Site, PNNL-SA-29502, November 1997.

189. Wootan, D. W., R. P. Omberg, C. Grandy, "The U.S. Knowledge Preservation Program for Fast Flux Test Facility Data," Proceedings of the International Conference on Fast Reactor and Related Fuel Cycles, Yekaterinburg, Russia, June 26-29, 2017.

190. Wootan, D. W., R. P. Omberg, C. Grandy, "Lessons Learned from Fast Flux Test Facility Experience," Proceedings of the International Conference on Fast Reactor and Related Fuel Cycles, Yekaterinburg, Russia, June 26-29, 2017.

191. Van Tuyle, G. J., G. C. Slovik, B. C. Chan, R. J. Kennett, H. S. Cheng, P. G. Kroger, "Summary of Advanced LMR Evaluations - PRISM and SAFR," U.S. Nuclear Regulatory Commission, NUREG/CR-5364, February 1989.

192. Lancet, R. T., R. Z. Litwin, R. C. Amar, R. D. Rogers, A. V. Von Arx, "Safety and Licensing of SAFR - An Advanced Liquid-Metal Reactor,” Nuclear Technology, Vol. 91, (1990): 203-214. 
193. King, T. L., R. R. Landry, E. D. Throm, J. N. Wilson, "Preapplication Safety Evaluation Report for the Sodium Advanced Fast Reactor (SAFR) Liquid-Metal Reactor," U.S. Nuclear Regulatory Commission, NUREG-1369, December 1991.

194. “Technical Options for the Advanced Liquid Metal Reactor - Background Paper,” U.S. Congress, Office of Technology Assessment, OTA-BP-ENV-126, May 1994.

195. Salerno, L. N., R. C. Berglund, G. L. Gyorey, F. E. Tippets, P. M. Tschamper, "PRISM Concept, Modular LMR Reactors," Nuclear Engineering and Design, Vol. 109, (1988): 79-86.

196. Kwant, W., C. E. Boardman, "PRISM - Liquid Metal Cooled Reactor Plant Design and Performance," Nuclear Engineering and Design, Vol. 135, (1992): 111-120.

197. "Preapplication Safety Evaluation Report for the Power Reactor Innovative Small Module (PRISM) Liquid-Metal Reactor: Final Report," S. Nuclear Regulatory Commission, NUREG-1368, February 1994.

198. Gluekler, E. L., "U.S. Advanced Liquid Metal Reactor (ALMR)," Progress is Nuclear Energy, Vol. 31, No. 1/2, (1997): 43-61.

199. Hylko, J. M., "PRISM: A Promising Near-Term Reactor Option,” Power (www.powermag.com), (August 2011): 68-74.

200. Triplett, B. S., E. P. Loewn, B. J. Dooies, "PRISM: A Competitive Small Modular Sodium-Cooled Reactor," Nuclear Technology, Vol. 178, (May 2012): 186-200.

201. "Demonstration Sodium-Cooled Fast Reactor GE-PRISM," GE Hitachi Nuclear Energy, 003N4516, Revision 2, March 2016.

202. Feder, H.M., N. Chellew, M. Ader, "Melt Refining of Uranium," Progress in Nuclear Energy: Process Chemistry, McGraw-Hill Book Company, (1956): 301-308.

203. Burris, L., H. M. Feder, S. Lawroski, W. A. Rodger, R. C. Vogel, "The Melt Refining of Irradiated Uranium: Application to EBR-II Fast Reactor Fuel. I. Introduction," Nuclear Science and Engineering, 6, (1959): 493-495.

204. Bernstein, G. J., G. A. Bennet, N. R. Chellew, V. G. Trice, "The Melt Refining of Irradiated Uranium: Application to EBR-II Fast Reactor Fuel. II. Experimental Furnaces,” Nuclear Science and Engineering, 6, (1959): 496-500.

205. Hampson, D. C., G. A. Bennett, N. R. Chellew, "The Melt Refining of Irradiated Uranium: Application to EBR-II Fast Reactor Fuel. III. Preparation of Experimental Alloys," Nuclear Science and Engineering, 6, (1959): 501-503.

206. Rosen, C. L., N. R. Chellew, H. M. Feder, "The Melt Refining of Irradiated Uranium: Application to EBR-II Fast Reactor Fuel. IV. Interaction of Uranium and Its Alloys with Refractory Oxides," Nuclear Science and Engineering, 6, (1959): 504-510.

207. Bennett, G. A., N. R. Chellew, D. C. Hampson, "The Melt Refining of Irradiated Uranium: Application to EBR-II Fast Reactor Fuel. V. Yield of Fissionable Material Upon Pouring," Nuclear Science and Engineering, 6, (1959): 511-513.

208. Trice, V. G., N. R. Chellew, "The Melt Refining of Irradiated Uranium: Application to EBR-II Fast Reactor Fuel. VI. The Behavior of Plutonium in the Melt-Refining Process," Nuclear Science and Engineering, 9, (1961): 55-58. 
209. Schneider, A., N. R. Chellew, "The Melt Refining of Irradiated Uranium: Application to EBR-II Fast Reactor Fuel. VII. The Evolution of Xenon and Krypton," Nuclear Science and Engineering, 9, (1961): 59-63.

210. Chellew, N. R., G. A. Bennett, V. G. Trice, "The Melt Refining of Irradiated Uranium: Application to EBR-II Fast Reactor Fuel. VIII. The Behavior of Rare Earths, Yttrium, Barium, Strontium, and Cesium," Nuclear Science and Engineering, 9, (1961): 64-70.

211. Wolkoff, J., A. A. Chilenskas, "The Melt Refining of Irradiated Uranium: Application to EBR-II Fast Reactor Fuel. IX. Sorption and Retention of Sodium and Cesium Vapor on Stationary Beds at Elevated Temperature," Nuclear Science and Engineering, 9, (1961): 71-77.

212. Chellew, N. R., V. G. Trice, "The Melt Refining of Irradiated Uranium: Application to EBR-II Fast Reactor Fuel. X. The Behavior of Zirconium,” Nuclear Science and Engineering, 9, (1961): 78-81.

213. Chellew, N. R., M. Ader, "The Melt Refining of Irradiated Uranium: Application to EBR-II Fast Reactor Fuel. XI. Behavior of Iodine in Melt Refining," Nuclear Science and Engineering, 9, (1961): 82-86.

214. Chellew, N. R., G. A. Bennett, "The Melt Refining of Irradiated Uranium: Application to EBR-II Fast Reactor Fuel. XII. The Behavior of Ruthenium, Molybdenum, Palladium, Rhodium, Technetium, Antimony, Cadmium, and Tellurium,” Nuclear Science and Engineering, 9, (1961): 87-90.

215. Carson, N. J., S. B. Brak, "Equipment for the Remote Demolding, Sizing, and Inspection of EBR-II Cast Fuel Pins," Nuclear Science and Engineering, 12, (1962(: 412-418.

216. Jelinek, H. E., G. M. Iverson, "Equipment for Remote Injection Casting of EBR-II Fuel," Nuclear Science and Engineering, 21, (1962): 405-411.

217. Hesson, J. C., M. J. Feldman, L. Burris, "Description and Proposed of the Fuel Cycle Facility for the Second Experimental Breeder Reactor (EBR-II)," Argonne National Laboratory, ANL-6605, April 1963.

218. Trice, V. G., R. K. Steunenberg, "Small-Scale Demonstration of the Melt Refining of Highly Irradiated Uranium-Fissium Alloy," Argonne National Laboratory, ANL-6696, August 1963.

219. Lawroski, S., L. Burris, "Processing of Reactor Fuel Materials by Pyrometallurgical Methods," Atomic Energy Review, Vol. 2, No. 3, (1964): 3-69.

220. Burris, L., I. G. Dillon, R. K. Steunenberg, "The EBR-II Skull Reclamation Process. Part I. General Process Description and Performance,” Argonne National Laboratory, ANL-6818, January 1964.

221. Johnson, T. R., R. D. Pierce, L. Burris, R. K. Steunenberg, "The EBR-II Skull Reclamation Process. Part II. Oxidation of Melt-Refining Skulls," Argonne National Laboratory, ANL-6874, April 1964.

222. Miller, W. E., G. J. Berstein, R. M. Fryer, R. F. Malecha, M. A. Slawecki, R. C. Paul, "The EBR-II Skull Reclamation Process. Part III. Skull Oxidation Equipment," Argonne National Laboratory, ANL-7338, October 1967.

223. Hampson, D. C., R. M. Fryer, J. W. Rizzle, "Melt Refining of EBR-II Fuel," Nuclear Metallurgy, Vol. 15, Symposium on Reprocessing of Nuclear Fuels, Ames, IA, (August 25-27, 1969): 57-76. 
224. Winsch, I. O., R. D. Pierce, D. E. Grosvenor, L. Burris, T. F. Cannon, P. J. Mack, K. Nishio, K. R. Tobias, "The EBR-II Skull Reclamation Process. Part IV. Pilot-Plant Development," Argonne National Laboratory, ANL-7614, September 1969.

225. Hampson, D. C., R. M. Fryer, J. W. Rizzle, "Melt Refining of EBR-II Fuel," Proceedings of the Symposium on Reprocessing of Nuclear Fuels, American Institute of Mining, Metallurgical, and Petroleum Engineers, Iowa States University, Ames, Iowa, August 25-27, 1969.

226. Winsch, I. O., R. D. Pierce, G. J. Bernstein, W. E. Miller, L. Burris, “EBR-II Skull Reclamation Process," Proceedings of the Symposium on Reprocessing of Nuclear Fuels, American Institute of Mining, Metallurgical, and Petroleum Engineers, Iowa States University, Ames, Iowa, August 25-27, 1969.

227. Bernstein, G. J., D. E. Grosvenor, J. F. Lenc, W. E. Miller, I. O. Winsch, J. Wolkoff, R. C. Paul, "The EBR-II Skull Reclamation Process. Part V. Design and Development of Plant-Scale Equipment,” Argonne National Laboratory, ANL-7772, January 1971.

228. Stevenson, C. E., M. J. Feldman, D. C. Hampson, D. M. Paige, N. J. Suauron, "Operations of a Pyrochemical Processing - Remote Refabrication Plant: The EBR-II Fuel Cycle Facility," Recent Advances in Reprocessing of Irradiated Fuel, Chemical Engineering progress Symposium, Series 94, Vol. 65, 1969.

229. Bowersox, D. F., "Review of Partitioning Proposals for Spent Nuclear Fuels," Los Alamos Scientific Laboratory, LA-6442, September 1976.

230. LaPlante, J. P., D. A. Wenz, R. K. Steunenberg, "Chlorination of Uranium and Fission Product Oxides in Molten Halide Media," Argonne National Laboratory, ANL-6546, May 1962.

231. Bennett, G. A., L. Burris, R. C. Vogel, "Halide Slagging of Uranium-Plutonium Alloys," Argonne National Laboratory, ANL-6918, July 1964.

232. Chellew, N. R., R. L. Steunenberg, "Extraction of Plutonium from Uranium-Plutonium Alloy with Uranium Trichloride," Nuclear Applications, 3, (1967): 142-146.

233. Steunenberg, R. K., "Pyrometallurgical Processing of Fast Reactor Fuel," Reprocessing of Fuel from Present and Future Power Reactors, Advanced Course Organized by the NetherlandsNorwegian Reactor School at Institutt for Atomenergi, Norway, August 21 - September 1, 1967.

234. Burris, L., M. J. Steindler, "Role and Application of Pyroprocessing," Transactions of the American Nuclear Society, Vol. 32, (1979): 359.

235. Burris, L., M. Steindler, W. Miller, "A Proposed Pyrometallurgical Process for Rapid Recycle of Discharged Fuel Materials from the Integral Fast Reactor," American Nuclear Society International Topical Meeting, Fuel Reprocessing and Waste Management, Jackson Hole, WY, August 26-29, 1984.

236. Lineberry, M., R. D. Phipps, J. P. Burelbach, "Economic and Demonstration Potential of IFR Fuel Cycle," Transactions of the American Nuclear Society, Vol. 50, (1985): 208-209.

237. Burris, L., L. C. Walters, "The Proposed Fuel-Cycle for the Integral Fast-Reactor," Transactions of the American Nuclear Society, Vol. 49, (1985): 90-92.

238. Johnson, T. R., W. E. miller, R. K. Steunenberg, "Proposed Methods for Treating High-Level Pyrochemical Process Wastes," Transactions of the American Nuclear Society, Vol. 50, (1985): 206-208. 
239. Miller, W. E., T. R. Johnson, Z. Tomczuk, "Choice of Pyroprocess for Integral Fast Reactor Fuel," American Nuclear Society, Winter Meeting, San Francisco, CA, November 10-14, 1985.

240. Burris, L., R. K. Steunenberg, W. E. Miller, "The Application of Electrorefining for Recovery and Purification of Fuel Discharged from the Integral Fast Reactor," American Institute of Chemical Engineers (AIChE) National Meeting, Miami Beach, FL, November 2-7, 1986.

241. Johnson, T. R., "Plans for the Development of the IFR Fuel Cycle," $6^{\text {th }}$ Annual Plutonium Pyrochemical Workshop, Los Alamos, NM, October 7-8, 1986.

242. Lineberry, M., R. D. Phipps, “A Demonstration Facility for the IFR Fuel Cycle,” International Conference on Fuel Reprocessing and Waste Management (RECOD'87), Paris, France, August 23-27, 1987.

243. Johnson, I., "The Thermodynamics of Pyrochemical Processes for Liquid Metal Reactor Fuel Cycle," Journal of Nuclear Materials, Vol. 154, (1988): 169-180.

244. Burris, L., W. E. Miller, E. C. Gay, J. P. Ackerman, Z. Tomczuk, J. E. Herceg, W. J. Kann, “Update on Development of the IFR Pyroprocess," American Nuclear Society Annual Meeting, San Diego, CA, June 12-16, 1988.

245. Ackerman, J. P., "PYRO, A System for Modeling Fuel Reprocessing," Transactions of the American Nuclear Society, Vol. 60, (1989): 168-169.

246. Liaw, J. R., J. P. Ackerman, "PYRO - New Capability for Isotopic Mass Tracking in Pyroprocess Simulation," Transactions of the American Nuclear Society, Vol. 60, (1989): 169-170.

247. Lineberry, M., R. D. Phipps, "Preparations for the IFR Fuel Cycle Demonstration," Transactions of the American Nuclear Society, Vol. 60, (1989): 170-171.

248. Liaw, J. R., J. P. Ackerman, "PYRO - New Capability for Isotopic Mass Tracking in Pyroprocess Simulation," International Conference on the Physics of Reactors: Operation, Design and Computation, Marseilles, France, April 23-26, 1990.

249. Peterson, D. E., B. R. Seidel, “The Safety Basis of the Integral Fast Reactor Program,” Nuclear Safety, Vol. 10, (1990): 443-458.

250. Lineberry, M. J., R. D. Phipps, R. H. Rigg, R. W. Benedict, M. D. Carnes, J. E. Herceg, R. E. Holtz, "IFR Fuel Cycle Demonstration in the EBR-II Fuel Cycle Facility," International Conference on Fast Reactors and Related Fuel Cycles, FR'91, Volume II, Kyoto, Japan, October 28 - November 1, 1991.

251. Ackerman, J. P., J. L. Settle, "Partition of Lanthanum and Neodymium Metals and Chloride Salts Between Molten Cadmium and Molten LiCl-KCl Eutectic," Journal of Alloys and Compounds, Vol. 177, (1991): 129-141.

252. Johnson, T. R., J. E. Battles, "Waste Management in the IFR Fuel Cycle," Waste Management, Tucson, AZ, February 24-28, 1991.

253. Battles, J. E., W. E. Miller, E. C. Gay, "Pyrometallurgical Processing of Integral Fast Reactor Metal Fuels," $3{ }^{\text {rd }}$ International Conference on Nuclear Fuel Reprocessing and Waste Management (RECOD'91), Sendai, Japan, April 14-18, 1991.

254. Lineberry, M. J., D. R. Pedersen, L. C. Waiters, J. E. Cahalan, "Advances by the Integral Fast Reactor Program,” American Power Conference, Chicago, IL, April 20 - May 1, 1991. 
255. Orechwa, Y., C. H. Adams, A. M. White, "Mass Tracking and Materials Accounting in the Integral Fast Reactor (IFR)," $32^{\text {nd }}$ Annual Meeting, Institute of Nuclear Materials Management, New Orleans, LA, July 28-31, 1991.

256. Ackerman, J. P., "Chemical Basis for Pyrochemical Reprocessing of Nuclear Fuel," Industrial \& Engineering Chemistry Research, Vol. 30, (1991): 141-145.

257. Hannum, W. H., "IFR Modern Nuclear Fuel Cycle," American Society of Mechanical Engineers Annual Meeting, San Diego, CA, October 6-10, 1991.

258. Westphal, B. R., R. W. Benedict, "Process Evaluations for Uranium Recovery from Scrap Material,” TMS Annual Meeting, San Diego, CA, Mar 1-5, 1992.

259. Laidler, J. J., W. E. Miller, T. R. Johnson, J. P. Ackerman, J. E. Battles, "IFR Fuel Cycle Pyroprocess Development," OECD/NEA Meeting: International Information Exchange Program on Actinide and Fission Separation and Transmutation, Chicago, IL, November 11-13, 1992.

260. Lineberry, M. J., R. D. Phipps, R. W. Benedict, J. J. Laidler, J. E. Battles, W. E. Miller, "Fuel Cycle and Waste Management Demonstration in the IFR Program," 1992 ANS/ASME Nuclear Energy Conference, San Diego, CA, August 23-26, 1992.

261. Battles, J. E., W. E. Miller, M. J. Lineberry, R. D. Phipps, "IFR Fuel Cycle," $54^{\text {th }}$ Annual American Power Conference, Chicago, IL, April 3-15, 1992.

262. Ackerman, J. P., J. L. Settle, "Distribution of Plutonium, Americium, and Several Rare Earth Fission Product Elements Between Liquid Cadmium and LiCl-KCl Eutectic," Journal of Alloys and Compounds, Vol. 199, (1993): 77-84.

263. Johnson, T. R., M. A. Lewis, A. E. Newman, J. J. Laidler, "Treatment of High-Level Wastes from the IFR Fuel Cycle," American Chemical Society Meeting $\left(204^{\text {th }}\right)$, Chemical Pretreatment of Nuclear Waste for Disposal, Washington, DC, August 23-28, 1992.

264. Chow, L. S., J. K. Basco, J. P. Ackerman, T. J. Johnson, "Molten Salt/Metal Extractions for Recovery of Transuranic Elements," International Symposium on Energy, Environment, and Information Management, Argonne National Laboratory, Argonne, IL, September 15-18, 1992.

265. Pierce, R. D., T. R. Johnson, C. C. McPheeters, J. J. Laidler, "Progress in the Pyrochemical Processing of Spent Nuclear-Fuels," JOM, Vol. 45, (1993): 40-44.

266. Benedict, R. W., K. M. Goff, "Transuranic Material Recovery in the Integral Fast Reactor Fuel Cycle Demonstration,” Waste Management 1993, Tucson, AZ, February 28 - March 4, 1993.

267. Rigg, R. H., "IFR Fuel Cycle Process Equipment Design Environment and Objectives," American Nuclear Society Topical Meeting on Robotics and Remote Systems, Knoxville, TN, April 25-30, 1993.

268. Goff, K. M., A. Schneider, J. E. Battles, "Cadmium Transport Through Molten Salt in the Reprocessing of Spent Fuel for the Integrated Fast Reactor," Nuclear Technology, Vol. 102, (1993): 331-340.

269. Mariani, R. D., R. M. Lell, R. W. Benedict, R. B. Turski, "Criticality Safety Strategy for the Fuel Cycle Facility Electrorefiner at Argonne National Laboratory West," International Conference on Future Nuclear Systems, Seattle, Washington, September 12-17, 1993. 
270. Ackerman, J. P., T. R. Johnson, "Partition of Actinides and Fission Products Between Metal and Molten Salt Phases: Theory, Measurement, and Application to IFR Pyroprocess Development," Actinides 1993, Santa Fe, NM, September 19-24, 1993.

271. Benedict, R. W., D. A. Tate, "Fuel Cycle Facility Control System for the Integral Fast Reactor Program," Joint Power Generation Conference, Kansas City, MO, October 17-21, 1993.

272. Goff, K. M., R. D. Mariani, R. W. Benedict, K. H. Park, J. P. Ackerman, "Simulated First Operating Campaign for the Integral Fast Reactor Fuel Cycle Demonstration," Global 93, Seattle, WA, September 12-17, 1993.

273. Benedict, R. W., J. R. Krsul, R. D. Mariani, K. Park, G. M. Teske, "Small-Scale Irradiated Fuel Electrorefining," Global 93, Seattle, WA, September 12-17, 1993.

274. Chow, L. S., J. K. Basco, J. P. Ackerman, T. J. Johnson, "Continuous Extraction of Molten Chloride Salts with Liquid Cadmium Alloys," Global 93, Seattle, WA, September 12-17, 1993.

275. Laidler, J. J., J. E. Battles, W. E. Miller, E. C. Gay, "Development of IFR Pyroprocessing Technology," Global 93, Seattle, WA, September 12-17, 1993.

276. Gay, E. C., Z. Tomczuk, W. E. Miller, "Plant-Scale Anodic Dissolution of Unirradiated N-Reactor Fuel," Global 93, Seattle, WA, September 12-17, 1993.

277. Lineberry, M. J., R. D. Phipps, H. F. McFarlane, "Status of IFR Fuel Cycle Demonstration," Global 93, Seattle, WA, September 12-17, 1993.

278. Mariani, R. D., R. W. Benedict, R. M. Lell, R. B. Turski, E. K. Fujita, "Criticality Safety Strategy and Analysis Summary for the Fuel Cycle Facility Electrorefiner at Argonne National Laboratory West," Global 93, Seattle, WA, September 12-17, 1993.

279. Laidler, J. J., "Pyrochemical Recovery of Actinides," $55^{\text {th }}$ Annual American Power Conference, Chicago, IL, April 13-15, 1993.

280. Ackerman, J. P., T. R. Johnson, "New High-Level Waste Management Technology for IFR Pyroprocessing Wastes," Global 93, Seattle, WA, September 12-17, 1993.

281. Laidler, J. J., "The Integral Fast Reactor: A Practical Approach to Waste Management," Global 93, Seattle, WA, September 12-17, 1993.

282. Westphal, B. R., R. W. Benedict, “Actinide Recovery Technique Utilizing Electromechanical Processes," TMS Annual Meeting, International Symposium on Actinide Processing: Methods and Materials, San Francisco, CA, February 27 - March 3, 1994.

283. Battles, J. E., J. J. Laidler, C. C. McPheeters, W. E. Miller, "Pyrometallurgical Process for Recovery of Actinide Elements," The Minerals, Metals, and Materials Society, International Symposium on Actinides Processing: Methods and Materials, San Francisco, CA, February 27 March 3, 1994.

284. Courtney, J. C., M. J. Lineberry, "Behavior of Actinides in the Integral Fast Reactor Fuel Cycle," $207^{\text {th }}$ National Meeting of the American Chemical Society, San Diego, CA, March 13-18, 1994.

285. Gay, E. C., W. E. Miller, J. J. Laidler, "Method for Removal of Heavy Metal from Molten Salt in IFR Fuel Pyroprocessing," International Conference on Nuclear Fuel Reprocessing and Waste Management, London, UK, April 24-28, 1994. 
286. Gay, E. C., W. E. Miller, J. J. Laidler, "Method for Removal of Heavy Metal from Molten Salt," Electrochemical Society Conference International Symposium on Molten Salt, San Francisco, CA, May 8-13, 1994.

287. Willit, J. L., Z. Tomczuk, W. E. Miller, J. J. Laidler, "Ion Replacement Electrorefining," Electrochemical Society Meeting, San Francisco, CA, May 22-27, 1994.

288. Adams, C. H., J. C. Beitel, G. Birgersson, R. G. Bucher, C. B. Carrico, T. A. Daly, R. W. Keyes, "The Mass Tracking System for the Integral Fast Reactor Fuel Cycle," $35^{\text {th }}$ Annual Meeting of the Institute for Nuclear Materials Management, Naples, Florida, July 17-20, 1994.

289. Orechwa, Y., R. G. Bucher, "Measurement Control Design and Performance Assessment in the Integral Fast Reactor Fuel Cycle," $35^{\text {th }}$ Annual Meeting of the Institute for Nuclear Materials Management, Naples, Florida, July 17-20, 1994.

290. Benedict, R. W., K. M. Goff, H. F. McFarlane, "Status of the Integral Fast Reactor Fuel Cycle Demonstration and Waste Management Practices," International Nuclear and Hazardous Waste Management Conference, Atlanta, GA, August 14-18, 1994.

291. Ackerman, J. P., "Chemistry of Pyroprocessing for Nuclear Waste Transmutation," International Conference on Accelerator-Driven Transmutation Technologies and Applications, Las Vegas, NV, July 25 - August 1, 1994.

292. Yacount, A. M., R. G. Bucher, Y. Orechwa, "Fuel Conditioning Facility Material Accountancy," $36^{\text {th }}$ Annual Meeting of the Institute for Nuclear Materials Management, Palm Desert, California, July 9-12, 1995.

293. Westphal, B. R., "Distillation Modeling of a Uranium Refining Process," TMS Annual Meeting, Light Metals, Anaheim, CA, February 4-8, 1996.

294. Mariani, R. D., R. W. Benedict, R. M. Lell, R. B. Turski, E. K. Fujita, "Criticality Safety Strategy and Analysis Summary for the Fuel Cycle Facility Electrorefiner at Argonne National Laboratory West," Nuclear Technology, Vol. 114, (1996): 224-234.

295. Laidler, J. J., J. E. Battles, W. E. Miller, J. P. Ackerman, E. L. Carls, "Development of Pyroprocessing Technology," Progress in Nuclear Energy, Vol. 31, No. 1-2, (1997): 131-140.

296. Ackerman, J. P., T. R. Johnson, L. S. H. Chow, E. L. Carls, W. H. Hannum, J. J. Laidler, "Treatment of Wastes in the IFR Fuel Cycle," Progress in Nuclear Energy, Vol. 31, No. 1-2, (1997): 141-154.

297. McFarlane, H. F., M. J. Lineberry, "The IFR Fuel Cycle Demonstration," Progress in Nuclear Energy, Vol. 31, No. 1-2, (1997): 155-173.

298. Pierce, R. D., J. P. Ackerman, G. K. Johnson, T. P. Mulcahey, D. S. Poa, "Recycle of LWR Actinides to an IFR," 3rd International Conference on Nuclear Fuel Reprocessing and Waste Management (RECOD’91), Sendai, Japan, April 14-18, 1991.

299. McPheeters, C. C., R. D. Pierce, T. P. Mulccahey, "Application of the Pyrochemical Process to Recycle of Actinides from LWR Spent Fuel," Progress in Nuclear Energy, Vol. 31, No. 1-2, (1997): 175-186.

300. McPheeters, C. C., R. D. Pierce, G. K. Johnson, D. S. Pea, P. S. Maiya, "Pyrochemical Processes for LWR Spent Fuel," OECD/NEA Meeting: International Information Exchange Program on Actinide and Fission Separation and Transmutation, Chicago, IL, November 11-13, 1992. 
301. "Argonne National Laboratory's Redirected Nuclear R\&D Program: Program Plan," Argonne National Laboratory, February 13, 1994.

302. "The Integral Fast Reactor Program and Related Facilities: Termination Plan," Argonne National Laboratory, February 13, 1995.

303. $103^{\text {rd }}$ Congress, $1^{\text {st }}$ Session, H.R. 2365.

304. "An Assessment of Continued R\&D Into an Electrometallurgical Approach for Treating DOE Spent Nuclear Fuel," Committee on Electrometallurgical Techniques for DOE Spent Fuel Treatment, Board on Chemical Sciences and Technology. Commission on Physical Sciences, Mathematics, and Applications, National Research Council, 1995.

305. "An Evaluation of the Electrometallurgical Approach for Treatment of Excess Weapons Plutonium," Committee on Electrometallurgical Techniques for DOE Spent Fuel Treatment, Board on Chemical Sciences and Technology. Commission on Physical Sciences, Mathematics, and Applications, National Research Council, 1996.

306. "Electrometallurgical Techniques for DOE Spent Fuel Treatment: Status Report on Argonne National Laboratory's R \& D Activity Through Spring 1997," Committee on Electrometallurgical Techniques for DOE Spent Fuel Treatment, Board on Chemical Sciences and Technology. Commission on Physical Sciences, Mathematics, and Applications, National Research Council, 1997.

307. "Electrometallurgical Techniques for DOE Spent Fuel Treatment: Spring 1998 Status on Argonne National Laboratory's R \& D Activity," Committee on Electrometallurgical Techniques for DOE Spent Fuel Treatment, Board on Chemical Sciences and Technology. Commission on Physical Sciences, Mathematics, and Applications, National Research Council, 1998.

308. Presentations from the National Research Council, Committee on Electrometallurgical Techniques for DOE Spent Fuel Treatment Meeting, Argonne National Laboratory-West, June 25-26, 1998.

309. "Electrometallurgical Techniques for DOE Spent Fuel Treatment: Status Report on Argonne National Laboratory's R \& D Activity as of Fall 1998," Committee on Electrometallurgical Techniques for DOE Spent Fuel Treatment, Board on Chemical Sciences and Technology. Commission on Physical Sciences, Mathematics, and Applications, National Research Council, 1999.

310. "Electrometallurgical Techniques for DOE Spent Fuel Treatment: An Assessment of Waste Form Development and Characterization," Committee on Electrometallurgical Techniques for DOE Spent Fuel Treatment, Board on Chemical Sciences and Technology. Commission on Physical Sciences, Mathematics, and Applications, National Research Council, 1999.

311. "Electrometallurgical Techniques for DOE Spent Fuel Treatment Final Report," Committee on Electrometallurgical Techniques for DOE Spent Fuel Treatment, Board on Chemical Sciences and Technology. Commission on Physical Sciences, Mathematics, and Applications, National Research Council, April 18, 2000.

312. "Department of Energy Programmatic Spent Nuclear Fuel Management and Idaho National Engineering Laboratory Environmental Restoration and Waste Management Programs Final Environmental Impact Statement, Summary," U.S. Department of Energy Office of Environmental Management, Idaho Operations Office, DOE/EIS-0203-F, April 1995.

313. "Department of Energy Programmatic Spent Nuclear Fuel Management and Idaho National Engineering Laboratory Environmental Restoration and Waste Management Programs Final 
Environmental Impact Statement, Volume 1," U.S. Department of Energy Office of Environmental Management, Idaho Operations Office, DOE/EIS-0203-F, April 1995.

314. "Department of Energy Programmatic Spent Nuclear Fuel Management and Idaho National Engineering Laboratory Environmental Restoration and Waste Management Programs Final Environmental Impact Statement, Volume 1, Appendix A to C," U.S. Department of Energy Office of Environmental Management, Idaho Operations Office, DOE/EIS-0203-F, April 1995.

315. "Department of Energy Programmatic Spent Nuclear Fuel Management and Idaho National Engineering Laboratory Environmental Restoration and Waste Management Programs Final Environmental Impact Statement, Volume 1, Appendix D to F," U.S. Department of Energy Office of Environmental Management, Idaho Operations Office, DOE/EIS-0203-F, April 1995.

316. "Department of Energy Programmatic Spent Nuclear Fuel Management and Idaho National Engineering Laboratory Environmental Restoration and Waste Management Programs Final Environmental Impact Statement, Volume 2, Part A," U.S. Department of Energy Office of Environmental Management, Idaho Operations Office, DOE/EIS-0203-F, April 1995.

317. "Department of Energy Programmatic Spent Nuclear Fuel Management and Idaho National Engineering Laboratory Environmental Restoration and Waste Management Programs Final Environmental Impact Statement, Volume 3, Part A," U.S. Department of Energy Office of Environmental Management, Idaho Operations Office, DOE/EIS-0203-F, April 1995.

318. "Programmatic Spent Nuclear Fuel Management and Idaho National Engineering Laboratory Environmental Restoration and Waste Management: Record of Decision," Federal Register, Vol. 60, No. 105, June 1, 1995.

319. "Environmental Assessment: Electrometallurgical Treatment Research and Demonstration Project in the Fuel Conditioning Facility at Argonne National Laboratory - West," U.S. Department of Energy Office of Nuclear Energy, Science, and Technology, DOE/EA-1148, May 15, 1996.

320. "Technical Strategy for the Management of INEEL Spent Nuclear Fuel: A Report of the INEEL Spent Nuclear Fuel Task Team," Prepared for the Department of Energy Office of Spent Fuel Management, March 1997.

321. "Notice of Intent to Prepare an Environmental Impact Statement for Electrometallurgical Treatment of Sodium-Bonded Spent Nuclear Fuel in the Fuel Conditioning Facility at Argonne National Laboratory-West, Idaho National Engineering and Environmental Laboratory, Idaho," Federal Registry, Vol. 64, No. 34, February 22, 1999.

322. "Final Environmental Impact Statement for the Treatment and Management of Sodium-Bonded Spent Nuclear Fuel: Summary," U.S. Department of Energy Office of Nuclear Energy, DOE/EIS0306, July 2000.

323. "Final Environmental Impact Statement for the Treatment and Management of Sodium-Bonded Spent Nuclear Fuel: Volume 1," U.S. Department of Energy Office of Nuclear Energy, DOE/EIS0306, July 2000.

324. "Final Environmental Impact Statement for the Treatment and Management of Sodium-Bonded Spent Nuclear Fuel: Volume 2," U.S. Department of Energy Office of Nuclear Energy, DOE/EIS0306, July 2000.

325. Laidler, J. J., "Conditioning of Spent Nuclear Fuel for Permanent Disposal," Dixy Lee Ray Memorial Symposium on Science-Based Environmental Management, Seattle, WA, August 30 September 2, 1994. 
326. Goff, K. M., R. W. Benedict, D. Levinskas, "Spent Fuel Treatment at ANL-West," DOE Spent Nuclear Fuel Meeting: Challenges and Initiatives, Salt Lake City, Utah, December 13-16, 1994.

327. Laidler, J. J., "Pyrochemical Processing of DOE Spent Nuclear Fuel," American Nuclear Society, Proceedings of DOE Spent Nuclear Fuel: Challenges and Initiatives, Salt Lake City, UT, December 13-16, 1994.

328. Westphal, B. R., D. D. Keiser, R. H. Rigg, D. V. Laug, "Production of Metal Waste Forms For Spent Fuel Treatment," American Nuclear Society, Proceedings of DOE Spent Nuclear Fuel: Challenges and Initiatives, Salt Lake City, UT, December 13-16, 1994.

329. McFarlane, H. F., M. J. Lineberry, "Spent Fuel Pyroprocessing Demonstration," Fuel Management and Handling Conference, Edinburgh, UK, March 20-22, 1995.

330. Goff, K. M., R. D. Mariani, N. L. Bonomo, "Depleted Uranium Start-Up of Spent Fuel Treatment Operation at Argonne National Laboratory West," Winter Meeting of the American Nuclear Society, San Francisco, CA, October 29 - November 2, 1995.

331. Lineberry, M. J., H. F. McFarlane, “The EBR-II Spent Fuel Treatment Program,” Global 1995, Versailles, France, September 11-14, 1995.

332. Ackerman, J. P., C. C. McPheeters, “Advanced Waste Forms from Spent Nuclear Fuel," American Nuclear Society International Conference on Evaluation of Emerging Nuclear Fuel Cycle Systems, Versailles, France, September 11-14, 1995.

333. Abraham, D. P., S. M. McDeavitt, J. Park, "Metal Waste Forms From the Electrometallurgical Treatment of Spent Nuclear Fuel," American Nuclear Society Topical Meeting on DOE Spent Nuclear Fuel and Fissile Material Management, Reno, Nevada, June 16-20, 1996.

334. Chow, L. S., J. K. Basco, E. L. Carls, T. J. Johnson, "Testing of Pyrochemical Centrifugal Contactors," American Nuclear Society Topical Meeting on DOE Spent Nuclear Fuel and Fissile Material Management, Reno, Nevada, June 16-20, 1996.

335. Goff, K. M., R. D. Mariani, D. Vaden, N. L. Bonomo, S. S. Cunningham, "Fuel Conditioning Facility Electrorefiner Start-Up Results," American Nuclear Society Topical Meeting on DOE Spent Nuclear Fuel and Fissile Material Management, Reno, Nevada, June 16-20, 1996.

336. Goff, K. M., R. W. Benedict, K. Bateman, M. A. Lewis, C. Pereira, C. A. Musick, "Spent Fuel Treatment and Mineral Waste Form Development at Argonne National Laboratory-West," SPECTRUM 1996: International Conference on Nuclear and Hazardous Waste Management, Seattle, WA, August 18-23, 1996.

337. Adams, C. H., J. C. Beitel, G. Birgersson, R. G. Bucher, K. L. Derstine, B. J. Toppel, R. W. Goin, R. W. Keyes, M. A. Volmer, "The Mass Tracking System - Computerized Support for MC\&A and Operations at FCF," American Nuclear Society Topical Meeting on DOE Spent Nuclear Fuel and Fissile Material Management, Reno, Nevada, June 16-20, 1996.

338. Liaw, J. R., S. X. Li, R. W. Benedict, "FCFPYRO - Simulation of the First Year FCF Hot Operation Plan," American Nuclear Society Topical Meeting on DOE Spent Nuclear Fuel and Fissile Material Management, Reno, Nevada, June 16-20, 1996.

339. Orechwa, Y., R. G. Bucher, "Fuel Conditioning Facility Electrorefiner Special Nuclear Mass Estimation," American Nuclear Society Topical Meeting on DOE Spent Nuclear Fuel and Fissile Material Management, Reno, Nevada, June 16-20, 1996. 
340. Orechwa, Y., R. G. Bucher, "Performance of the Fuel Conditioning Facility Electronic In-Cell Mass Balances," American Nuclear Society Topical Meeting on DOE Spent Nuclear Fuel and Fissile Material Management, Reno, Nevada, June 16-20, 1996.

341. Vaden, D., R. W. Benedict, K. M. Goff, R. W. Keyes, R. D. Mariani, "Material Accountancy in an Electrometallurgical Fuel Conditioning Facility," American Nuclear Society Topical Meeting on DOE Spent Nuclear Fuel and Fissile Material Management, Reno, Nevada, June 16-20, 1996.

342. Westphal, B. R., D. V. Laug, A. R. Brunsvold, P. D. Roach, "Initial Cathode Processing Experiences and Results for the Treatment of Spent Fuel," American Nuclear Society Topical Meeting on DOE Spent Nuclear Fuel and Fissile Material Management, Reno, Nevada, June 16-20, 1996.

343. Ahluwalia, R. K., H. K. Geyer, "GC Computer Code for Flow Sheet Simulation of Pyrochemical Processing of Spent Nuclear Fuels," Nuclear Technology, Vol. 116, (1996): 180-195.

344. Benedict, R. W., S. P. Henslee, "EBR-II Spent-Fuel Demonstration Project," American Nuclear Society Winter Meeting, Albuquerque, NM, November 16-20, 1997.

345. McFarlane, H. F., K. M. Goff, F. S. Felicione, C. C. Dwight, D. B. Barber, "Hot Demonstration of Nuclear Waste Processing Technologies," JOM, Vol. 49, (1997): 14-21 and 83.

346. Totemeier, T. C., R. D. Mariani, "Morphologies of Uranium and Uranium-Zirconium Electrodeposits," Journal of Nuclear Materials, Vol. 250, (1997): 131-146.

347. Benedict, R. W., M. J. Lineberry, H. F. McFarlane, R. H. Rigg, "Hot Startup Experience with Electrometallurgical Treatment of Spent Fuel," Global 1997, Yokohama, Japan, October 5-10, 1997.

348. Mariani, R. D., S. X. Li, D. Vaden, B. R. Westphal, D. W. Maddison, "Selected Uranium Product Characteristics for the EBR-II Spent Fuel Treatment Program," Transactions of the American Nuclear Society, Vol. 77, (1997): 76-78.

349. Westphal, B. R., D. Vaden, J. R. Liaw, J. R. Krsul, "Initial Results for Uranium Product from EBR-II Spent Fuel Treatment," Transactions of the American Nuclear Society, Vol. 76, (1997): 74-76.

350. Mariani, R. D., D. Vaden, "Initial Electrorefining Operations with Spent Fuel from EBR-II at ANLWest," Transactions of the American Nuclear Society, Vol. 76, (1997): 70-72.

351. Westphal, B. R., R. D. Mariani, J. R. Krsul, "Uranium Product Compositions for the EBR-II Spent Fuel Treatment Program," Transactions of the American Nuclear Society, Vol. 77, (1997): 78-79.

352. Keiser, D. D., B. R. Westphal, R. S. Herbst, S. G. Johnson, "Initial Results of Metal Waste-Form Development Activities at ANL-West," Transactions of the American Nuclear Society, Vol. 77, (1997): 80-81.

353. Ackerman, J. P., L. S. H. Chow, S. M. McDeavitt, C. Pereira, R. H. Woodman, "Isolating Wastes in the Electrometallurgical Treatment of Spent Nuclear Fuel," JOM, Vol. 49, (1997): 26-28.

354. Benedict, R. W., H. F. McFarlane, "EBR-II Spent Fuel Treatment Demonstration Project Status," Radwaste Solutions, Vol. 5, (1998): 23-28.

355. Li, S. X., T. Sofu, R. A. Wigeland, "Experimental Observations to the Electrical Field for Electrorefining of Spent Nuclear Fuel in the Mark-IV Electrorefiner," Electrochemical Society $11^{\text {th }}$ International Symposium on Molten Salts, San Diego, CA, May 3-8, 1998. 
356. Benedict, R. W., S. P. Henslee, "EBR-II Spent Fuel Treatment Demonstration Project Status," $5^{\text {th }}$ International Conference on Recycling, Conditioning, and Disposal (RECOD'98), Nice, France, October 25-28, 1998.

357. Benedict, R. W., H. F. McFarlane, "Success Criteria for the Electrometallurgical Treatment Demonstration," American Nuclear Society Topical Meeting on DOE Spent Nuclear Fuel and Fissile Materials Management, Charleston, SC, September 8-11, 1998.

358. Battisti, T. J., K. M. Goff, K. J. Bateman, M. F. Simpson, J. P. Lind, "Ceramic Waste Form Production and Testing at ANL-West," American Nuclear Society Topical Meeting on DOE Spent Nuclear Fuel and Fissile Materials Management, Charleston, SC, September 8-11, 1998.

359. Herrmann, S. D., R. W. King, K. R. Durstine, C. S. Eberle, "Pilot-Scale Equipment Development for Lithium-Based Reduction of Spent Oxide Fuel," American Nuclear Society Topical Meeting on DOE Spent Nuclear Fuel and Fissile Materials Management, Charleston, SC, September 8-11, 1998.

360. Keiser, D. D., B. R. Westphal, "Consolidation of Cladding Hulls from the Electrometallurgical Treatment of Spent Fuel," American Nuclear Society Topical Meeting on DOE Spent Nuclear Fuel and Fissile Materials Management, Charleston, SC, September 8-11, 1998.

361. Li, S. X., R. D. Mariani, T. J. Battisti, R. S. Herbst, "Initial Results for Electrochemical Dissolution of Spent EBR-II Fuel," American Nuclear Society Topical Meeting on DOE Spent Nuclear Fuel and Fissile Materials Management, Charleston, SC, September 8-11, 1998.

362. McKnight, R. D., B. J. Topple, J. R. Krsul, "Characterization of Spent EBR-II Driver Fuel," American Nuclear Society Topical Meeting on DOE Spent Nuclear Fuel and Fissile Materials Management, Charleston, SC, September 8-11, 1998.

363. Vaden, D., "Fuel Conditioning Facility Electrorefiner Cadmium Vapor Trap Operation," American Nuclear Society Topical Meeting on DOE Spent Nuclear Fuel and Fissile Materials Management, Charleston, SC, September 8-11, 1998.

364. Westphal, B. R., J. R. Krsul, D. W. Maddison, "Salt Distillation Efficiencies for Cathode Processing of Spent Nuclear Fuel," American Nuclear Society Topical Meeting on DOE Spent Nuclear Fuel and Fissile Materials Management, Charleston, SC, September 8-11, 1998.

365. Yacout, A. M., R. S. Herbst, T. J. Battisti, R. D. Mariani, "FCF Metallic Waste Data Uncertainty Analysis," American Nuclear Society Topical Meeting on DOE Spent Nuclear Fuel and Fissile Materials Management, Charleston, SC, September 8-11, 1998.

366. Ahluwalia, R. K., T. Q. Hua, H. K. Geyer, "Behavior of Uranium and Zirconium in Direct Transport Tests with Irradiated EBR-II Fuel,” Nuclear Technology, Vol. 126, (1999): 289-302.

367. Yacout, A. M., R. G. Bucher, R. D. McKnight, R. D. Mariani, D. Vaden, B. Westphal, T. Battisti, J. R. Krsul, "Nuclear Material Estimation and Uncertainties for the Spent Fuel Treatment at FCF," $40^{\text {th }}$ Annual Meeting of the Institute of Nuclear Materials Management, Phoenix, AZ, July 25-29, 1999.

368. Herrmann, S. D., K. R. Durstine, M. F. Simpson, D. R. Wahlquist, "Pilot-Scale Equipment Development for Pyrochemical Treatment of Spent Oxide Fuel," Global 1999, Jackson, WY, August 29 - September 3, 1999. 
369. Yacout, A. M., R. D. McKnight, R. D. Mariani, B. Westphal, T. Battisti, "MC\&A Sampling Activities at FCF," $6^{\text {th }}$ International Conference on Facility Operations-Safeguards Interface, Jackson Hole, WY, September 20-24, 1999.

370. Westphal, B. R., R. D. Mariani, D. Vaden, S. R. Sherman, S. X. Li, "Recent Advances During the Treatment of Spent EBR-II Fuel," American Nuclear Society Topical Meeting on DOE Spent Nuclear Fuel and Fissile Materials Management, San Diego, CA, June 4-8, 2000.

371. Brunsvold, A. R., P. D. Roach, B. R. Westphal, "Design and Development of a Cathode Processor for Electrometallurgical Treatment of Spent Nuclear Fuel," $8^{\text {th }}$ International Conference on Nuclear Engineering (ICONE 8), Baltimore, MD, April 2-6, 2000.

372. Goff, K. M., R. W. Benedict, S. G. Johnson, R. D. Mariani, M. F. Simpson, B. R. Westphal, "Electrometallurgical Treatment Demonstration at ANL-West," American Nuclear Society Topical Meeting on DOE Spent Nuclear Fuel and Fissile Material Management, San Diego, CA, June 4-8, 2000 .

373. Li, S. X., D. Vaden, R. D. Mariani, T. A. Johnson, "Experimental Observations on the Role of the Cadmium Pool in Mark-IV ER," American Nuclear Society Topical Meeting on DOE Spent Nuclear Fuel and Fissile Material Management, San Diego, CA, June 4-8, 2000.

374. McFarlane, H. F., R. W. Benedict, "Management of Super-Grade Plutonium in Spent Nuclear Fuel," American Nuclear Society Topical Meeting on DOE Spent Nuclear Fuel and Fissile Material Management, San Diego, CA, June 4-8, 2000.

375. Westphal, B. R., R. D. Mariani, "Uranium Processing During the Treatment of Sodium-Bonded Spent Nuclear Fuel,” JOM, Vol. 52, (2000): 21-25.

376. Benedict, R. W., S. P. Henslee, S. E. Aumeier, D. B. Barber, D. S. Lee, "Environmental-Nuclear Technology Activities at Argonne National Laboratory - West," Waste Management Conference, Tucson, AZ, February 25 - March 1, 2001.

377. Johnson, S. G., K. M. Goff, W. L. Ebert, S. McDeavitt, "Process Implementation and Qualification of Electrometallurgical High Level Waste Forms," Waste Management Conference, Tucson, AZ, February 25 - March 1, 2001.

378. Benedict, R. W., H. F. McFarlane, K. M. Goff, "Electrometallurgical Treatment of Sodium-Bonded Spent Nuclear Fuel," Global 2001, Paris, France, September 9-13, 2001.

379. Herrmann, S. D., R. W. King, K. R. Durstine, C. S. Ebert, "Pilot-Scale Equipment Development for Pyrochemical Reduction of Spent Oxide Fuel," Actinide Separations Conference. Chattanooga, TN, April 20-23, 1998.

380. Simpson, M. F., T. J. Battisti, "Adsorption of Eutectic LiCl-KCl into Zeolite 4A Using a Mechanically Fluidized Vacuum System," Industrial and Engineering Chemistry Research, Vol. 38, (1999): 2496-2473.

381. Keiser, D. D., R. D. Mariani, "Zr-Rich Layers Electrodeposited onto Stainless Steel Cladding During the Electrorefining of EBR-II Fuel," Journal of Nuclear Materials, Vol. 270, (1999): 279289.

382. Herrmann, S. D., K. R. Dusrstine, M. F. Simpson, D. R. Wahlquist, "Pilot-Scale Equipment Development for Pyrochemical Treatment of Spent Oxide Fuel," Global 1999, Jackson Hole, WY, August 29 - September 3, 1999. 
383. Li, S. X., "Anodic Behaviors of Uranium and Zirconium During Electrorefining Spent Nuclear Fuel in Molten Salt," American Society of Mechanical Engineers 8th International Conference on Nuclear Engineering (ICONE 8), Baltimore, Maryland, April 2-6, 2000.

384. Li, S. X., T. Sofu, T. R. Johnson, R. A. Wigeland, D. V. Laug, "Experimental Observations on Electrorefining Spent Nuclear Fuel in Molten LiCl-KCl/Liquid Cadmium System," Journal of New Materials for Electrochemical Systems, Vol. 3, (2000): 259-268.

385. Totemeier, T. C., N. L. Dietz, "Morphologies of Uranium Deposits Produced During Electrorefining of EBR-II Spend Nuclear Fuel," American Nuclear Society Topical Meeting on DOE Spent Nuclear Fuel and Fissile Material Management, San Diego, CA, June 4-8, 2000.

386. Totemeier, T. C., S. D. Herrmann, "Materials Compatibility Testing for a Pilot-Scale Oxide Reduction System," TMS Fall Meeting, Materials Issues in Nuclear Waste Management, St. Louis, MO, October 9-12, 2000.

387. McDeavitt, S. M., K. M. Goff, D. P. Abraham, W. L. Ebert, M. C. Hash, S. G. Johnson, D. D. Keiser, D. Lexa, T. P. O’Holleran, M. K. Richmann, M. F. Simpson, B. R. Westphal, “The Development, Processing and Qualification of Ceramic and Metal Waste Forms from the Electrometallurgical Treatment of Spent Nuclear Fuel," TMS Fall Meeting, Materials Issues in Nuclear Waste Management, St. Louis, MO, October 9-12, 2000.

388. Ahluwalia, R. K., T. Q. Hua, H. K. Geyer, "Removal of Zirconium in Electrometallurgical Treatment of Experimental Breeder Reactor II Spent Fuel,” Nuclear Technology, Vol. 133, (2001): 103-119.

389. Simpson, M. F., K. M. Goff, S. G. Johnson, K. J. Bateman, T. J. Battisti, K. L. Toews, S. M. Frank, T. L. Moschetti, T. P, O’Holleran, W. Sinkler, A Description of the Ceramic Waste Form Production Process form the Demonstration Phase of the Electrometallurgical Treatment of EBR-II Spent Fuel," Nuclear Technology, Vol. 134, (2001): 263-277.

390. Simpson, M. F., S. Lance, G. Moore, "Kinetics of Molten Chloride Salt Sorption into Zeolite-4A," TMS Annual Meeting, Light Metals, Seattle, WA, February 17-21, 2002.

391. Westphal, B. R., J. R. Krsul, D. W. Maddison, "Molten Salt Separation from Uranium During the Processing of Spent Nuclear Fuel," TMS Annual Meeting, Light Metals, Seattle, WA, February 17-21, 2002.

392. Li, S. X., "Anodic Process of Electrorefining Spent Nuclear Fuel in Molten LiCl-KCl-UCl ${ }_{3} / \mathrm{Cd}$ System," Electrochemical Society $13^{\text {th }}$ International Symposium on Molten Salts, Philadelphia, OA, May 12-17, 2002.

393. Goff, K. M., R. W. Benedict, G. M. Teske, T. J. Johnson, "Production Electrometallurgical Treatment of EBR-II Spent Fuel," American Nuclear Society Topical Meeting on DOE Spent Nuclear Fuel and Fissile Materials, Charleston, SC, September 17-20, 2002.

394. Herrmann, S. D., S. X. Li, M. F. Simpson, D. R. Wahlquist, "Electrolytic Reduction of Spent Oxide Fuel - Bench-Scale Test Preparations," American Nuclear Society Topical Meeting on DOE Spent Nuclear Fuel and Fissile Materials, Charleston, SC, September 17-20, 2002.

395. Keiser, D. D., S. G. Johnson, W. L. Ebert, "Monitoring the Consistency of the Metallic Waste Form Derived from Electrometallurgical Processing," American Nuclear Society Topical Meeting on DOE Spent Nuclear Fuel and Fissile Materials, Charleston, SC, September 17-20, 2002.

396. Toews, K. L., S. D. Herrmann, R. G. Pahl, R. H. Rigg, D. A. Sell, “Application of the MEDEC Process to Treat Fermi-1 Sodium-Bonded Spent Nuclear Fuel," American Nuclear Society Topical 
Meeting on DOE Spent Nuclear Fuel and Fissile Materials, Charleston, SC, September 17-20, 2002.

397. Westphal, B. R., D. Vaden, T. Q. Hua, J. L. Willit, D. V. Laug, "Recent Developments at the Cathode Processor for Spent Fuel Treatment," American Nuclear Society Topical Meeting on DOE Spent Nuclear Fuel and Fissile Materials, Charleston, SC, September 17-20, 2002.

398. Vaden, D., S. X. Li, T. A. Johnson, "Electrometallurgical Processing of Experimental Breeder Reactor-II Fuel," American Nuclear Society Topical Meeting on DOE Spent Nuclear Fuel and Fissile Materials, Charleston, SC, September 17-20, 2002.

399. Li, S. X., S. D. Herrmann, "Experimental Observations of a Thoria Oxide-Ion Sensor in a Molten Salt System,” Journal of the Electrochemical Society, Vol. 149, (2002): H39-H43.

400. Ahluwalia, R. K., T. Q. Hua, "Electrotransport of Uranium from a Liquid Cadmium Anode to a Solid Cathode,” Nuclear Technology, Vol. 140, (2002): 41-50.

401. Benedict, R., M. Goff, G. Teske, T, Johnson, "Progress in Electrometallurgical Treatment of Spent Nuclear Fuel," Journal of Nuclear Science and Technology, Sup. 3, (2002): 749-752.

402. Herrmann, S. D., S. X. Li, M. F. Simpson, "Electrolytic Reduction of Spent Oxide Fuel: BenchScale Testing," $27^{\text {th }}$ Actinide Separations Conference, Argonne, IL, June 2003.

403. Li, S. X., S. D. Herrmann, K. M. Goff, M. F. Simpson, "Actinide Recovery Experiments with Bench Scale Liquid Cadmium Cathode in Molten Salt Electrolyte Containing Fission Products," $27^{\text {th }}$ Actinide Separations Conference, Argonne, IL, June 2003.

404. Westphal, B. R., D. Vaden, L. W. Scott, S. R. Sherman, T. Q, Hua, "Investigation of Plutonium in Uranium Products During Spent Fuel Treatment," $3^{\text {rd }}$ Topical Conference on Plutonium and Actinides, Plutonium Futures: The Science, Albuquerque, NM, July 6-10, 2003.

405. Li, S. X., S. D. Herrmann, M. F. Simpson, D. R. Wahlquist, "Electrochemical Reduction of Uranium Oxide Fuel in a Molten $\mathrm{LiCl} / \mathrm{Li}_{2} \mathrm{O}$ System," Global 2003, New Orleans, LA, November 16-20, 2003.

406. Simpson, M. F., M. L. Gougar, "Two Site Equilibrium Model for Ion Exchange Between Monovalent Cations and Zeolite-A in a Molten Salt," Industrial and Engineering Chemistry Research. Vol. 42, (2003): 4208-4212.

407. Herrmann, S. D., S. X. Li, M. F. Simpson, "Electrolytic Reduction of Spent Oxide Fuel: BenchScale Test Results," $28^{\text {th }}$ Actinide Separations Conference, Asheville, NC, June 2004.

408. Li, S. X., S. D. Herrmann, K. M. Goff, M. F. Simpson, "Bench-Scale Actinide Recovery Experiments in Fission Product Laden Molten Salt," $28^{\text {th }}$ Actinide Separations Conference, Asheville, NC, June 2004.

409. Li, S. X., M. F. Simpson, S. D. Herrmann, "Oxygen Ion Oxidation Process on a Platinum Electrode in $\mathrm{LiCl}-\mathrm{Li}_{2} \mathrm{O}$ at $650^{\circ} \mathrm{C}$," $14^{\text {th }}$ International Symposium on Molten Salts and $206^{\text {th }}$ Meeting of the Electrochemical Society, Honolulu, HI, October 3-8, 2004.

410. Herrmann, S. D., K. L. Howden, D. A. Sell, "Evaporative Removal of Bond Sodium from Low Burn-up Blanket Fuel," ANS Winter Meeting, Washington D.C., November 14-18, 2004.

411. Ahluwalia, R. K., T. Q. Hua, D. Vaden, "Uranium Transport in a High-Throughput Electrorefiner for EBR-II Blanket Fuel," Nuclear Technology, Vol. 145, (2004): 67-81. 
412. Marsden, K. C., C. Knight, K. J. Bateman, B. R. Westphal, R. P. Lind, "Process and Equipment Qualification of the Ceramic and Metal Waste Forms for Spent Fuel Treatment," Global 2005, Tsukuba, Ibaraki, Japan, October 9-13, 2005.

413. Goff, K. M., R. W. Benedict, K. L. Howden, G. M. Teske, T. A. Johnson, "Pyrochemical Treatment of Spent Nuclear Fuel," Global 2005, Tsukuba, Ibaraki, Japan, October 9-13, 2005.

414. Herrmann, S. D., S. X. Li, M. F. Simpson, "Electrolytic Reduction of Spent Oxide Fuel - BenchScale Test Results," Global 2005, Tsukuba, Ibaraki, Japan, October 9-13, 2005.

415. Li, S. X., T. A. Johnson, B. R. Westphal, K. M. Goff, R. W. Benedict, "Electrorefining Experience for Pyrochemical Reprocessing of Spent EBR-II Fuel," Global 2005, Tsukuba, Ibaraki, Japan, October 9-13, 2005.

416. Phongikaroon, S., S. D. Herrmann, S. X. Li, M. F. Simpson, "Determination of Bubble Size Distribution in an Oxide Reduction Electrochemical Cell," AIChE 2005 Annual Meeting, Cincinnati, OH, October 30 - November 4, 2005.

417. Li, S. X., T. A. Johnson, B. R. Westphal, K. M. Goff, R. W. Benedict, "Electrochemical Cocollection of Uranium and Zirconium in Mark-IV Electrorefiner for Treating Spent EBR-II Driver Fuel,” American Nuclear Society Winter Meeting, Washington DC, November 13-17, 2005.

418. Li, S. X., M. F. Simpson, "Anodic Process of Electrorefining Spent Driver Fuel in Molten LiCl$\mathrm{KCl}-\mathrm{UCl}_{3} / \mathrm{Cd}$ System," Journal of Mineral and Metallurgical Processing, Vol. 22, (2005): 192-198.

419. Simpson, Michael F., David B. Barber, Robert W. Benedict, Gregory M. Teske, "EBR-II and FFTF Spent Fuel Processing Options Report," Idaho National Laboratory, April 2006.

420. Herrmann, S. D., "Pyroprocessing of Spent Nuclear Oxide Fuel at Bench Scale," 2006 International Pyroprocessing Research Conference, Idaho Falls, ID, August 8-10, 2006.

421. Li, S. X., S. D. Herrmann, R. W. Benedict, K. M. Goff, M. F. Simpson, “Actinide Recovery Experiments with Bench-Scale Liquid Cadmium Cathode in Fission Product Laden Molten Salt," 2006 International Pyroprocessing Research Conference, Idaho Falls, ID, August 8-10, 2006.

422. Simpson, M. F., S. D. Herrmann, "Modeling the Pyrochemical Reduction of Spent $\mathrm{UO}_{2}$ Fuel in a Pilot-Scale Reactor," 2006 International Pyroprocessing Research Conference, Idaho Falls, ID, August 8-10, 2006.

423. Herrmann, S. D., S. X. Li, "Electrorefining of Reduced Spent Nuclear Oxide Fuel at Bench Scale," AIChE 2006 Annual Meeting, San Francisco, CA, November 12-17, 2006.

424. Li, S. X., T. A. Johnson, R. W. Benedict, D. Vaden, B. R. Westphal, "Integrated Electrorefining Efficiency Test for Pyrochemical Fuel Cycle," American Nuclear Society Winter Meeting, Albuquerque, NM, November 12-16, 2006.

425. Li, S. X., D. Vaden, R. W. Benedict, K. M. Goff, "Electrochemical Dissolution of Spent EBR-II Driver Fuel in Molten Salt Electrolyte," Transactions of the American Nuclear Society, Vol. 94, (2006): 106-107.

426. Phongikaroon, S., S. D. Herrmann, S. X. Li, M. F. Simpson, "Measurement and Analysis of Gas Bubbles near a Reference Electrode in Aqueous Solutions," Industrial \& Engineering Chemistry Research, Vol. 45, (2006): 7679-7687. 
427. Herrmann, S. D., S. X. Li, M. F. Simpson, S. Phongikaroon, "Electrolytic Reduction of Spent Nuclear Oxide Fuel as Part of an Integrated Process to Separate and Recover Actinides from Fission Products," Separation Science and Technology, Vol. 41, (2006): 1965-1983.

428. Solbrig, C. W., D. Vaden, "Electrorefiner Liquid Cadmium Cathode Crucible Thermal Shock," Separation Science and Technology, Vol. 41, (2006): 1985-2001.

429. Vaden, D., "Fuel Conditioning Facility Electrorefiner Process Model," Separation Science and Technology, Vol. 41, (2006): 2003-2012.

430. Herrmann, S. D., S. X. Li, M. F. Simpson, "Electrolytic Reduction of Spent Light Water Reactor Fuel: Bench-Scale Experimental Results," Journal of Nuclear Science and Technology, Vol. 44, (2007): 361-367.

431. Westphal, B. R., J. C. Price, D. Vaden, R. W. Benedict, "Engineering-Scale Distillation of Cadmium for Actinide Recovery," Journal of Alloys and Compounds, Vol. 444, (2007): 561-564.

432. "Idaho National Laboratory Preferred Disposition Plan for Sodium-Bonded Spent Nuclear Fuel," Idaho National Laboratory, January 2007.

433. Herrmann, S. D., S. X. Li, "Separation and Recovery of Uranium from Spent Light Water Reactor Fuel via Electrolytic Reduction and Electrorefining at Bench Scale," $31^{\text {st }}$ Annual Actinide Separations Conference, Las Vegas, NV, June 11-14, 2007.

434. Solbrig, C. W., B. R. Westphal, T. A. Johnson, S. X. Li, K. Marsden, "Pyroprocessing Progress at Idaho National Laboratory,” Global 2007, Boise, Idaho, September 9-13, 2007.

435. Benedict, R. W., C. Solbrig, B. Westphal, T. A. Johnson, S. X. Li, K. Marsden, K. M. Goff, "Pyroprocessing Progress at Idaho National Laboratory", Global 2007, Boise, Idaho, September 9-13, 2007.

436. Herrmann, S. D., S. X. Li, D. A. Sell, B. R. Westphal, "Electrolytic Reduction of Spent Nuclear Oxide Fuel: Effects of Fuel Form and Cathode Containment Materials on Bench-Scale Operations," Global 2007, Boise, Idaho, September 9-13, 2007.

437. Li, S. X., D. Vaden, R. W. Benedict, B. R. Westphal, G. L. Fredrickson, "Integrated Efficiency Test for Pyrochemical Fuel Cycles," Global 2007, Boise, Idaho, September 9-13, 2007.

438. Simpson, M. F., T. S. Yoo, R. W. Benedict, S. Phongikaroon, S. Frank, "Strategic Minimization of High Level Waste From Pyroprocessing of Spent Nuclear Fuel," Global 2007, Boise, Idaho, September 9-13, 2007.

439. Vaden, D., G. L. Fredrickson, "Material Control and Accountability Experience at the Fuel Conditioning Facility," Global 2007, Boise, Idaho, September 9-13, 2007.

440. Simpson, M. F., P. Sachdev, "Development of Electrorefiner Waste Salt Disposal Process for the EBR-II Spent Fuel Treatment Project," Nuclear Engineering and Technology, Vol. 40, (2008): 175182.

441. Westphal, B. R., K. C. Marsden, J. C. Price, D. V. Laug, "On the Development of a Distillation Process for the Electrometallurgical Treatment of Irradiated Spent Nuclear Fuel," Nuclear Engineering and Technology, Vol. 40, (2008): 163-174.

442. Li, S. X., "Experimental Observations on the Roles of the Cadmium Pool in the Mark-IV Electrorefiner," Nuclear Technology, Vol. 162, (2008): 144-152. 
443. Vaden, D., S. X. Li, B. R. Westphal, K. B. Davies, T. A. Johnson, D. M. Pace, "Engineering-Scale Liquid Cadmium Cathode Experiments,” Nuclear Technology, Vol. 162, (2008): 124-128.

444. Simpson, M. F., S. D. Herrmann, "Modeling the Pyrochemical Reduction of Spent $\mathrm{UO}_{2}$ Fuel in a Pilot-Scale Reactor,” Nuclear Technology, Vol. 162, (2008): 179-183.

445. Vaden, D., "Fuel Conditioning Facility Electrorefiner Model Predictions Versus Measurements," Separation Science and Technology, Vol. 43, (2008): 2684-2694.

446. Wahlquist, D. L., K. J. Bateman, B. R. Westphal, "Second Generation Experimental Equipment Design to Support Voloxidation Testing at INL," $16^{\text {th }}$ International Conference on Nuclear Engineering (ICONE 16), Orlando, Florida, May 11-15, 2008.

447. Li, S. X., S. D. Herrmann, "Electrochemical Analysis of Rare Earth Constituents in Uranium/Plutonium Collected by a Liquid Cadmium Cathode," 2008 International Pyroprocessing Research Conference, Jeju Island, Republic of Korea, August 24-27, 2008.

448. Herrmann, S. D., S. X. Li, B. R. Westphal, "Electrolytic Reduction of Fast Reactor MOX Fuel at Bench Scale," 2008 International Pyroprocessing Research Conference, Jeju Island, Republic of Korea, August 24-27, 2008.

449. Westphal, B. R., D. L. Wahlquist, D. A. Sell, K. J. Bateman, S. D. Herrmann, "Investigation of Decladding via Oxidation for MOX Fast Reactor Fuel," 2008 International Pyroprocessing Research Conference, Jeju Island, Republic of Korea, August 24-27, 2008.

450. Goff, K. M., M. F. Simpson, "Dry Processing of Used Nuclear Fuel," Global 2009, Paris, France, September 6-11, 2009.

451. Herrmann, S. D., S. X. Li, B. E. Serrano-Rodriguez, "Observations of Oxygen Ion Behavior in the Lithium-Based Electrolytic Reduction of Uranium Oxide," Global 2009, Paris, France, September 6-11, 2009.

452. Choi, I., B. E. Serrano, S. X. Li, S. D. Herrmann, "Determination of Exchange Current Density of $\mathrm{U}^{3+} / \mathrm{U}$ Couple in LiCl-KCl Eutectic Mixture," Global 2009, Paris, France, September 6-11, 2009.

453. Li, S. X., S. D. Herrmann, M. F. Simpson, "Experimental Investigations into U/TRU Recovery Using a Liquid Cadmium Cathode and Salt Containing High Rare Earth Concentrations," Global 2009, Paris, France, September 6-11, 2009.

454. Westphal, B. R., D. Vaden, S. X. Li, G. L. Fredrickson, R. D. Mariani, "Fate of Noble Metals during the Pyroprocessing of Spent Nuclear Fuel," Global 2009, Paris, France, September 6-11, 2009.

455. Hoover, R., S. Phongikaroon, S. X. Li, M. F. Simpson, T. S. Yoo, "A Computational Model of the Mark-IV Electrorefiner: Phase 1-Fuel Basket/Salt Interface," Journal of Engineering for Gas Turbines and Power, Vol. 131, 2009.

456. Li, S. X., S. D. Herrmann, K. M. Goff, M. F. Simpson, R. W. Benedict, “Actinide Recovery Experiments with Bench-Scale Liquid Cadmium Cathode in Real Fission Product-Laden Molten Salt," Nuclear Technology, Vol. 165, (2009): 190-199.

457. Li, S. X., D. Vaden, B. R. Westphal, G. L. Fredrickson, R. W. Benedict, "Integrated Efficiency Test for Pyrochemical Fuel Cycles," Nuclear Technology, Vol.166, (2009): 180-186. 
458. Li, S. X., S. D. Herrmann, M. F. Simpson, "Electrochemical Analysis of Actinides and Rare Earth Constituents in Liquid Cadmium Cathode Product from Spent Fuel Electrorefining," Nuclear Technology, Vol.171, (2009): 292-299.

459. Westphal, B. R., K. C. Marsden, J. C. Price, "Development of a Ceramic-Lined Crucible for the Separation of Salt from Uranium," Metallurgical and Materials Transactions A, Vol. 40A, (2009): 2861-2866.

460. Herrmann, S. D., S. X. Li, "Separation and Recovery of Uranium Metal from Spent Light Water Reactor Fuel via Electrolytic Reduction and Electrorefining," Nuclear Technology, Vol. 171, (2010): 247-265.

461. Hoover, R., S. Phongikaroon, M. F. Simpson, S. X. Li, T. S. Yoo, "Development of Computational Models for the Mark-IV Electrorefiner - Effect of Uranium, Plutonium, and Zirconium Dissolution at the Fuel Basket-Salt Interface," Nuclear Technology, Vol. 171, (2010): 276-284.

462. Morrison, M. C., K. J. Bateman, M. F. Simpson, "Scale Up of Ceramic Waste Forms for the EBR-II Spent Fuel Treatment Process," Journal of Nuclear Fuel Cycle and Waste Technology, Vol. 13, (2010): 55-75.

463. Herrmann, S. D., K. S. Norbash, "Separation and Recovery of Uranium from Aluminum Clad LowEnriched Uranium-Molybdenum Fuel at Bench Scale," $34^{\text {th }}$ Annual Actinide Separation Conference, Argonne National Laboratory, Argonne, IL, May 17-20, 2010.

464. Westphal, B. R., K. C. Marsden, D. Vaden, J. C. Price, M. F. Simpson, "Transformation of Uranium Products from the Pyrometallurgical Processing of Used Nuclear Fuel," Plutonium Futures: The Science 2010, Keystone, CO, September 19-23, 2010.

465. Herrmann, S. D., S. X. Li, B. R. Westphal, "Separation and Recovery of Uranium and Group Actinide Products from Irradiated Fast Reactor MOX Fuel via Electrolytic Reduction and Electrorefining," Proceedings of the International Pyroprocessing Research Conference, Dimitrovgrad, Russia, November 29 - December 3, 2010.

466. Westphal, B. R., S. X. Li, G. L. Fredrickson, D. Vaden, T. A. Johnson, "Evaluation of 2.25Cr-1Mo Alloy for Containment of LiCl-KCl Eutectic During the Pyrometallurgical Processing of Used Nuclear Fuel," TMS Annual Meeting, Proceedings of Chloride Symposium, San Diego, CA, Feb 27 - March 3, 2011.

467. Phongikaroon, S., S. D. Herrmann, M. F. Simpson, "Diffusion Model for Electrolytic Reduction of Uranium Oxides in a Molten LiCl-Li ${ }_{2} \mathrm{O}$ Salt," Nuclear Technology, Vol. 174, (2011): 85-93.

468. Westphal, B. R., J. C. Price, R. D. Mariani, "Synthesis of Uranium Trichloride for the Pyrometallurgical Processing of Used Nuclear Fuel," Fray International Symposium on Metals and Materials Processing, Proceedings of the Molten Salts and Ionic Liquids Symposium, Cancun, Mexico, November 27 - December 01, 2011.

469. Simpson, M. F., T. S. Yoo, D. Labrier, M. Lineberry, M. Shaltry, "Selective Reduction of Active Metal Chlorides from Molten LiCl-KCl Using Lithium Drawdown," Nuclear Engineering and Technology, Vol. 44, (2012): 767-772.

470. Herrmann, S. D., S. X. Li, B. R. Westphal, "Separation and Recovery of Uranium and Group Actinide Products from Irradiated Fast Reactor MOX Fuel via Electrolytic Reduction and Electrorefining," Separation Science and Technology, Vol. 47, (2012): 2044-2059. 
471. Westphal, B. R., J. C. Price, L. E. Foulkrod, M. Rodriquez, D. G. Cummings, J. J. Giglio, "Separation Characteristics of Manganese as a Surrogate for Americium during the Distillation Operations of Pyroprocessing," Separation Science and Technology, Vol. 47, (2012): 2060-2064.

472. Simpson, M. F., "Developments of Spent Nuclear Fuel Pyroprocessing Technology at Idaho National Laboratory,” Idaho National Laboratory, INL/EXT-12-25124, March 2012.

473. Herrmann, S. D., L. A. Wurth, N. J. Gese, "Behavior of Zirconium Oxide and Zirconium Metal in a $\mathrm{LiCl}-\mathrm{Li}_{2} \mathrm{O}-\mathrm{Based}$ Electrolytic Reduction System,” 2012 International Pyroprocessing Research Conference, Fontana, Wisconsin, August 26-29, 2012.

474. Marsden, K. C., B. R. Westphal, M. N. Patterson, Pesic, "Purity of Uranium Product Recovered from Electrochemical Recycling of Used Metallic Fuel," TMS 2013, Proceedings of the High Temperature Electrochemistry Symposium, San Antonio, TX, March 3-7, 2013.

475. Herrmann, S. D., B. R. Westphal, G. L. Fredrickson, S. B. Park, S. H. Kim, "Pyroprocessing of Used Light Water Reactor Fuel - A Study of Integrated Unit Operations at Laboratory Scale," TMS 2013, Proceedings of the High Temperature Electrochemistry Symposium, San Antonio, TX, March 3-7, 2013.

476. Herrmann, S. D., L. A. Wurth, N. J. Gese, "Pyroprocessing of Oxidized Sodium-Bonded Fast Reactor Fuel - An Experimental Study of Treatment Options for Degraded EBR-II Fuel," Global 2013, Salt Lake City, UT, September 29 - October 2, 2013.

477. Westphal, B. R., G. L. Fredrickson, G. G. Galbreth, D. Vaden, M. D. Elliot, "Pyroprocessing of Fast Flux Test Facility Nuclear Fuel," Global 2013, Salt Lake City, UT, September 29 - October 2, 2013.

478. Yoo, T. S., G. L. Fredrickson, D. Vaden, B. R. Westphal, "Analysis of Cadmium in Undissolved Anode Materials of Mk-IV Electrorefiner," Global 2013, Salt Lake City, UT, September 29 October 2, 2013.

479. Westphal, B. R., J. C. Price, K. J. Bateman, K. C. Marsden, "Zirconium Determination by Cooling Curve Analysis during the Pyroprocessing of Used Nuclear Fuel," Journal of Nuclear Materials, Vol. 457, (2015): 241-245.

480. Westphal, B. R., S. M. Frank, W. M. McCartin, D. G. Cummings, J. J. Giglio, T. P. O’Holleran, P. A. Hahn, T. S. Yoo, K. C. Marsden, K. J. Bateman, M. N. Patterson, "Characterization of Irradiated Metal Waste from the Pyrometallurgical Treatment of Used EBR-II Fuel," Metallurgical Transactions A, Vol. 46A, (2015): 83-92.

481. Herrmann, S. D., C. Baker, R. O. Hoover, N. J. Gese, J. M. Hur, "Study of Oxygen Ion Diffusion during the Electrolytic Reduction of Uranium Oxide in Molten LiCl- $\mathrm{Li}_{2} \mathrm{O}$," $39^{\text {th }}$ Annual Actinide Separations Conference, Salt Lake City, UT, May 18-21, 2015.

482. Westphal, B. R., J. C. Price, E. E. Chambers, M. N. Patterson, "Investigations for the Recycle of Pyroprocessed Uranium," $10^{\text {th }}$ International Conference on Molten Slags, Fluxes, and Salts (MOLTEN16), Seattle, WA, May 22-25, 2016.

483. Herrmann, S. D., "Initial Operation of Kg-Scale Electrolytic Reduction and Salt Distillation Equipment for the Pyroprocessing of Uranium Oxide in a Hot Cell," 2106 International Pyroprocessing Research Conference, Jeju Island, Korea, September 21-23, 2016.

484. Westphal, B. R., J. C. Price, M. N. Patterson, "Further Studies on the Recycle of Pyroprocessed Uranium," Journal of Sustainable Metallurgy, Vol. 3, (2017): 690-695. 
485. Rechard, R. P., T. Hadgu, Y. Wang, L. C. Sanchez, P. McDaniel, C. Skinner, N. Fathi, S. Frank, M. Patterson, "Feasibility of Direct Disposal of Salt Waste from Electrochemical Processing of Spent Nuclear Fuel," International High-Level Radioactive Waste Management (IHLRWM 2017), Charlotte, NC, April 9-13, 2017.

486. Herrmann, S. D., P. K. Tripathy, S. M. Frank, J. A. King, "Comparative Study of Monolithic Platinum and Iridium as Oxygen-Evolving Anodes during the Electrolytic Reduction of Uranium Oxide in a Molten LiCl- $\mathrm{Li}_{2} \mathrm{O}$ Electrolyte," Journal of Applied Electrochemistry, Accepted for Publication on January 22, 2019.

487. Fredrickson, G., G. Cao, R. Gakhar, T. S. Yoo, "Molten Salt Reactor Processing - Technology Status,” Idaho National Laboratory, INL/EXT-18-51033, August 2018.

488. Miller, P. D., C. L. Peterson, E. L. White, F. W. Fink, "Evaluation of Container Materials for ZIRCEX and DAREX Nuclear Fuel-Recovery Processes," Battelle Memorial Institute, BMI-1242, December 1957.

489. Peterson, C. L., P. D. Miller, E. L. White, W. E. Clark, "Materials of Construction for Head-End Processes Aqueous Reprocessing of Nuclear Fuels," Industrial and Engineering Chemistry, 51, 1 (1959): 32-37.

490. Gens, T. A., R. L. Jolley, "New Laboratory Developments in the ZIRCEX Process," Oak Ridge National Laboratory, ORNL-2992, 1961.

491. Gens, T. A., "ZIRCEX and Modified ZIRFLEX Processes for Dissolution of $8 \% \mathrm{U}-91 \% \mathrm{Zr}-1 \%$ H TRIGA Reactor Fuel,” Oak Ridge National Laboratory, ORNL-3065, 1961.

492. Gens, T. A., "Laboratory Development of a Combined Chloride Volatility-Aqueous Processing Method for Uranium-Zirconium Nuclear Fuels,” Oak Ridge National Laboratory, ORNL-TM-645, 1963.

493. Schmets, J. J., "Review of Halide Volatility Processes,” Kjeller Report, Reprocessing of Fuel from Present and Future Power Reactors, Advanced Course Organized by the Netherland's - Norwegian Reactor School, Institutt for Atomenergi, KR-126, (September 1967): 361-384.

494. Bond, W. D., J. C. Mallen, G. E. Michaels, "Evaluation of Methods for Decladding LWR Fuel for a Pyroprocessing-Based Reprocessing Plant," Oak Ridge National Laboratory, ORNL-TM-12104, October 1992.

495. Collins, E. D., G. D. DelCul, B. B. Spencer, R. R. Brunson, J. A. Johnson, D. S. Terekhov, N. V. Emmanuel, "Process Development Studies for Zirconium Recovery/Recycle from Used Nuclear Fuel Cladding," Procedia Chemistry, 7 (2012): 72-76.

496. Beebe, C. L., "F\&ORs for the Hybrid ZIRCEX Process Demonstration - Pre-Conceptual Design Input," Idaho National Laboratory, INL/EXT-19-55597, September 2019.

497. Nevarez, R. B., B. McNamara, F. Poineau, "Recovery of Zirconium from Zircaloys Using a Hydrochlorination Process," Nuclear Technology, 2020, DOI: 10.1080/00295450.2020.1757961.

498. Barghusen, J. J., "Volatility Processes," Reactor and Fuel-Processing Technology, 11, 1 (1967-1698): 54-59.

499. Kamoshida, M., F. Kawamura, A. Sasahira, T. Fukusawa, T. Sawa, J. Yamashita, "A New Concept for the Nuclear Fuel Recycle System: Application of the Fluoride Volatility Reprocessing," Progress in Nuclear Energy, 37, 1-4 (2000): 145-150. 
500. Amano, O., K. Yasui, A. Sasahira, Y. Kani, M. Takahashi, T. Fukasawa, Y. Shibata, F. Kawamura, "FLUOREX Reprocessing Technology with Uranium Removal from Spent Fuel by Fluorination Volatilization Reaction of Uranium," Journal of Nuclear Science and Technology, Sup. 3 (2002): 890-893.

501. Kobayashi, H., O. Amano, F. Kawamura, M. Aoi, K. Hoshino, A. Sasahira, Y. Kani, "FLUOREX Reprocessing System for the Thermal Reactors Cycle and Future Thermal/Fast Reactors (Coexistance) Cycle," Progress in Nuclear Energy, 47, 1-4 (2005): 380-388.

502. Kani, K., A. Sasahira, K. Hoshino, F. Kawamura, "New Reprocessing System for Spent Nuclear Reactor Fuel Using Fluoride Volatility Method," Journal of Fluorine Chemistry, 130 (2009): 74-82.

503. Fukasawa, T., K. Hoshino, D. Watanabe, A. Sasahira, "Application of Fluoride Volatility Method to the Spent Fuel Reprocessing," Journal of Nuclear Science and Technology, 57, 1 (2020): 49-56.

504. Strickland, G., F. L. Horn, R. Johnson, "The Nitrofluor Process for Reactor Fuel”, Symposium on Volatility Reprocessing of Nuclear Reactor Fuels: Part 1, Fifty-Fourth Annual Meeting, American Institute of Chemical Engineers, New York, New York, December 2-7, 1961.

505. Strickland, G., F. L. Horn, "Nitrofluor Process - A Non-Aqueous Fluoride-Volatility Method for Recovering Uranium and Plutonium from Various Reactor Fuels", Progress in Nuclear Energy, Series III, Process Chemistry, Volume 4, Pergamon Press, (1970): 399-425.

506. "Research and Development on Nonaqueous Processing," Reactor Fuel Processing, 5, 1, (1962): $22-40$.

507. Milford, R. P., "Engineering Design of Oak Ridge Fluoride Volatility Pilot Plant," Industrial and Engineering Chemistry, 50, 2 (1958): 187-191.

508. Thoma, R. E., B. J. Strum, E. H. Guinn, "Molten-Salt Solvents for Fluoride Volatility Processing of Aluminum-Matrix Nuclear Fuel Elements," Oak Ridge National Laboratory, ORNL-3594, August 1964.

509. Bennett, M. R., G. I. Cathers, R. P. Milford, W. W. Pitt, J. W. Ullmann, "Fused-Salt FluorideVolatility Process for Recovering Uranium from Spent Aluminum-Based Fuel Elements," Industrial and Engineering Chemistry, Process Design and Development, 4, 4 (1965): 387-394.

510. Szulinski, M. J., "Fluoride Volatility Processing of Reactor Fuels," Isochem Inc, Richland, Washington, ISO-627, December 1966.

511. Reilly, J. J., S. J. Wachel, R. Johnson, E. Wirsing, L. P. Hatch, "Fluidized Bed Reprocessing of Graphite Matrix Nuclear Fuel," Industrial and Engineering Chemistry, Process Design and Development, 5, 1 (1966): 51-59.

512. Breton, D. L., R. B. Schappel, J. R. Merriman, J. H. Pashley, C. C. Littlefield, K. E. Habiger, “A Conceptual Study of a Fluoride Volatility Plant for Reprocessing Light Water Reactor Fuels," Union Carbide Corporation, K-1759, December 1968.

513. Uhlif, J., M. Marecek, "Fluoride Volatility Method for Reprocessing of LWR and FR Fuels," Journal of Fluorine Chemistry, 130 (2009): 89-93.

514. Uhlif, J., M. Marecek, J. Skarohlid, "Current Progress in R\&D of Fluoride Volatility Method," Procedia Chemistry, 7 (2012): 110-115.

515. Neidrach, L. W., B. E. Dearing, "Electrowinning of Uranium from its Oxides I. Laboratory Studies," Knolls Atomic Power Laboratory, KAPL-1761, 1957. 
516. Niedrach, L. W., A. C. Schafer, "Electrowinning of Uranium from its Oxides II. A Preliminary Engineering Evaluation,” Knolls Atomic Power Laboratory, KAPL-1668, 1957.

517. Piper, R. D., R. F. Leifield, "Electro Reduction of Uranium Oxides to Massive Uranium Metal," Mallinckrodt Chemical Works, MCW-1447, 1960.

518. Piper, R. D., R. F. Leifield, "Electrolytic Production of Uranium Metal from Uranium Oxides," Industrial \& Engineering Chemistry Process Design and Development, 1 (1962): 208-212.

519. "Process Development Quarterly Progress Report," Mallinckrodt Chemical Works, MCW-1479, 1962.

520. Piper, R. D., J. D. Vie, J. N. Reyland, R. J. Kornfeld, D. E. Treadway, "Methods for Tapping Molten Uranium from an Electrolytic Cell," Mallinckrodt Chemical Works, MCW-1481, 1963.

521. Piper, R. D., "Laboratory Development of the Uranium Electroreduction Process," Mallinckrodt Chemical Works, MCW-1500, 1966.

522. Haas, P. A., P. W. Adcock, A. C. Coroneos, D. E. Hendrix, "Small cell experiments for electrolytic reduction of uranium oxides to uranium metal using fluoride salts," Metallurgical and Materials Transactions B, 25 (1994): 505-518.

523. Shimada, T., N. Tedzuka, Y. Shimizu, M. Miyake, "Electrode reactions of uranium during electrolysis of its oxide in a molten fluoride mixture," Journal of Alloys and Compounds, 206 (1994): 249-253.

524. Shimada, T., N. Tedzuka, Y. Shimizu, M. Miyake, "Electrochemical reduction of uranium oxide in molten fluoride mixture," Journal of Alloys and Compounds, 204 (1994): 1-4.

525. Hoshino, Y., et al., "Corrosion Behaviors of Materials Used in Uranium Metal Production," ECS Proceedings, 1996-7 (1996): 222-229.

526. Takasawa, Y., et al., "Improvement of Current Efficiency in Electrowinning Uranium Metal in Molten Fluorides," Electrochemistry, 67 (1999): 718-725.

527. Alangi, N., J. Mukherjee, P. Anupama, "Electrolytic Reduction of Uranium Oxide in Molten Fluoride Baths in Small Electrolytic Cells," Thorium - Energy for the Future, Springer Singapore, (2019): 157-169.

528. Morrison, B. H., R. E. Blanco, "The HERMEX Process for Metal Decontamination by HeProcessing," Oak Ridge National Laboratory, CF-56-1-151, January 25, 1956.

529. Blanco, R. E., W. K. Eister, D. E. Ferguson, "Power Reactor Fuel Processing Preliminary Report," Oak Ridge National Laboratory, CF-56-5-48, May 14, 1956.

530. Blanco, R. E., W. K. Eister, D. E. Ferguson, "Power Reactor Fuel Processing Status Report for July, 1956," Oak Ridge National Laboratory, CF-556-7-101, July 15, 1956.

531. Culler, F. L., O. C. Dean, "A Proposed Fuel Element Design to Facilitate Reprocessing by the HERMEX Process,” Oak Ridge National Laboratory, CF-56-8-200, August 31, 1956.

532. Blanco, R. E., "Processing of Power Reactor Fuels," Nuclear Science and Engineering, Vol. 1, (1956): 409-419.

533. Culler, F. L., R. E. Blanco, H. E. Goeller, C. D. Watson, “An Analysis of Power Reactor Fuel Reprocessing," Oak Ridge National Laboratory, ORNL-2265(Del.), March 27, 1957. 
534. Dean, O. C., E. Sturch, B. H. Morrison, R. E. Blanco, "Status of the HERMEX Process," Oak Ridge National Laboratory, ORNL-2242, August 12, 1957.

535. Dean, O. C., G. K. Ellis, "The Preparation of Thorium Metal by Sodium Amalgam Reduction of Thorium Chloride: The METALLEX Process," Nuclear Science and Engineering, Vol. 4, (1958): 509-521.

536. Smith, M. O., "Summer Quarter, 1958, Co-Op Report," Oak Ridge National Laboratory, CF-58-972, September 25, 1958.

537. Bowersox, D. F., J. A. Leary, "The Solubility of Plutonium in Mercury," Journal of Inorganic Nuclear Chemistry, Vol. 9, (1959): 108-112.

538. Dean, O. C., A. F. Messing, J. C. Forsberg, "Use of Mercury in Reprocessing Nuclear Fuels," Oak Ridge National Laboratory, CF-60-2-3, 1960.

539. Messing, A. F., O. C. Dean, "Solubilities of Selected Metals in Mercury: HERMEX Process," Oak Ridge National Laboratory, ORNL-2871, June 28, 1960.

540. Messing, A. F., O. C. Dean, "Processing of High-Fired Uranium Dioxide Fuels by a Reduction Mercury Extraction - Oxidation Process,” Oak Ridge National Laboratory, ORNL-2909, August 12, 1960.

541. Bowersox, D. F., J. A. Leary, "Purification of Plutonium Fuels by Mercury Processing (Experimental Survey)," Los Alamos National Laboratory, Report LAMS-2518, May 1961.

542. Dean, O. C., "Mercury Costs in HERMEX Process," Oak Ridge National Laboratory, ORNL-TM699, October 9, 1963.

543. Selvaduray, G., M. K. Goldstein, R. N. Anderson, "Survey of Nuclear Fuel Reprocessing Technologies," Conservation and Recycling, Vol. 3, (1979): 93-134.

544. “Annual Report 1959,” Hanford Atomic Products Operation, HW-64000 DEL, April 1, 1960.

545. Bond, W. R., G. Jansen, L. K. Mudge, "Demonstration of the Salt Cycle Process in a High-Level Radiochemical Facility,” Pacific Northwest Laboratory, BNWL-355, December 1966.

546. Harmon, K. M., G. Jansen, "6.1 The Salt Cycle Process," Progress in Nuclear Energy, Series III, Process Chemistry, Volume 4, C. E. Stevenson et al. Editors, Pergamon Press, (1970): 429-460.

547. Bychlov, A. V., O. V. Skiba, "Review of Non Aqueous Nuclear Fuel Reprocessing and Separation Methods," Chemical Separation Technologies and Related Methods of Nuclear Waste Management NATO Science Series, Kluwer Academic Publishers, Vol. 53, (1999): 7198.

548. Lyon, W. L., E. E. Voiland, "The Preparation of Uranium Dioxide from a Molten Salt Solution of Uranyl Chloride," Hanford Atomic Products Operation, HW-62431, October 20, 1959.

549. Benedict, G. E., W. L. Lyon, L. K. Mudge, J. J. Swanson, M. T. Walling, "The Salt Cycle Process," Hanford Laboratories Operation, HW-SA-1936, August 1960.

550. Robins, R. G., "Uranium Dioxide Single Crystals by Electrodeposition," Journal of Nuclear Materials, Vol. 3, No. 3, (1961): 294-301.

551. Chalkley, J. R., “The Pilot Plant Production of Electrolytic Uranium Dioxide,” Journal of LessCommon Metals, Vol. 3, (1961): 98-109.

552. Swanson, J. L., G. E. Benedict, R. C. Smith, G. R. Horn, "Demonstration of an Irradiated $\mathrm{UO}_{2}$ Fuel Recycle: First Recycle,” Hanford Atomic Products Operation, HW-69027, September 1961. 
553. Harmon, K. M., “The Salt Cycle Process Concept,” General Electric, HW-SA-2247, October 30, 1961.

554. Harmon, K. M., "The Salt Cycle Process Concept," Proceedings of the American Nuclear Society Winter Meeting, Chicago, IL, November 8, 1961.

555. Johnson, B. M., "Application of Continuous Zone Melting to Salt Cleanup in the Salt-Cycle Process,” Hanford Atomic Products Operation, HW-72054, November 1961.

556. Chalkley, J. R., “The Pilot Plant Production of Electrolytic Uranium Dioxide,” Journal of Less Common Metals, Vol. 3, (1961): 98-109.

557. Sharp, R. K., “A Process for Decontamination of Molten LiCl-KCl Solutions Containing Uranium and Plutonium Chloride Preliminary to Incorporation in the "Salt Cycle" Process," Hanford Atomic Products Operation, Report of Invention, HW-72151, January 1962.

558. Wilks, R. S., "A Study of the Mechanism of the Electrolysis of $\mathrm{UO}_{2} \mathrm{Cl}_{2}$ in Molten $\mathrm{NaCl}-\mathrm{KCl}$ Eutectic," Journal of Nuclear Materials, Vol. 7, No. 2, (1962): 157-164.

559. Huck, C. E., O. H. Koski, "Development of Salt Cycle Process Instrumentation," Hanford Atomic Products Operation, HW-74968, September 1962.

560. Scott, F. A., L. K. Mudge, "The Electrolytic Preparation of Single Crystals of Uranium Dioxide," Journal of Nuclear Materials, Vol. 9, No. 3, (1963) 245-251.

561. Bond, W. R., G. Jansen, L, K, Mudge, "Hanford Salt Cycle Process. II. Engineering Development in a High Level Radiochemical Facility," Hanford Atomic Products Operation, HW-SA-3527, January 1964.

562. Benedict, G. E., R. A. Nixon, "Hanford Salt Cycle Process. I. Plutonium Chemistry,” Hanford Atomic Products Operation, HW-SA-3622, January 1964.

563. Wenz, D. A., M. D. Adams, R. K. Steunenberg, "Formation and Spectra of Uranyl(V) Chloride in Molten Chloride Solvents,” Inorganic Chemistry, Vol. 3, No. 7, (1964): 898-992.

564. Swanson, J. L., "Plutonyl Species in Molten Chloride Salt Solutions," The Journal of Physical Chemistry, Vol. 68, No. 2, (1964): 438-439.

565. Benedict, G. E., R. A. Nixon, "Hanford Salt Cycle Process. I. Plutonium Chemistry," Proceedings of the $145^{\text {th }}$ American Chemical Society National Meeting, New York City, NY, September 8-13, 1964.

566. Bond, W. R., "A Preliminary Economic Study of the Preparation of Reactor Grade $\mathrm{PuO}_{2}-\mathrm{UO}_{2}$ by the Salt Cycle Process," Hanford Atomic Products Operation, HW-83984, September 1964.

567. Stromatt, R. W., "Studies of the Formation of Uranyl (VI) from Uranium Dioxide and Chlorine in Molten Alkali Chlorides," Journal of Inorganic \& Nuclear Chemistry, Vol. 27, (1965): 2331-2339.

568. Schlechter, M., J. Kooi, R. Billiau, R. A. Charlier, G. L. Dumont, "The Preparation of $\mathrm{UO}_{2}$ by Fused Salt Electrolysis Using $\mathrm{UO}_{2}$ or $\mathrm{UF}_{4}$ as Starting Material," Journal of Nuclear Materials, Vol. 15, No. 3, (1965): 189-200.

569. McKee, R. W., "Economic Evaluation of Closed Coupled Fuel Processing with Plutonium Recycle," Pacific Northwest Laboratory, BNWL-28, July 1965.

570. Baily, W. E., W. L. Lyon, "Some Electrical Properties of the Plutonium-Uranium Mixed Oxide System," Advanced Products Operation, General Electric, GEAP-4675, September 1965. 
571. Benedict, G. E., W. R. Bond, G. Jansen, L. G. Morgan, J. R. Lundquist, "Status of the Salt Cycle Process for Processing Oxide Fuels," Pacific Northwest Laboratory, BNWL-SA-205, September 1965.

572. Benedict, G. E., L. G. Morgan, R. A. Nixon, "Plutonium Chemistry of the Salt Cycle Process," Pacific Northwest Laboratory, 1966.

573. Bloom, G. R., "Melt Atmosphere Control Studies for the Salt Cycle Process," Pacific Northwest Laboratory, BNWL-CC-772, January 1966.

574. Bloom, G. R., "Detection and Oxidation Rate Studies of U(IV) in the Salt Cycle Process," Pacific Northwest Laboratory, BNWL-CC-373, January 1966.

575. Mudge, L. K., J. R. Lundquist, "Chlorine Recovery and Radioiodine Behavior in the Salt Cycle Process,” Pacific Northwest Laboratory, BNWL-279, July 1966.

576. Jansen, G., L. K. Mudge, P. W. Smith, "Engineering Development of the Salt Cycle Process," Pacific Northwest Laboratory, BNWL-354, December 1966.

577. Bychlov, A. V., O. V. Skiba, S. K. Vavilov, M. V. Kormilitzyn, A. G. Osipenco, "Overview of RIAR Activity on Pyroprocess Development and Application to Oxide Fuel and Plans in the Coming Decade," Proceedings of the Workshop on Pyrochemical Separations, Avignon, France, March 14-16, (2000): 37-46.

578. Bychkov, A. V., S. K. Vavilov, P. T. Porodnov, O. V. Skiba, "Pyroelectrochemical Reprocessing of Irradiated Uranium Plutonium Oxide Fuel for Fast Reactors," Global 1993, (1993): 1351-1356.

579. Fedorov, Yu. S., B. Ya. Zil'berman, A. S. Aloi, E. A. Puzikov, A. Yu. Shadrin, M. Yu. Alyapyshev, "Problems of Modernization of Spent Nuclear Fuel Extraction Processing," Russian Journal of General Chemistry, Vol. 81, No. 9; (2011): 1932-1948.

580. Grachev, A. F., A. A. Maershin, O. V. Skiba, V. A. Tsykanov, A. V. Bychkov, M. V. Kormilitsyn, Yu. S. Sokolovskii, "Prospective Power Reactor Fuel Cycles Based on Water Free Reprocessing of Spent Fuel," Atomic Energy, Vol. 96, No. 5, (2004): 320-326.

581. Joseph, B., K. A. Venkatasan, K. Nagarajan, P. R. Vasudeva Rao, "Electrowinning of $\mathrm{UO}_{2}$ from Ionic Liquid Medium,” Separation Science and Technology, Vol. 48, (2013): 2506-2511.

582. Kobayashi, T., M. Fukushima, K. Fujii, "Low Current Efficiency in MOX Deposition Tests," Journal of Nuclear Science and Technology, Vol. 42, No. 10, (2005): 861-868.

583. Kobayashi, T., S. K. Vavilov, F. Sato, M. Myochin, T. Namba, K. Fujii, "Plutonium Precipitation in the MOX Co deposition Tests for the Oxide Electrowinning Process," Journal of Nuclear Science and Technology, Vol. 42, No. 3, (2005): 295-300.

584. Kofuji, H., N. Okamura, K. Mizuguchi, M. Myochin, "Effect of Pulse Electrolysis on Morphology of Co-Deposited MOX Granules," Journal of Nuclear Science and Technology, Vol. 45, No. 9, (2008): 942-950.

585. Kofuji, H., F. Sato, M. Myochin, S. Nakanishi, M. V. Kormilitsyn, V. S. Ishunin, A. V. Bychkov, "Results and evaluation of the Pu tests of MOX deposition at RIAR," Global 2005, Tsukuba, Japan, October 9-13, 2005.

586. Kofuji, H., F. Sato, M. Myochin, S. Nakanishi, M. V. Kormilitsyn, V. S. Ishunin, A. V. Bychkov, "MOX Co deposition Tests at RIAR for SF Reprocessing Optimization," Journal of Nuclear Science and Technology, Vol. 44, No. 3, (2007): 349-353. 
587. Kormilitsyn, M. V., A. V. Bychkov, V. S. Ishunin, "Pyroelectrochemical reprocessing of irradiated fuel of fast reactors. VI. Generalization of experience on BOR 60 spent nuclear fuel reprocessing using approaches "UO2-UO2" "MOX-PuO2" and "MOX-MOX," Global 2003, New Orleans, LA, November 16-20, (2003): 782-783.

588. Kosugi, K., M. Fukushima, M. Myochin, K. Mizuguchi, T. Oomori, "Deposition behavior of UO2 and noble metal elements in oxide electrowinning reprocessing," Journal of Physics and Chemistry of Solids, Vol. 66, (2005): 629-633.

589. Nagai, T., A. Uehara, T. Fujii, O. Shirai, M. Myochin, H. Yamana, "Redox equilibria of Pu4+/Pu3+ and $\mathrm{PuO} 22+/ \mathrm{Pu} 4+$ couples in molten $\mathrm{NaCl} \mathrm{CsCl}$ eutectic as measured by absorption spectrophotometry," Radiochimica Acta, Vol. 97, (2009): 209-212.

590. Osipenko, A. G., R. S. Galiev, M. V. Kormilitsyn, V. A. Stupin, V. N. Suzev, A. D. Yurchenko, A. V. Bychkov, "Experimental check and justification of application of pyrochemical origin plutonium dioxide for fabrication pellet fuel," Global 2009, Paris, France, (September 6-11, 2009): 1324.

591. Osipenko, A. G., R. S. Galiev, V. V. Novikov, M. V. Kormilitsyn, A. V. Bychkov, “Application of pyrochemical method for Am 241 production," Global 2009, Paris, France, (September 6-11, 2009): 1268.

592. Polyakov, A. S., B. S. Zakharkin, V. S. Smelov, V. I. Volk, I. V. Mukhin, V. D. Safutin, M. I. Zavadskii, A. V. Serov, A. V. Bychkov, B. Ya. Zil'berman, "Status and Prospects for Spent Fuel Reprocessing Technology,” Atomic Energy, Vol. 89, No. 4, (2000): 804-811.

593. "Pyrochemical Separations in Nuclear Applications: A Status Report," Nuclear Energy Agency, NEA No. 5427, 2004.

594. Sato, F., M. Fukushima, M. Myochin, T. Namba, M. V. Kormilitsyn, V. S. Ishunin, A. V. Bychov, T. Inagaki, "Effect of Ce ions on MOX codeposition in oxide electrowinning reprocessing," Journal of Physics and Chemistry of Solids, Vol. 66, (2005): 675-680.

595. Serebryakov, V. V., A. P. Kirillovich, A. V. Bychkov, M. V. Kormilitsyn, V. S. Ishunin, "Safety of Pyroelectrochemical Reprocessing of Spent BOR 60 Fuel," Atomic Energy, Vol. 98, No. 4, (2005): 270-277.

596. Serebryakov, V. V., A. P. Kirillovich, A. A. Maershin, O. V. Shishalov, A. V. Orishchenko, "Radiation Conditions During the Fabrication of Experimental Fuel Elements from Reprocessed Fuel," Atomic Energy, Vol. 98, No. 5, (2005): 334-342.

597. Skiba, O. V., Yu. P. Savochkin, A. V. Bychkov, P. T. Porodnov, L. G. Babikov, S. K. Vavilov, "Technology of Pyroelectrochemical Reprocessing and Production of Nuclear Fuel," Global 1993, (1993): 1344-1350.

598. Vandarkuzhali, S., P. Venkatesh, S. Ghosh, G. Seenivasan, B. P. Reddy, T. Subramanian, N. Sivaraman, K. Nagarajan, "Electrochemistry of rare earth oxy ions REO+ $(\mathrm{RE}=\mathrm{Ce}, \mathrm{La}, \mathrm{Nd})$ in molten $\mathrm{MgCl} 2 \mathrm{NaCl} \mathrm{KCl}$ eutectic," Journal of Electroanalytical Chemistry, Vol. 611, (2007): 181191.

599. Vavilov, S., T. Kobayashi, M. Myochin, "Principle and Test Experience of the RIAR's Oxide Pyro Process," Journal of Nuclear Science and Technology, Vol. 41, No. 10, (2004): 1018-1025.

600. Knighton, J. B., R. K. Steunenberg, "Preparation of Metals by Magnesium-Zinc Reduction. Part III. Reduction of Plutonium Dioxide," Argonne National Laboratory, ANL-7059, June 1965. 
601. Vogel, R. C., M. Levenson, J. H. Schraidt, J. Royal, “Chemical Engineering Division Research Highlights, May 1965 - April 1966,” Argonne National Laboratory, ANL-7175, April 1966.

602. Barghuse, J. J., W. J. Mecham, T. R. Johnson, R. K. Steunenberg, "Research and Development on Nonaqueous Processing - Volatility Processes - Compact Pyrochemical Processes," Reactor Fuel Processing, Vol. 9, (1966): 202-224.

603. Miller, W. E., R. K. Steunenberg, "Compact Pyrochemical Processes," Reactor and Fuel-Processing Technology, Vol. 10, No. 1, (1967): 314-318.

604. Johnson, T. R., "Compact Pyrochemical Processes," Reactor and Fuel-Processing Technology, Vol. 10, No. 3, (1967): 2234-2240.

605. Miller, W. E., R. K. Steunenberg, “Compact Pyrochemical Processes," Reactor and Fuel-Processing Technology, Vol. 11, No. 1, (1967): 60-64.

606. Miller, W. E., R. K. Steunenberg, “Compact Pyrochemical Processes,” Reactor and Fuel-Processing Technology, Vol. 11, No. 2, (1968): 96-100.

607. Miller, W. E., R. K. Steunenberg, “Compact Pyrochemical Processes," Reactor and Fuel-Processing Technology, Vol. 11, No. 3, (1968): 154-158.

608. Miller, W. E., R. K. Steunenberg, "Compact Pyrochemical Processes," Reactor and Fuel-Processing Technology, Vol. 11, No. 4, (1968): 219-226.

609. Steunenberg, R. K., I. Johnson, R. D. Pierce, "Salt Transport Process for Fast Breeder Reactor Fuels," Transactions of the American Nuclear Society, Vol. 11, (1968): 447-448.

610. Walsh, W. J., R. D. Pierce, R. K. Steunenberg, "Liquid-Metal Decladding Processes for Fast Breeder Fuel Reprocessing," Transactions of the American Nuclear Society, Vol. 12, (1969): 445.

611. Knighton, J. B., I. Johnson, R. K. Steunenberg, "Uranium Purification by the Process of Salt Transport," Symposium on Reprocessing of Nuclear Fuels, Jointly Sponsored by Metallurgical Society of AIME and AMES Laboratory of the US Atomic Energy Commission, Iowa State University, Ames, Iowa, August 25-27, 1969.

612. Steunenberg, R. K., R. D. Pierce, I. Johnson, "Status of the Salt Transport Process for Fast Breeder Reactor Fuels," Symposium on Reprocessing of Nuclear Fuels, Jointly Sponsored by Metallurgical Society of AIME and AMES Laboratory of the US Atomic Energy Commission, Iowa State University, Ames, Iowa, August 25-27, 1969.

613. Steunenberg, R. K., R. D. Pierce, L. Burris, "Pyrometallurgical and Pyrochemical Fuel Processing Methods," Progress in Nuclear Energy, Series III, Process Chemistry, Volume 4, Pergamon Press, (1970): 461-505.

614. Johnson, I., "The Thermodynamics of Plutonium and Uranium in Liquid Alloys and Application to Pyrochemical Reprocessing of Fast Breeder Reactor Fuels," Journal of Nuclear Materials, Vol. 51, (1974): 163-177.

615. Knighton, J. B., G. J. Bernstein, G. N. Vargo, R. D. Pierce, "Development of a Mixer-Settler for Liquid Metal-Salt Systems,” Argonne National Laboratory, ANL-7810, June 1971.

616. Knighton, J. B., "Conceptual Design Pyrochemical Process Facility," Rockwell International, RFP-2365, March 12, 1976.

617. Knighton, J. B., "Pyrochemical Processing of LWR and LMFBR Fuels by the Salt Transport Method," Radiochimica Acta, Vol. 25, (1978): 181-190. 
618. Mullins, L. J., J. A. Leary, W. J. Maraman, "Removal of Fission Product Elements by Slagging," Industrial and Engineering Chemistry, 52, 3, (1960): 227-230.

619. Sennewald, G., C. David, J. G. Wurm, "Halide Slagging of Rare earth Fission Products in Molten Uranium," European Atomic Energy Community - EURATOM, EUR-4184-e, 1968.

620. Mullins, L. J., J. A. Leary, W. J. Maraman, "Reprocessing Plutonium Reactor Fuel: Removal of Fission Product Elements by Slagging," Industrial and Engineering Chemistry, Vol. 52, (1960): 227-230.

621. Leary, J. A., R. Benz, D. F. Bowersox, C. W. Bjorklund, K. W. R. Johnson, W. J. Maraman, L. J. Mullins, J. G. Reavis, "Pyrometallurgical Purification of Plutonium Reactor Fuels," Second United Nations International Conference on the Peaceful Uses of Atomic Energy, Geneva, Switzerland, June 1958.

622. Leary, J. A., W. J. Maraman, R. Benz, "Pyrometallurgy Experiments on Plutonium-Rich Reactor Fuels," Los Alamos National Laboratory, LA-2132, September 16, 1957.

623. Karell, E. J., R. D. Pierce, T. P. Mulcahey, "Treatment of Oxide Spent Fuel Using the Lithium Reduction Process," Proceedings of the American Nuclear Society Meeting, Reno, NV, June 16-20, 1996.

624. Karell, E. J., K. V. Gourishankar, "Electrometallurgical Treatment of Oxide Spent Fuel Engineering-Scale Development," Proceedings of the American Nuclear Society, Third Topical Meeting on DOE Spent Nuclear Fuel and Fissile Materials Management, Charleston, SC, September 8-11, 1998.

625. Gourishankar, K. V., E. Karell, "Application of Lithium in Molten-Salt Reduction Process," Proceedings of TMS 1999, February 28 to March 4, 1999, San Diego, CA.

626. Merwin, A., W. C. Phillips, M. A. Williamson, J. L. Willit, P. N. Motsegood, D. Chidambaram, "Presence of Li Clusters in Molten LiCl-Li," Scientific Reports, 6, 25435, 2016, https://doi.org/10.1038/srep25435.

627. Merwin, A., M. A. Williamson, J. L. Willit, D. Chidambaram, "Review - Metallic Lithium and the Reduction of Actinide Oxides," Journal of the Electrochemical Society, 164, 8, H5236-H5246, 2017.

628. Ferris, L. M., A. H. Kibbey, M. J. Bradley, J. F. Land, "Process for Recovery of Uranium and Thorium from Graphite-Based Fuel Elements," Oak Ridge National Laboratory, ORNL-3186, 1961.

629. Langer, S., N. L. Baldwin, H. R. Phillips, "Head-End Separations of Triso-coated Fissile and Fertile Particles for High-Temperature Gas-Cooled Reactors," Nuclear Technology, 12 (1971): 26-30.

630. Heath, C. A., M. E. Spaeth, "Reprocessing Development for HTGR Fuels," ANL Nuclear Fuel Cycle Division Topical Meeting, Toronto, Canada, April 27-30, 1975.

631. Fitzgerald, C. L., V. C. A. Vaughen, K. J. Notz, R. S. Lowrie, "Head-End Reprocessing Studies

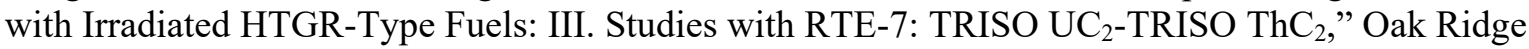
National Laboratory, ORNL-50901, 1975.

632. Notz, K. J., "Selected Studies in HTGR Reprocessing Development," Oak Ridge National Laboratory, ORNL/TM-5328, 1976. 
633. Notz, K. J., “An Overview of HTGR Fuel Recycle,” Oak Ridge National Laboratory, ORNL-TM4747, 1976.

634. Hoogen, N. G., E. R. Merz, "Evaluation of Potential Head-End Procedures for Graphite-Containing Fuel Elements," Nuclear Technology, 61 (1983): 380-387.

635. Del Cul, G. D., B. B. Spencer, C. W. Forsberg, E. D. Collins, W. S. Rickman, "TRISO-Coated Fuel Processing to Support High-Temperature Gas-Cooled Reactors," Oak Ridge National Laboratory, ORNL/TM-2002/156, 2002.

636. Lee, J. H., J. B. Shim, E. H. Kim, J. H. Yoo, S. W. Park, C. T. Snyder, "A Feasibility Study for the Development of Alternative Methods to Treat a Spent Triso Fuel," Nuclear Technology, 162 (2008): 250-258.

637. Zhu, L., W. Duan, J. Xu, Y. Zhu, "Uranium extraction from TRISO-coated fuel particles using supercritical $\mathrm{CO}_{2}$ containing tri-n-butyl phosphate," Journal of Hazardous Materials, 241-242 (2012): 456-462.

638. Croff, A. G., E. D. Collins, G. D. Del Cul, R. G. Wymer, A. M. Krichinsky, B. B. Spencer, B. D. Patton, "ORNL Experience and Perspectives Related to Processing of Thorium and 233U for Nuclear Fuel," Nuclear Technology, 194 (2016): 252-270.

639. Christensen, E. L., L. J. Mullins, "Preparation of Anhydrous Plutonium Chloride," Los Alamos Scientific Laboratory, LA-1461, October 1952.

640. Barney, R. A., A. G. Buyers, D. Cubicciotti, F. J. Keneshea, A. Saul, "Separation of Plutonium from Uranium by Distillation, Magnesium Extraction, and Salt Extraction," Journal of the Electrochemical Society, Vol. 103, (1956): C63.

641. Leary, J. A., "Pyrometallurgy Experiments on Plutonium-Rich Reactor Fuel," Los Alamos Scientific Laboratory, LA-2218, July 1958.

642. Mullins, L. J., J. A. Leary, K. W. R. Johnson, "Removal of Fission Product Elements from Plutonium by Liquation," Extractive and Physical Metallurgy of Plutonium and Its Alloys, W. D. Wilkinson ed., Interscience Publishers, 1960.

643. Blumenthal, B., M. B. Brodsky, "The Preparation of High-Purity Plutonium," Plutonium 1960: Proceedings of the $2^{\text {nd }}$ International Conference on Plutonium Metallurgy, Grenoble, France, April 19-22, 1960.

644. Mullins, L. J., J. A. Leary, C. W. Bjorklund, "Large Scale Preparation of High Purity Plutonium Metal by Electrorefining: Preliminary Report," Los Alamos Scientific Laboratory, LAMS-2441, June 27, 1960.

645. Mullins, L. J., J. A. Leary, A. N. Morgan, W. J. Maraman, "Plutonium Electrorefining," Los Alamos Scientific Laboratory, LA-2666, February 2, 1962.

646. Mullins, L. J., J. A. Leary, A. N. Morgan, W. J. Maraman, "Plutonium Electrorefining," Industrial and Engineering Chemistry Process Design and Development, Vol. 2, (1963): 20-24.

647. Mullins, L. J., J. A. Leary, "Multi-kilogram Electrorefining of Plutonium," Electrochemistry, Proceedings of the First Australian Conference, Sydney, February 13-15, and Hobart, February 18-20, 1963. 
648. Mullins, L. J., J. A. Leary, A. N. Morgan, "Operating Instructions, Procedures, and Equipment for the Los Alamos Plutonium Electrorefining Plant," Los Alamos Scientific Laboratory, LA-2981, December 18, 1963.

649. Mullins, L. J., J. A. Leary, "Fused Salt Electrorefining of Molten Plutonium and Its Alloys," Symposium on High Temperature Processing in the Nuclear Industry, American Chemical Society Meeting, Chicago, IL, September 2, 1964.

650. Mullins, L. J., J. A. Leary, "Fused Salt Electrorefining of Molten Plutonium and Its Alloys," Los Alamos Scientific Laboratory, LA-3118, November 6, 1964.

651. Mullins, L. J., J. A. Leary, A. N. Morgan, "Large Scale Electrorefining of Plutonium from Plutonium-Iron Alloys," Los Alamos Scientific Laboratory, LA-3029, April 7, 1964.

652. Mullins, L. J., J. A. Leary, "Fused-Salt Electrorefining of Molten Plutonium and Its Alloys by LAMEX Process," Industrial and Engineering Chemistry Process Design and Development, Vol. 4, (1965): 394-400.

653. Long, J. L., R. D. Schweikhardt, "Plutonium Electrorefining at Rocky Flats," The Dow Chemical Company, Rocky Flats Division, TID-4500, April 17, 1967.

654. Mullins, L. J., A. J. Beaumont, J. A. Leary, "Distribution of Americium between Liquid Plutonium and a Fused Salt. Evidence for Divalent Americium," Journal of Inorganic and Nuclear Chemistry, Vol. 30, (1968): 147-156.

655. Wade, W. Z., T. Wolf, "The Production of Plutonium Metal by Direct Reduction of the Oxide," Lawrence Radiation Laboratory, UCRL-50403, February 22, 1968.

656. Christensenk, E. L., W. J. Maraman, "Plutonium Processing at the Los Alamos Scientific Laboratory," Los Alamos Scientific Laboratory, LA-3542, April 1969.

657. Wade, W. Z., T. Wolf, "Preparation of Massive Plutonium Metal Directly from Its Oxide," Journal of Nuclear Science and Technology, Vol. 6, (1969): 402-407.

658. Felt, R. E., "A Pyrochemical Process for the Reduction of Plutonium Dioxide to Metal," Atlantic Richfield Hanford Company, ARH-SA-72, May 15, 1972.

659. Mullins, L. J., A. N. Morgan, "A Review of Operating Experience at the Los Alamos Plutonium Electrorefining Facility, 1963-1977," Los Alamos National Laboratory, LA-8943, December 1981.

660. Mullins, L. J., D. C. Christensen, B. R. Babcock, "Fused Salt Processing of Impure Plutonium Dioxide to High-Purity Plutonium Metal," Los Alamos National Laboratory, LA-9154-MS, January 1982.

661. Mullins, L. J., C. L. Foxx, “Direct Reduction of ${ }^{238} \mathrm{PuO}_{2}$ and ${ }^{239} \mathrm{PuO}_{2}$ to Metal," Los Alamos National Laboratory, LA-9073, February 1982.

662. Mullinsk, L. J., A. N. Morgan, S. A. Apgar, D. C. Christensen, "Six Kilogram Scale Electrorefining of Plutonium Metal,” Los Alamos National Laboratory, LA-9469-MS, September 1982.

663. Christensen, E. L., L. W. Gray, J. D. Navratil, W. W. Schulz, "Present Status and Future Directions of Plutonium Process Chemistry," Plutonium Chemistry, ACS Symposium Series 216, 184 ${ }^{\text {th }}$ Meeting of the American Chemical Society, Kansas City, MO, September 12-17, 1982.

664. Baldwin, C. E., "Pyrochemical Development at Rocky Flats for Recovery and Purification of Plutonium," Actinide Recovery from Waste and Low-Grade Sources (J. D. Navratil and W. W. Schulz, Eds.), Harwood Academic Publishers, (1982): 56-60. 
665. Baldwin, C. E., J. D. Navratil, "Plutonium Process Chemistry at Rocky Flats," Plutonium Chemistry, ACS Symposium Series 216, 184th Meeting of the American Chemical Society, Kansas City, MO, September 12-17, 1982.

666. Coops, M. S., J. B. Knighton, L. J. Mullins, “Technology Review Report: Pyrochemical Processing of Plutonium," Plutonium Chemistry, ACS Symposium Series 216, 184th Meeting of the American Chemical Society, Kansas City, MO, September 12-17, 1982.

667. Christensen, D. C., L. J. Mullins, "Plutonium Metal Production and Purification at Los Alamos," Plutonium Chemistry, ACS Symposium Series 216, 184th Meeting of the American Chemical Society, Kansas City, MO, September 12-17, 1982.

668. Christensen, D. C., L. J. Mullins, "Salt Stripping, A Pyrochemical Approach to the Recovery of Plutonium Electrorefining Salt Residues,” Los Alamos Scientific Laboratory, LA-9464-MS, October 1982.

669. Christensen, D. C., L. J. Mullins, "Present Status of Plutonium Metal Production and Purification at Los Alamos - 1982," Los Alamos National Laboratory, Report LA-9674-MS, June 1983.

670. Coops, M. S., J. B. Knighton, L. J. Mullins, "Pyrochemical Processing of Plutonium," Plutonium Chemistry (W. T. Carnell and G. R. Choppin, Eds.), American Chemical Society, (1983): 386-398.

671. Christensen, D. C., L. J. Mullins, "Plutonium Metal Production and Purification at Los Alamos," Plutonium Chemistry (W. T. Carnell and G. R. Choppin, Eds.), American Chemical Society, (1983): 409-431.

672. Moser, W. S., J. D. Navratil, "Review of Major Plutonium Pyrochemical Technology," Journal of the Less-Common Metals, Vol. 100, (1984): 171-187.

673. Navratil, J. D., "Plutonium and Americium Processing Chemistry and Technology," Inorganica Chimica Acta, Vol. 94, (1984): 263-269.

674. Christensen, D. C., J. D. Williams, J. A. McNeese, K. W. Fife, "Plutonium Metal Preparation and Purification at Los Alamos - 1984," Proceedings of the International Symposium on Actinide/Lanthanide Separations, Honolulu, HI, December 16-22, 1984.

675. Reavis, J. G., "Experimental Studies of Actinides in Molten Salts," Los Alamos National Laboratory, LA-10340, June 1985.

676. McNeese, J. A., D. F. Bowersox, D. C. Christensen, "Recovery of Plutonium by PYROREDOX Processing," Los Alamos National Laboratory, LA-10457, September 1985.

677. Fife, K. W., D. F. Bowersox, D. C. Christensen, J. D. Williams, "The Preparation of Fused Chloride Salts for Use in Pyrochemical Plutonium Recovery Operations at Los Alamos," Los Alamos National Laboratory, LA-10681, July 1986.

678. McNeese, J. A., D. F. Bowersox, D. C. Christensen, "Recovery of Plutonium by PYROREDOX Processing," Proceedings of the Electrochemical Society, PV 1986-1, (1986): 474-484.

679. Bowersox, D. F., D. C. Christensen, J. D. Williams, “Application of Molten Salts in Plutonium Processing," Proceedings of the Electrochemical Society, PV 1987-7, (1987): 872-887.

680. Fife, K. W., D. F. Bowersox, L. E. McCurry, P. C. Lopez, C. Brown, "Status of Plutonium Purification by Bismuth Solvent Anode Electrorefining," Proceedings of the Electrochemical Society, PV 1987-7, (1987): 888-895. 
681. Bowersox, D. F., J. A. McNeese, D. C. Christensen, "Studies of a Liquid Anode for Plutonium Electrorefining," Journal of Separation Science and Technology, Vol. 22, (1987): 1183-1197.

682. Rense, C. E. C., K. W. Fife, D. F. Bowersox, M. D. Ferran, "Materials Compatibility During the Chlorination of Molten $\mathrm{CaCl}_{2} \bullet \mathrm{CaO}$ Salts," Los Alamos National Laboratory, LA-10700-MS, January 1987.

683. Fife, K. W., D. F. Bowersox, C. C. Davis, E. D. McCormick, "Direct Oxide Reduction (DOR) Solvent Salt Recycle in Pyrochemical Plutonium Recovery Operations," Los Alamos National Laboratory, LA-10891-MS, February 1987.

684. Fife, K. W., M. H. West, "Pyrochemical Investigations into Recovering Plutonium from Americium Extraction Salt Residues,” Los Alamos National Laboratory, LA-10963-MS, May 1987.

685. Christensen, D. C., D. F. Bowersox, B. J. McKerley, R. L. Nance, "Wastes from Plutonium Conversion and Scrap Recovery," Los Alamos National Laboratory, LA-11069-MS, March 1988.

686. West, M. H., M. D. Ferran, K. W. Fife, “The Chlorination of Plutonium Dioxide,” Los Alamos National Laboratory, LA-11256, September 1988.

687. Owens, S., K. Axler, G. Bird, M. Reimus, E. Garcia, "Investigations at Los Alamos National Laboratory of Calcium Chloride Based Molten Salt Systems," Proceedings of the Electrochemical Society, PV 1992-16, (1992): 204-214.

688. Willit, J. L., W. E. Miller, and J. E. Battles, "Electrorefining of Uranium and Plutonium - A Literature Review," Journal of Nuclear Materials, Vol. 195, (1992): 229-249.

689. "Nuclear Materials: Plutonium Processing in the Nuclear Weapons Complex," U.S. General Accounting Office, Fact Sheet for the Chairman, Environmental, Energy, and Natural Resources Subcommittee, Committee on Government Operations, House of Representatives, GAO/RCED-92109FS, August 1992.

690. "Plutonium Processing at Los Alamos," Los Alamos National Laboratory, Actinide Research Quarterly, $3^{\text {rd }}$ Quarter 2008.

691. Medalia, J. E., "Nuclear Weapon "Pit" Production: Options to Help Meet a Congressional Requirement," Congressional Research Service, R44033, May 14, 2015. 